Beatriz Moura dos Santos

\title{
As ZEIS e o acesso à cidade: o impacto das ZEIS na desigualdade da habitação por promoção privada em São Paulo
}

São Paulo 


\section{As ZEIS e o acesso à cidade: o impacto das ZEIS na desigualdade da habitação por promoção privada em São Paulo}

\section{Versão Corrigida}

Dissertação apresentada à Escola Politécnica da Universidade de São Paulo para obtenção do título de Mestre em Ciências.

Área de concentração: Engenharia de Transportes

Subárea: Informações Espaciais

Orientadora: Profa. Dra. Mariana Abrantes Giannotti

São Paulo 
Autorizo a reprodução e divulgação total ou parcial deste trabalho, por qualquer meio convencional ou eletrônico, para fins de estudo e pesquisa, desde que citada a fonte.

Este exemplar foi revisado e corrigido em relação à versão original, sob responsabilidade única do autor e com a anuência de seu orientador.

São Paulo, 31 de julho de 2020

Assinatura do autor: Beatriz heura dos Setos"

Assinatura do orientador:

Catalogação-na-publicação

Santos, Beatriz Moura dos

As ZEIS e o acesso à cidade: o impacto das ZEIS na desigualdade da habitação por promoção privada em São Paulo/ Santos, Beatriz Moura dos. - São Paulo, 2020-

$101 \mathrm{p}$.

Dissertação (Mestrado) - Escola Politécnica da Universidade de São Paulo.

Departamento de Engenharia de Transportes

1. Planejamento territorial urbano - São Paulo: Política habitacional 2. Habitação popular aspectos sociais 3. Zoneamento urbano 4. Espaço urbano 5. Segregação Urbana I. Universidade de São Paulo. Escola Politécnica. Departamento de Engenharia de Transportes. II. t. 
SANTOS, B. M. As ZEIS e o acesso à cidade: o impacto das ZEIS na desigualdade da habitação por promoção privada em São Paulo. 2020. 101p. Dissertação (Mestrado) - Escola Politécnica da Universidade de São Paulo, Departamento de Engenharia de Transportes, São Paulo, 2020.

Aprovada em: 03 de junho de 2020

Banca Examinadora

Profa. Dra. Mariana Abrantes

Giannotti

Orientadora

Profa. Dra. Flávia Fonseca Feitosa

Convidada 1

Profa. Dra. Paula Freire Santoro

Convidada 2

São Paulo 


\section{Agradecimentos}

à minha orientadora, Mariana, por me motivar, acreditar e se empolgar com o trabalho, às vezes mais do que eu mesma;

à profa. Flávia Feitosa e à profa. Paula Santoro, que contribuíram com novas perspectivas para esta pesquisa;

ao querido Vitor, pelo apoio incondicional, muito obrigada por existir e compartilhar a vida comigo;

ao meu irmão, Bruno, muito obrigada pelas conversas diárias, pelo apoio, por tudo. Estou fazendo essa por nós;

aos meus pais, Cida e Elias, cheguei até aqui por causa de vocês;

às parceiras do LabGeo, de aula e de desabafos acadêmicos, Bruna, Juliana, Tainá e Tamara, obrigada por ouvirem e tentarem ajudar, mesmo quando não entendiam o que eu estava tentando fazer;

às amigas de longa data, Camila e Gabriela, nosso crescimento só me dá orgulho, obrigada por existirem;

ao Conselho Nacional de Desenvolvimento Científico e Tecnológico (CNPq), pela concessão da bolsa de mestrado e pelo apoio financeiro para a realização dessa pesquisa. 
"(...)

Vi condomínios rasgarem mananciais

A mando de quem fala de Deus e age como Satanás

(Uma lei:) Quem pode menos, chora mais

Corre do gás, luta, morre, enquanto o sangue escorre

É nosso sangue nobre que a pele cobre

Tamo no corre, dias melhores, sem lobby

Ei, pequenina, não chore

Tv cancerígena aplaude prédio em cemitério indígena

Auschwitz ou gueto? Índio ou preto?

Mesmo jeito, extermínio

Reportagem de um tempo mau, tipo Plínio

Alphaville foi invasão, incrimine-os

Grito como fuzis, uzis, por Brasis

Que vem de baixo igual Machado de Assis

Ainda vivemos como nossos pais, Elis

Quanto vale uma vida humana? Me diz

(...)

É só um pensamento, bote no orçamento

Nosso sofrimento, mortes e lamentos

Forte esquecimento de gente em nosso tempo

Visto como lixo, soterrado nos desabamento

Em favela, disse Marighella, elo

Contra porcos em castelo

O povo tem que cobrar com os parabelo

Porque a justiça deles só vai em cima de quem usa chinelo

E é vítima, agressão de farda é legítima

Barracos no chão enquanto chove

Meus heróis também morreram de overdose

De violência, sob coturnos de quem dita decência

Homens de farda são maus, era do caos

Frios como Halls, engatilha e "Plau!"

Carniceiros ganham prêmios

Na terra onde bebês respiram gás lacrimogênio"

(Emicida e Renan Samam - Dedo na ferida, 2012) 


\section{Resumo}

Sustentabilidade social, no que se refere a equidades sociais, está relacionada a iguais oportunidades para todos os indivíduos de uma sociedade. Para tanto, melhores localizações com maior acesso à cidade e às oportunidades devem ser consideradas em políticas habitacionais destinadas à população de baixa renda. Uma das políticas existentes para o incentivo da produção desse tipo de habitação - Habitação de Interesse Social (HIS) - em boas localizações no município de São Paulo é a Zona Especial de Interesse Social (ZEIS) através da Lei de Zoneamento. Porém, a partir do relatório produzido pela prefeitura municipal de São Paulo, foi verificado que o uso das ZEIS foi ineficiente entre 2002 e 2013 em relação à produção de HIS. Desse modo, o presente trabalho tem como objetivo avaliar qual seria o impacto das restrições de uso das ZEIS e de construção de HIS no município de São Paulo nas desigualdades de localização entre os empreendimentos propostos pela iniciativa privada, tanto pelo Programa Minha Casa Minha Vida (PMCMV) quanto pelo mercado imobiliário formal, entre 2009 a 2013. Para tanto, foi analisada a relação entre acessibilidade e isolamento da classe de renda baixa e com ela avaliada a inserção urbana dos empreendimentos contratados pelo PMCMV e lançados pela iniciativa privada. Ampliando o entendimento desta relação, prosseguimos com a análise comparando a localização desses empreendimentos e verificamos que habitações destinadas à renda média têm localizações semelhantes às destinadas à renda baixa, com baixa acessibilidade e alto isolamento. Por fim, avaliamos a inserção urbana das ZEIS, a partir do indicador de acessibilidade, e simulamos cenários com diferentes níveis de restrição de uso delas. A partir desta última análise, verificamos que o uso efetivo das ZEIS é capaz de reduzir as diferenças de acessibilidade entre os empreendimentos analisados, mas que a produção do período é ineficiente para reduzir as desigualdades do município. Desse modo, reforçamos as discussões existentes sobre a localização dos empreendimentos destinados a baixa renda, as quais argumentam que o mercado imobiliário ignora este estrato e prioriza as classes mais altas; e também sobre as aplicações das leis, que sugerem que as leis são instrumentos de manutenção de poder e concentração de privilégios, além de serem aplicadas arbitrariamente.

Palavras-chave: Zona Especial de Interesse Social. Habitação de Interesse Social. Acessibilidade. Segregação Urbana. Localização. 


\section{Abstract}

Social sustainability, regarding social equity, is related to equal opportunities to all. Therefore, housing policies destined for the lower-income group should consider the best locations with higher access to the city and opportunities. One of the existent policies at Sao Paulo to support the production of social housing (Habitação de Interesse Social - HIS) at better locations is the Special Zones of Social Interest (Zonas Especiais de Interesse Social - ZEIS). However, a city hall report verified that ZEIS were inefficient for the production of HIS between 2002 and 2013. Hence, this paper aims to evaluate the impact of the use of ZEIS constraints and the social housing construction at the municipality of Sao Paulo on inequalities among the developments proposed by the real estate market between 2009 and 2014. First, we analyzed the relation between accessibility to jobs and the lower-income group's isolation. Then, we evaluated the location of the developments proposed by the My House My Life Program and the regular real estate market and verified that most of the housing for the medium class has similar locations of the social housing, with lower accessibility and higher segregation. Afterward, we evaluated the location of ZEIS, using accessibility to jobs, and simulated scenarios in which we proposed different levels of constraints for the housing production inside ZEIS. From this last analysis, we verified that the effective use of ZEIS is capable of reducing the accessibility differences among the analyzed developments. Therefore, we reinforce the discussions regarding the location of the developments for the lower class, which argue that the real estate market ignores this group and prioritizes the higher classes. And the discussions about law enforcement, which suggests that the laws are instruments of maintenance of power and privilege concentration and are arbitrarily applied.

Keywords: Special Zones of Social Interest. Social Housing. Accessibility. Urban Segregation. Location. 


\section{Lista de ilustrações}

Figura 1 - Meta e contratação de unidades habitacionais (em milhar) . . . . . . . 20

Figura 2 - Mapas das Zonas Especiais de Interesse Social por PDE . . . . . . . . 26

Figura 3 - Relações entre componentes de acessibilidade . . . . . . . . . . . . . 31

Figura 4 - Eixos de acessibilidade . . . . . . . . . . . . . . . 34

Figura 5 - Eixos de segregação urbana . . . . . . . . . . . . . . 35

Figura 6 - Distribuição de viagens por motivo no destino . . . . . . . . . . . . 39

Figura 7 - Empregos formais em São Paulo . . . . . . . . . . . . . . . 40

Figura 8 - Distribuição das células por célula . . . . . . . . . . . . . 40

Figura 9 - Acessibilidade a empregos . . . . . . . . . . . . . . . . 42

Figura 10 - Distribuição e predominância espacial dos grupos . . . . . . . . . . . 45

Figura 11 - Isolamento de G1 . . . . . . . . . . . . . . . . . . . . . . . . 46

Figura 12 - Distribuição do isolamento por largura de banda . . . . . . . . . . . . . 46

Figura 13 - Mapas de acessibilidade, isolamento e bivariado . . . . . . . . . . . 47

Figura 14 - Mapas LISA de Moran, agrupamentos e significância . . . . . . . . . . 48

Figura 15 - Localização dos empreendimentos do PMCMV em São Paulo . . . . . . 50

Figura 16 - Gráficos de acessibilidade por segregação, divididos por fase e faixa. . . 51

Figura 17 - Boxplots da área útil da UH e preço por $\mathrm{m}^{2}$ de área útil da UH . . . . 52

Figura 18 - Total de unidades (\%) lançadas por tipo de empreendimento . . . . . . 53

Figura 19 - Mapa de concentração de unidades habitacionais por período e tipo . . 54

Figura 20 - Gráficos de acessibilidade por segregação, divididos por fase e classe . . 55

Figura 21 - Mapas de acessibilidade de 2010 e 2014, escala relativa ao total de empregos por ano . . . . . . . . . . . . . . 56 56

Figura 22 - Boxplot de acessibilidade por classe e origem de produção . . . . . . . 57

Figura 23 - Lorenz de acessibilidade por unidades habitacionais . . . . . . . . . . 57

Figura 24 - Distribuição de acessibilidade por ZEIS e ano . . . . . . . . . . . . . 58

Figura 25 - Distribuição de UHs por ZEIS e padrão de construção . . . . . . . . . 59

Figura 26 - Distribuição de acessibilidade por HIS, HMP e ZEIS não usadas . . . . 60

Figura 27 - Realocação das unidades habitacionais por cenário . . . . . . . . . . . 62

Figura 28 - Distribuição de acessibilidade por tipo de empreendimento e cenário . . 63

Figura 29 - Índices de Gini para os cenários simulados . . . . . . . . . . . . . . . 64

Figura 30 - Lorenz de acessibilidade por UH dos cenários simulados . . . . . . . . . 64

Figura 31 - Comparação entre os Ginis dos cenários simulados e o cenário original . 65

Figura 32 - Lorenz de acessibilidade por famílias dos cenários simulados em relação ao município . . . . . . . . . . . . . . . . 66

Figura 33 - Distribuição das células por acessibilidade e limite de tempo . . . . . . 96

Figura 34 - Total de unidades (\%) lançadas por tipo de empreendimento e caso . . 98 
Figura 35 - Mapas de acessibilidade de 2010 e 2014, escala em percentil por ano . . 99

Figura 36 - Mapas de empregos de 2002, 2007, 2010 e 2014 . . . . . . . . . . . . 100

Figura 37 - Distribuição das células por emprego e ano . . . . . . . . . . . . . . . 100

Figura 38 - Mapas de acessibilidade de 2003, 2007, 2010 e 2014, escala relativa ao total de empregos por ano . . . . . . . . . . . . . . . . . . . . 101

Figura 39 - Distribuição das células por acessibilidade e ano . . . . . . . . . . . . 101 


\section{Lista de quadros}

Quadro 1 - Definições e parâmetros das ZEIS $2002 \ldots \ldots$. . . . . . . . 25

Quadro 2 - Parâmetros de HIS e HMP . . . . . . . . . . . . . . 27

Quadro 3 - Medidas de acessibilidade . . . . . . . . . . . . . 32

Quadro 4 - Medidas de acessibilidade com competição . . . . . . . . . . . 34

Quadro 5 - Variáveis utilizadas. . . . . . . . . . . . . . 44

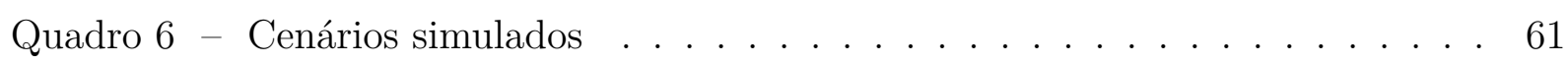




\section{Lista de tabelas}

Tabela 1 - Divisão das faixas . . . . . . . . . . . . . . . . . 19

Tabela 2 - Metas e contratações do programa . . . . . . . . . . . . 21

Tabela 3 - Áreas por tipos de ZEIS . . . . . . . . . . . . . . 26

Tabela 4 - Produção de habitação nas ZEIS no período entre 2002-2013 . . . . . . 28

Tabela 5 - Datas das inaugurações das estações de Metrô e Trem de São Paulo . . 78 


\section{Lista de abreviaturas e siglas}

AEIS Área Especial de Interesse Social

CEM Centro de Estudos da Metrópole

Censo 2010 Censo demográfico de 2010

Embraesp Empresa Brasileira de Patrimônio

HIS Habitação de Interesse Social

HMP Habitação para Mercado Popular

LabGeo Laboratório de Geoprocessamento da Poli-USP

Metrô Companhia do Metropolitano

MSP Município de São Paulo

OD 2017 Pesquisa Origem e Destino de 2017

PDE 2002 Plano Diretor Estratégico de 2002

PDE 2014 Plano Diretor Estratégico de 2014

PlanHab Plano Nacional de Habitação

PMH 2011 Plano Municipal de Habitação de 2011

PMH 2016 Plano Municipal de Habitação de 2016

PREZEIS Plano de Regularização das Zonas Especiais de Interesse Social

PROFAVELA Programa Municipal de Regularização de Favelas

RAIS Relação Anual de Informações Sociais

RMSP Região Metropolitana de São Paulo

SEHAB Secretaria Municipal de Habitação

SMDU Secretaria Municipal de Desenvolvimento Urbano

SPTrans São Paulo Transporte

UH Unidade Habitacional

ZEIS Zonas Especiais de Interesse Social 


\section{Sumário}

Introdução

O MERCADO RESIDENCIAL FORMAL . . . . . . . . . . . . 17

$1.1 \quad$ O Programa Minha Casa Minha Vida . . . . . . . . . . . . . . . 18

1.1.1 Avaliação da localização dos empreendimentos . . . . . . . . . . . . 22

2 AS ZONAS ESPECIAIS DE INTERESSE SOCIAL . . . . . . . . 24

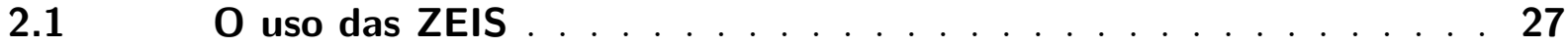

3 LOCALIZAÇÃO E POSSÍVEIS MEDIDAS . . . . . . . . . . . 30

$3.1 \quad$ Acessibilidade . . . . . . . . . . . . . . . . 31

$3.2 \quad$ Segregação espacial . . . . . . . . . . . . . . . . 35

4 DECISÕES DE PESQUISA . . . . . . . . . . . . . . . 38

$4.1 \quad$ Produção habitacional . . . . . . . . . . . . . . . . . . . . . . . . . 38

$4.2 \quad$ Acessibilidade no município de São Paulo . . . . . . . . . . . . . . . . 39

4.2.1 Oportunidades . . . . . . . . . . . . . . . . . 39

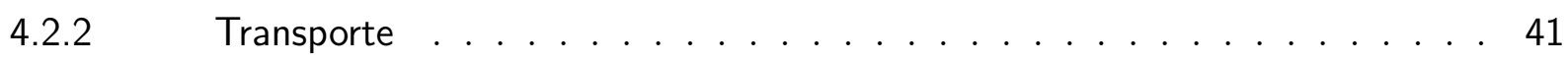

4.2 .3 Definição de limite de tempo . . . . . . . . . . . . . . . . . . . . . . 41

4.3 Segregação no município de São Paulo . . . . . . . . . . . . . . 42

4.3.1 População e grupos . . . . . . . . . . . . . . . . . . 43

4.3.2 Definição de limite de vizinhança . . . . . . . . . . . . . . . . . 45

$5 \quad$ ESTUDOS DE CASO $\ldots \ldots \ldots \ldots$

5.1 A relação entre acessibilidade e segregação e a localização dos empreendimentos . . . . . . . . . . . . . . . . . . 47

5.1.1 As localizações do PMCMV . . . . . . . . . . . . . . . . . . . 48

5.1.2 A localização dos empreendimentos do mercado imobiliário . . . . . . . . . 51

5.1.3 Comparação entre mercado imobiliário e PMCMV . . . . . . . . . . . . 55

$5.2 \quad$ A localização das ZEIS e seu uso . . . . . . . . . . . . . . . 58

5.2.1 Simulação de realocação dos empreendimentos . . . . . . . . . . . . 60

5.2.1.1 Comparação entre os empreendimentos . . . . . . . . . . . . . . . . 62

5.2.1.2 Comparação com o município . . . . . . . . . . . . . . . 65

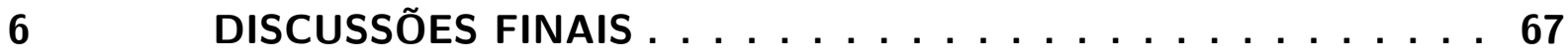

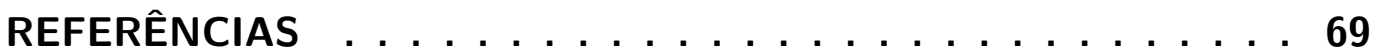


APÊNDICE A-DECISÕES DE PESQUISA . . . . . . . 78

APÊNDICE B - ESTUDO DE CASO . . . . . . . . . . . . 97

B.1 Empreendimentos do mercado formal . . . . . . . . . . . . 97

B.2 Acessibilidade . . . . . . . . . . . . . . . 99 


\section{Introdução}

O problema da moradia no município de São Paulo (MSP) é levantado desde a década de 70, com o aumento da população, o espraiamento da mancha urbana e a falta de infraestrutura. Para a revisão do Plano Municipal Habitacional (PMH) (São Paulo (cidade), 2016b) em 2016, foram levantadas as necessidades habitacionais e demandas por tipo de intervenção. Ao todo, ainda que com sobreposição, é preciso intervir em quase 830 mil domicílios em situação irregular, produzir mais de 350 mil unidades habitacionais e regularizar o mercado de aluguel para mais de 200 mil domicílios (São Paulo (cidade), 2016b, p. 44).

$\mathrm{Na}$ tentativa de atender esta demanda, diferentes políticas habitacionais foram propostas ao longo dos anos nas diversas esferas. No caso federal, devido a produção em larga escala, se destacam o período do Banco Nacional da Habitação (BNH), entre 1964 e 1985, e o do Programa Minha Casa Minha Vida (PMCMV), de 2009 a 2018. No entanto, a maioria dos estudos direcionam suas críticas à localização dos empreendimentos dessas políticas (BONDUKI, 2014; FERREIRA, 2015a; ROLNIK et al., 2015; SÍGOLO; SIGOLO, 2014), mesmo entendendo que o objetivo delas é a redução do déficit habitacional (CARDOSO; ARAGÃO; ARAUJO, 2011).

Atendendo a esta questão, o direito à moradia digna e à cidade estão cada vez mais presentes em planos e leis voltados à cidade e à habitação, tal como o Estatuto da Cidade (Brasil, 2001), o Plano Nacional da Habitação (PlanHab) (Brasil, 2010), a nível nacional; e o Plano Diretor Estratégico de 2014 (PDE 2014) (São Paulo (cidade), 2014) e o PMH 2016 (São Paulo (cidade), 2016b), a nível municipal (São Paulo).

No PDE 2014, moradia digna é definida como

aquela cujos moradores dispõem de segurança na posse do imóvel, com dimensões suficientes para comportar seus habitantes, executada com boa qualidade construtiva, com materiais adequados, ventilação e iluminação suficientes, assentada sobre terreno firme, salubre, seco e livre de contaminações, e dotada de abastecimento de água, coleta de esgoto, fornecimento de energia elétrica, iluminação pública, coleta de resíduos sólidos, trafegabilidade de vias, pavimentação viária, transporte coletivo, equipamentos sociais básicos, entre outros serviços, equipamentos e infraestruturas urbanas (São Paulo (cidade), 2014, p. 183-184, grifo nosso).

Portanto, o direito à moradia digna pode ser resumido como um "vetor de inclusão 
sócio-territorial"(São Paulo (cidade), 2011, p. 12). Uma das políticas propostas para o incentivo da produção de Habitação de Interesse Social (HIS) - habitação direcionada à população de baixa renda - em boas localizações no município de São Paulo é a Zona Especial de Interesse Social (ZEIS) através da Lei de Zoneamento (São Paulo (cidade), 2016a). Já que os coeficientes de aproveitamento ${ }^{1}$ são mais altos (CYMBALISTA; TSUKUMO, 2009 apud SANTORO; BORRELLI, 2015, p. 8).

Porém, o relatório produzido pela Secretaria Municipal de Desenvolvimento Urbano (SMDU) e a Secretaria Municipal de Habitação (SEHAB) para a revisão do PDE 2002 verificou que a produção de HIS em ZEIS no período de 2002 a 2013 foi menor do que o esperado (São Paulo (cidade), 2013) e maior em outras áreas da cidade. Santoro e Borrelli (2015, p. 8) levantaram a hipótese de que este resultado é devido a decretos (como o Decreto 44.667/04 e o 45.127/04) que flexibilizaram a construção de HIS fora de ZEIS.

Em vista disso, pretende-se avaliar, a partir de indicadores de localização, como acessibilidade $^{2}$ e segregação, se a aplicação das restrições de uso das ZEIS e construção de HIS no município de São Paulo afetaria as desigualdades entre os empreendimentos propostos no período em que o PDE 2002 era vigente e em que o PMCMV havia sido lançado (2009 a 2014). Portanto, temos como objetivos específicos:

a) avançar no entendimento da relação entre acessibilidade e segregação;

b) através desta relação, avaliar a inserção urbana dos empreendimentos contratados pelo PMCMV;

c) dentro do período analisado, verificar a inserção urbana das unidades habitacionais de empreendimentos lançados pelo mercado imobiliário e comparar com as contratações do PMCMV;

d) avaliar a inserção urbana das ZEIS do período a partir de indicadores de acessibilidade;

e) simular cenários com diferentes níveis de restrição de uso das ZEIS e verificar desigualdades entre os empreendimentos e em relação à cidade.

O trabalho está organizado em sete seções, esta em que é feita uma breve apresentação do trabalho. Seguida de duas seções (Capítulo 1 e Capítulo 2), as quais discutem o Programa Minha Casa Minha Vida e análises de localização sobre o mesmo; e o desenvolvimento e aplicação das ZEIS no município de São Paulo. Na terceira seção (Capítulo 3), apresentamos referenciais teóricos de localização e possíveis métricas para medi-la. Os materiais e decisões tomadas para a análise são descritos e mostrados no Capítulo 4. Por fim, os resultados estão no Capítulo 5 e as discussões finais no Capítulo 6 .

1 "Coeficiente de Aproveitamento é a relação entre a área edificada, excluída a área não computável, e a área do lote"(São Paulo (cidade), 2014, p. 182).

2 "Potencial de alcançar oportunidades espacialmente distribuídas"(PÁEZ; SCOTT; MORENCY, 2012). 


\section{0 mercado residencial formal}

O mercado imobiliário dedicado a moradia tem um histórico de produção voltado para classes de alta renda, justificada pela sua capacidade de compra (solvabilidade da demanda, discutida por Ribeiro (2015b)), que reduz os riscos dos produtores (ABRAMO, 2007b). Haddad e Meyer (2007) analisaram os lançamentos imobiliários no município de São Paulo em 2006 e verificaram que mais de um terço das unidades habitacionais destinavam a famílias com renda conjunta (pessoa responsável e cônjuge) de 45 salários mínimos $^{1}$, mesmo verificando que a quantidade de famílias nessa faixa era menor do que o ofertado.

Podemos relacionar essa análise empírica à teoria proposta por Abramo (2007a) da cidade caleidoscópica. A estrutura desta cidade se baseia na estratificação da sociedade e na produção das habitações para os segmentos de renda mais altos. Ao produzir habitações diferenciadas para esse mercado, ocorre a "depreciação fictícia"dos locais em que esse grupo mora, criando então uma nova demanda para consumir o novo produto. Desse modo, o espaço anteriormente ocupado fica vago e temos um efeito cascata, no qual a camada imediatamente inferior a que se mudou ocupa esse lugar e que resulta em uma nova conformação espacial da cidade.

Outro estudo empírico que também se relaciona a essa teoria é o de Haddad et al. (2005). Os autores analisaram os lançamentos no município em 1987 e, comparando os valores dos apartamentos com a renda média familiar de cada bairro, perceberam alguns outliers. A maioria desses empreendimentos lançados tinham valores acima do esperado para a renda familiar do bairro e indicavam a expansão de algum um bairro vizinho mais rico. Haddad et al. (2005) ainda verificaram que o perfil socioeconômico dessas áreas mudaram para famílias mais ricas passados dez anos após a implantação.

Ainda analisando os lançamentos, mas para a Região Metropolitana de São Paulo (RMSP) entre 1985 e 2013, Hoyler (2016) dividiu o período entre três ciclos de produção. O primeiro ciclo, entre 1985 e 1993, a autora verificou a predominância de lançamentos destinados a alta renda, a qual reduziu nos ciclos seguintes (1993-2005 e 2005-2013). A faixa que teve um aumento de seus lançamentos em relação ao restante no mesmo período foi a de baixa renda (de $5 \%$ no primeiro ciclo para $18 \%$ no último). Hoyler (2016) argumenta que esse aumento é resultado de políticas de crédito habitacionais que tornaram esse mercado mais atraente, além da abertura de capital das construtoras no início desse

$\overline{1}$ O salário mínimo em agosto de 2006 era de $\mathrm{R} \$ 350,00$, equivalente a $\mathrm{R} \$ 652,66$ em fevereiro de 2017. 
período, possibilitando maior investimento das mesmas em mercados não muito explorados, como mostram Haddad e Meyer (2007). No entanto, apenas com o lançamento do programa Minha Casa Minha Vida é que houve a consolidação dessas políticas de crédito para a compra a população de baixa renda (HOYLER, 2016).

\subsection{O Programa Minha Casa Minha Vida}

O programa Minha Casa Minha Vida (MCMV) foi lançado pelo Governo Federal em março de 2009 com o objetivo principal de reduzir o déficit habitacional que chegava a 5,9 milhões de moradias no ano de lançamento (Fundação João Pinheiro, 2012). Para atingi-lo, o programa trabalhou no incentivo da produção habitacional urbana e rural, através do financiamento de crédito gerido pela Caixa Econômica Federal (CEF) que serviu tanto para a construção quanto para a compra das unidades habitacionais (UH) (CARDOSO; ARAGÃO, 2013; Santo Amore, 2015).

Foram definidos dois subprogramas: o Programa Nacional de Habitação Urbana (PNHU) e o Programa Nacional de Habitação Rural (PNHR). Sendo o primeiro responsável em "promover a produção e aquisição de novas unidades habitacionais, ou a requalificação de imóveis urbanos"(Brasil, 2011, art. 5), e o segundo, "subsidiar a produção ou reforma de imóveis aos agricultores familiares e trabalhadores rurais"(Brasil, 2011, art. 14).

O PNHU é dividido entre faixas de renda familiar, as quais foram classificadas no lançamento do programa pela quantidade de salários mínimos recebidos, sendo a Faixa 1, até 3 salários mínimos² (SM); Faixa 2, de 3 a 6 SM; e Faixa 3, de 6 a 10 SM. No entanto, com o progressivo aumento do valor real do salário mínimo, os limites de divisão das faixas foram atualizados a cada fase (NASCIMENTO et al., 2015; Santo Amore, 2015), conforme indicados na Tabela 1.

Até a primeira parte da fase 3, vemos que as restrições de possíveis beneficiários aumentou, com o decréscimo real dos valores limites de cada faixa. Este decréscimo excluiu parte da população que acessava o programa pela Faixa 1, sendo criada uma faixa intermediária às faixas 1 e 2, a Faixa 1,5, na terceira fase do programa (NASCIMENTO et al., 2015). Apenas na segunda parte da fase 3 que os limites foram reajustados, com exceção da Faixa 1.

$\overline{2}$ O salário mínimo era de $\mathrm{R} \$ 465,00$ em julho de 2009, equivalente a $\mathrm{R} \$ 765,20$ em fevereiro de 2017 
Tabela 1 - Divisão das faixas

\begin{tabular}{cccccc}
\hline \multirow{2}{*}{ Fase } & Período & \multicolumn{5}{c}{ Faixa } \\
\cline { 2 - 6 } & & $\mathbf{1}$ & $\mathbf{1 , 5}$ & $\mathbf{2}$ & $\mathbf{3}$ \\
\hline \hline 1 & $03 / 2009-06 / 2011$ & $\mathrm{R} \$ 2.295,65$ & - & $\mathrm{R} \$ 4.591,30$ & $\mathrm{R} \$ 7.652,16$ \\
\hline 2 & $06 / 2011-12 / 2014$ & $\mathrm{R} \$ 2.321,72$ & - & $\mathrm{R} \$ 4.498,33$ & $\mathrm{R} \$ 7.255,38$ \\
\hline \multirow{2}{*}{3} & $03 / 2016-02 / 2017$ & $\mathrm{R} \$ 1.885,66$ & $\mathrm{R} \$ 2.461,83$ & $\mathrm{R} \$ 3.771,32$ & $\mathrm{R} \$ 6.809,32$ \\
\cline { 2 - 6 } & $02 / 2017-12 / 2018$ & $\mathrm{R} \$ 1.800,00$ & $\mathrm{R} \$ 2.600,00$ & $\mathrm{R} \$ 4.000,00$ & $\mathrm{R} \$ 9.000,00$ \\
\hline
\end{tabular}

Fonte - Brasil (2011). Elaboração própria.

Nota - Valores atualizados para 02/2017 pelo IPCA. Períodos definidos a partir dos lançamentos das fases.

Enquanto as faixas definem o limite de subsídios, valores máximos de aquisição das UH e taxas de financiamento para a compra das unidades, as modalidades do programa estão relacionadas ao modo de crédito, como o Fundo de Arrendamento Residencial (FAR), Fundo de Desenvolvimento Social (FDS) e o Fundo de Garantia por Tempo de Serviço (FGTS) (CARDOSO; ARAGÃO, 2013; Santo Amore, 2015). O atendimento à Faixa 1 pode ser via dois fundos: o FAR e o FDS (CARDOSO; ARAGÃO, 2013; Santo Amore, 2015). Via FAR, ele pode se desenvolver tanto através da construtora, que define todo o processo da construção (inclusive projeto e terreno) e o apresenta ao órgão gestor; quanto através da cooperação entre prefeitura, que doa terrenos, e construtora, que faz os projetos (CARDOSO; ARAGÃO, 2013; Santo Amore, 2015). O benefício para a construtora, nesta modalidade, é a certeza de venda após a contratação pelo órgão gestor, não correndo o risco de inadimplência pelos beneficiários, os quais são escolhidos através de listas de demanda fornecidas pelo município (CARDOSO; ARAGÃO, 2013; Santo Amore, 2015). O atendimento via FDS é também conhecido como MCMV Entidades, no qual entidades sem fins lucrativos e habilitadas pelo então Ministério das Cidades (hoje Ministério do Desenvolvimento Regional) apresentam projetos à CEF e os projetos selecionados recebem a verba para execução (CARDOSO; ARAGÃO, 2013; Santo Amore, 2015).

Já as faixa 2 e 3 são financiadas pelo FGTS (CARDOSO; ARAGÃO, 2013; Santo Amore, 2015). Nesta modalidade, as construtoras assumem também o trabalho de incorporação (lançamento e comercialização) dos empreendimentos (CARDOSO; ARAGÃO, 2013). Após a aprovação do projeto pela CEF e a venda mínima exigida, o empreendimento é contratado pelo órgão gestor e recebe o financiamento (CARDOSO; ARAGÃO, 2013).

Além dos limites das faixas, as fases se diferenciam pelas suas metas de contratação. Em seus primeiros anúncios, suas metas foram de um milhão para Fase 1, de dois milhões para a Fase 2 e de três milhões para a Fase 3 (Brasil, 2014; Brasil, 2016). Porém, com 
a revisão do Plano Pluri-Anual (PPA) de 2012/2015 em 2013, a meta da segunda fase aumentou para 2,2 milhões (Brasil, 2014), enquanto a terceira fase teve diferentes alterações durante a sua aplicação. Apesar de anunciada a meta de 3 milhões pelo PPA 2016/2019 (Brasil, 2016), a fase 3 apresentou em seu anúncio a meta de 2 milhões (MATOSO, 2016) e, após o impeachment da Presidenta Dilma Roussef (maio de 2016), o então ministro das cidades não garantiu o atendimento e paralisou novas contratações da Faixa 1 (ALVES, 2016).

As metas também se dividiam entre as faixas, na tentativa de priorizar o atendimento das faixas mais afetadas pelo déficit habitacional (Santo Amore, 2015). Nesse sentido, vemos a partir da Figura 1 que apesar de priorizar a faixa 1 nas duas primeiras fases e conseguir atender à expectativa na Fase 1, a contratação de UH da Faixa 2 é expressiva, principalmente ao comparar com a meta estabelecida na segunda fase. Além disso, verificamos que a prioridade se altera na Fase 3, com a redução da meta de contratação da Faixa 1 e o aumento para as faixas 2 e 3.

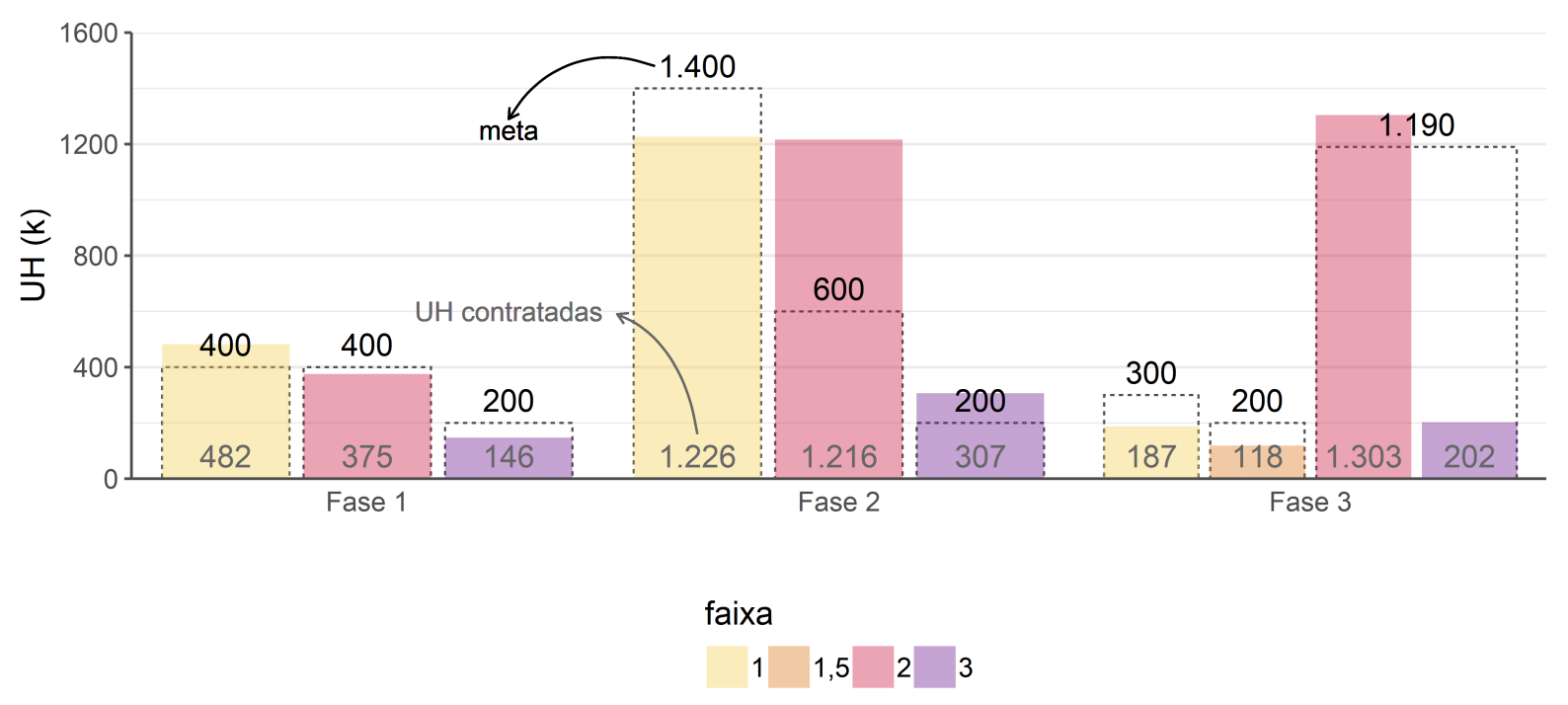

Figura 1 - Meta e contratação de unidades habitacionais (em milhar)

Fonte - Dados de Brasil (2014), Agência CBIC (2017), Fadul (2016), Ministério das Cidades (2018).

Elaboração própria.

Nota - As metas referentes às faixas 2 e 3 para a terceira fase foram apresentadas agrupadas nos anos de 2016 e 2017.

Quando comparadas com o déficit habitacional levantado pela Fundação João Pinheiro (Tabela 2), verificamos que as metas para as faixas 2 e 3 superam o déficit já na primeira fase (98\% e 281\%, respectivamente), enquanto que apenas $8 \%$ do déficit da Faixa 1 foi atendido pelas contratações. Vemos que a mesma estratégia se mantém nas fases seguintes e que mesmo que as metas e contratações estejam próximas do déficit habitacional das faixas mais altas, os valores se mantém relativamente constantes, sendo 
necessária uma análise aprofundada sobre essa defasagem entre demanda e oferta dos empreendimentos que não está dentro do escopo da nossa pesquisa.

Tabela 2 - Metas e contratações do programa

\begin{tabular}{|c|c|c|c|c|}
\hline Fase & Faixa & Déficit & Meta & \% do déficit \\
\hline \multirow{3}{*}{1} & 1 & 4.585 .332 & 400.000 & 8,7 \\
\hline & 2 & 407.133 & 400.000 & 98,2 \\
\hline & 3 & 71.248 & 200.000 & 280,7 \\
\hline \multicolumn{2}{|c|}{ Total da fase } & 5.063 .713 & 1.000 .000 & 19,7 \\
\hline \multirow{3}{*}{2} & 1 & 4.521 .394 & 1.600 .000 & 30,9 \\
\hline & 2 & 747.984 & 600.000 & 80,2 \\
\hline & 3 & 189.787 & 200.000 & 105,4 \\
\hline \multicolumn{2}{|c|}{ Total da fase } & 5.459 .165 & 2.400 .000 & 40,2 \\
\hline \multirow{2}{*}{3} & 1 & 4.459 .496 & 300.000 & 6,7 \\
\hline & $1,5,2$ e 3 & 781.342 & 1.390 .000 & 177,9 \\
\hline \multicolumn{2}{|c|}{ Total da fase } & 5.240 .838 & 1.690 .000 & 32,2 \\
\hline
\end{tabular}

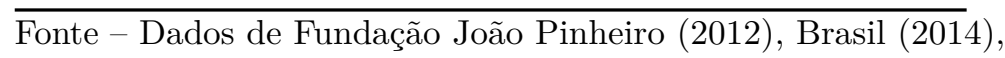
Fundação João Pinheiro (2015), Fadul (2016), Fundação João Pinheiro (2016), Agência CBIC (2017), Ministério das Cidades (2018). Elaboração própria.

Nota - Os dados de déficit habitacional são referentes aos anos de 2009, 2011 e 2014.

No entanto, não se pode analisar o sucesso de um programa apenas pela produção promovida por ele (MARICATO, 2009b), apesar de Ferreira (2015b) defender que a interferência nas políticas fundiárias locais e na localização dos empreendimentos não é dever de um programa de financiamento, como o PMCMV. Ainda assim, entende-se que o poder público, a nível municipal, deve aplicar instrumentos e leis urbanísticas para evitar problemas de localização (CARDOSO; ARAGÃO, 2013), como são criticados em estudos desenvolvidos por acadêmicos analisando a localização dos empreendimentos (CARDOSO; ARAGÃO; ARAUJO, 2011; CAMPOS; MENDONÇA, 2013; MARQUES; RODRIGUES, 2013; PEQUENO; FREITAS, 2013; LIMA et al., 2015; PEQUENO; ROSA, 2015; ROLNIK et al., 2015; RUFINO et al., 2015; Santo Amore; SHIMBO; RUFINO, 2015; SIQUEIRA-GAY; GALLARDO; GIANNOTTI, 2019). A seguir, é apresentada uma breve revisão destes estudos. 


\subsubsection{Avaliação da localização dos empreendimentos}

Esta seção tem como objetivo fazer uma breve revisão de trabalhos que desenvolveram alguma análise espacial dos empreendimentos promovidos pelo PMCMV. Sendo análises de visualização espacial dos empreendimentos (CAMPOS; MENDONÇA, 2013; PEQUENO; FREITAS, 2013; LIMA et al., 2015; ROLNIK et al., 2015), análises em menor escala, a partir de uma área de agregação ou município (CARDOSO; ARAGÃO; ARAUJO, 2011; RUFINO et al., 2015), cruzando com diferentes variáveis e as suas relações (MARQUES; RODRIGUES, 2013), e também utilizando indicadores espaciais para sintetizar essas informações (PEQUENO; ROSA, 2015; SIQUEIRA-GAY; GALLARDO; GIANNOTTI, 2019).

De modo semelhante, Campos e Mendonça (2013), Pequeno e Freitas (2013), Lima et al. (2015) avaliaram a localização dos empreendimentos a partir da visualização em mapa e o conhecimento prévio das regiões analisadas. Para a Região Metropolitana de Belo Horizonte entre 2009 e 2010, Campos e Mendonça (2013) chegaram à conclusão de que empreendimentos da Faixa 1 foram produzidos principalmente nas franjas das manchas urbanas dos municípios vizinhos de Belo Horizonte e nos bairros periféricos da capital. (LIMA et al., 2015) verificaram o mesmo padrão para a Região Metropolitana de Belém.

Os estudos de Pequeno e Freitas (2013), Rolnik et al. (2015) (RMFortaleza e RMCampinas e RMSão Paulo) também tiveram a mesma percepção. Complementando as análises, os autores verificaram, para suas respectivas áreas de estudo, relações entre porte, localização e faixa do empreendimento. Enquanto a maioria dos empreendimentos menores (poucas unidades habitacionais) se destinavam para as faixas 2 e 3 e se localizavam no entorno dos bairros centrais, os empreendimentos maiores se destinavam à Faixa 1 e estão em áreas periféricas da capital e em municípios vizinhos.

Além de usar a visualização da localização dos empreendimentos e descrição sobre a estrutura urbana do município do Rio de Janeiro, Cardoso, Aragão e Araujo (2011) avaliou os empreendimentos a partir da diferença entre população economicamente ativa (PEA) e empregos nas áreas de planejamento definidas pela prefeitura do município. O estudo concluiu que na área com maior quantidade de empreendimentos e UHs da Faixa 1 é também a área que já apresenta um desequilíbrio entre empregos e PEA.

Rufino et al. (2015) tiveram uma abordagem semelhante ao fazer uma análise espacial com dados agregados em macroescala para a Região Metropolitana da Baixada Santista, em São Paulo, comparando o atendimento do déficit habitacional por município e a quantidade de empreendimentos desenvolvidos. O grupo de estudo observou que os empreendimentos de Faixa 1 se localizavam em municípios de menor déficit habitacional e menor dinâmica e integração econômica. Enquanto municípios de maior déficit na região 
não apresentaram nenhum empreendimento.

Marques e Rodrigues (2013) avançaram em sua análise ao incluir proxies para avaliar acessibilidade (distância euclidiana a centralidades, subcentralidades, escolas, hospitais da rede pública e estações de transporte de massa) e segregação (dentro de um raio de 500m, características sociais, infraestrutura do domicílio e do entorno) dos empreendimentos da Região Metropolitana de São Paulo (RMSP). Ao comparar os resultados com os empreendimentos existentes promovidos pelo município e estado, os autores concluíram que a Faixa 1 acompanha o padrão existente, enquanto que os empreendimentos das faixas 2 e 3 têm valores melhores. Desse modo, eles refutam as afirmações de outros estudos em que o MCMV intensifica os padrões de segregação existentes.

Avançando na análise da RMF, Pequeno e Rosa (2015) avaliaram a localização dos empreendimentos a partir de um indicador sintético de qualidade do entorno (incluindo informações sobre rede de infraestrutura de saneamento, pavimentação, arborização, qualidade das calçadas e iluminação pública). Os autores verificaram que $84 \%$ dos empreendimentos produzidos até 2012 da Faixa 1 se localizavam em setores censitários avaliados como ruim e muito ruim.

Siqueira-Gay, Gallardo e Giannotti (2019) também usaram um indicador sintético que, além de integrar variáveis de infraestrutura do domicílio, ele agrega quantidade de área verde no setor censitário e indicadores de acessibilidade a trabalho, a escola e a equipamentos de saúde, que serão melhor explicados no Capítulo 3. O indicador foi aplicado no município de São Paulo e avaliou os empreendimentos direcionados à Faixa 1. As pesquisadoras observaram que alguns empreendimentos estão localizados nas áreas com a pior nota do indicador, sendo que outros estão em áreas muito melhores. Analisando os índices usados, as diferenças se dão devido a quantidade de área verde existente no setor. 


\section{As Zonas Especiais de Interesse Social}

Como já mencionado, uma das críticas à produção habitacional voltada à população de baixa renda é a localização dos empreendimentos (CARDOSO; ARAGÃO; ARAUJO, 2011; CAMPOS; MENDONÇA, 2013; CARDOSO, 2013; MARQUES; RODRIGUES, 2013; PEQUENO; FREITAS, 2013; BONDUKI, 2014; FERREIRA, 2015b; LIMA et al., 2015; PEQUENO; ROSA, 2015; ROLNIK et al., 2015; RUFINO et al., 2015; Santo Amore; SHIMBO; RUFINO, 2015; SIQUEIRA-GAY; GALLARDO; GIANNOTTI, 2019). Uma das causas levantadas é a falta de articulação com as políticas urbanas existentes (CARDOSO, 2013) e um dos instrumentos que possibilitariam uma melhor inserção urbana é a Zona Especial de Interesse Social.

As Zonas Especiais de Interesse Social "são porções do território destinadas, predominantemente, à moradia digna para a população de baixa renda"(São Paulo (cidade), 2014, art. 44). A ideia inicial das ZEIS foi a possibilidade de aumentar o acesso à terras, que normalmente estariam disponíveis apenas pelo mercado, para a população mais vulnerável (SANTORO; BORRELLI, 2015).

As ZEIS podem ser classificadas em duas categorias segundo o tipo de intervenção: as ZEIS de regularização e as ZEIS de vazios. As ZEIS de regularização são usualmente áreas ocupadas por assentamentos precários que estão irregulares perante a lei, sendo necessário que sejam assumidos diferentes parâmetros para facilitar a sua regularização. Já as ZEIS de vazios são caracterizadas por áreas não utilizadas ou subutilizadas, sendo destinadas para a produção de Habitação de Interesse Social ou do Mercado Popular (HMP) (ROLNIK; SANTORO, 2013; Santo Amore, 2013; São Paulo (cidade), 2014).

Mesmo que desde o início dos anos 1980 já existam as ZEIS de regularização (chamadas de Plano de Regularização das Zonas Especiais de Interesse Social - PREZEIS em Recife/PE e Programa Municipal de Regularização de Favelas - PROFAVELA - em Belo Horizonte/MG), apenas em 1994 foi instituída a Área Especial de Interesse Social (AEIS) de vazios no município de Diadema/SP em seu Plano Diretor (CALDAS, 2009; ROLNIK; SANTORO, 2013; Santo Amore, 2013; RIBEIRO; DANIEL; ABIKO, 2016). No entanto, somente com a sanção do Estatuto da Cidade, em 2001, o qual menciona as Zonas Especiais de Interesse Social (Brasil, 2001, art. 4), o instrumento se popularizou com as cartilhas e guias disponibilizadas pelo Ministério das Cidades (Santo Amore, 2013).

No caso de São Paulo, o Plano Diretor Estratégico instituiu as ZEIS como instrumento no município em 2002. Neste plano, foram definidas quatro ZEIS que se diferenciavam 
pelo tipo de ocupação existente, a intervenção prevista e parâmetros construtivos (Quadro 1). Dois parâmetros conhecidos e discutidos dentro do planejamento urbano são o coeficiente de aproveitamento (CA) e a taxa de ocupação máxima (TO). O coeficiente de aproveitamento é a relação entre a área edificada computável e a área do lote, que pode ser: básico, que resulta no potencial construtivo gratuito (igual a 1 para todas as ZEIS); máximo, que não pode ser ultrapassado; e mínimo, que abaixo desse valor o terreno pode ser considerado subutilizado (São Paulo (cidade), 2002). Já a taxa de ocupação máxima é a "relação entre a área da projeção horizontal da edificação ou edificações e a área do lote"(São Paulo (cidade), 2002, art. 146).

Quadro 1 - Definições e parâmetros das ZEIS 2002

\begin{tabular}{|c|c|c|c|c|}
\hline \multirow{2}{*}{ ZEIS } & \multirow{2}{*}{ Definição } & \multicolumn{2}{|c|}{$\mathbf{C A}$} & \multirow{2}{*}{ TO } \\
\hline & & $\min$ & máx & \\
\hline 1 & $\begin{array}{l}\text { Áreas ocupadas por população de baixa } \\
\text { renda, como favelas e loteamentos irre- } \\
\text { gulares }\end{array}$ & 0,2 & 2,5 & 0,5 \\
\hline 2 & $\begin{array}{l}\text { Áreas com predominância de glebas ou } \\
\text { lotes não edificados ou subutilizados }\end{array}$ & 0,2 & 2,5 & 0,5 \\
\hline 3 & $\begin{array}{l}\text { Áreas com predominância de terrenos } \\
\text { ou edificações subutilizados em áreas } \\
\text { com infra-estrutura, serviços urbanos e } \\
\text { oferta de emprego }\end{array}$ & 0,3 & 4,0 & 0,7 \\
\hline 4 & $\begin{array}{l}\text { Glebas ou terrenos não edificados em } \\
\text { áreas de proteção aos mananciais ou de } \\
\text { proteção ambiental }\end{array}$ & 0,1 & 1,0 & 0,5 \\
\hline
\end{tabular}

A atualização do PDE em 2014 dividiu as ZEIS 3 anterior entre ZEIS 3 e 5. Sendo a primeira relacionada a áreas com edifícios subutilizados e a segunda de áreas vazias, mas ambas "em regiões dotadas de serviços, equipamentos[,] (...) infraestruturas urbanas [e] boa oferta de empregos"(São Paulo (cidade), 2014, art. 45). A mesma atualização aumentou a quantidade de perímetros (964 para 2.281) (SANTORO; BORRELLI, 2015), e também 29,5\% o total em área, conforme a Tabela 3. Há um aumento significativo das ZEIS de vazios (107,9\%, somando ZEIS 2, 3 e 4): 109,6\% para ZEIS 2; 155,6\% para áreas vazias ou com edifícios subutilizados em regiões com boa infraestrutura; e 25,3\% das ZEIS 4, destinadas às áreas de mananciais. Conseguimos observar essas mudanças na Figura 2. 
Tabela 3 - Áreas por tipos de ZEIS

\begin{tabular}{cccc}
\hline $\begin{array}{c}\text { Tipo de } \\
\text { ZEIS }\end{array}$ & $\begin{array}{c}\text { PDE 2002 e Zoneamento } \\
\mathbf{2 0 0 4}\left(\mathrm{km}^{2}\right)\end{array}$ & $\begin{array}{c}\text { PDE 2014 } \\
\left(\mathrm{km}^{2}\right)\end{array}$ & $\begin{array}{c}\text { Crescimento } \\
\mathbf{( \% )}\end{array}$ \\
\hline \hline ZEIS 1 & 122,24 & 144,73 & 18,4 \\
\hline ZEIS 2 & 7,76 & 16,26 & 109,6 \\
\hline $\begin{array}{c}\text { ZEIS 3 } \\
*\end{array}$ & 5,92 & 15,13 & 155,6 \\
\hline ZEIS 4 & 3,57 & 4,47 & 25,3 \\
\hline \hline & $\mathbf{1 3 9 , 4 9}$ & $\mathbf{1 8 0 , 5 9}$ & $\mathbf{2 9 , 5}$ \\
\hline
\end{tabular}

$\overline{\text { Fonte - Adaptado de Gabinete do Vereador Nabil Bonduki, Câmara de Vereadores, }}$ 2014 apud Santoro e Borrelli (2015, p. 12)

Nota - * Foi adicionada à área da ZEIS 3 (2014) a área da ZEIS 5 (2014) por, em conjunto, terem a mesma definição que a ZEIS 3 (2002), permitindo melhor comparabilidade.

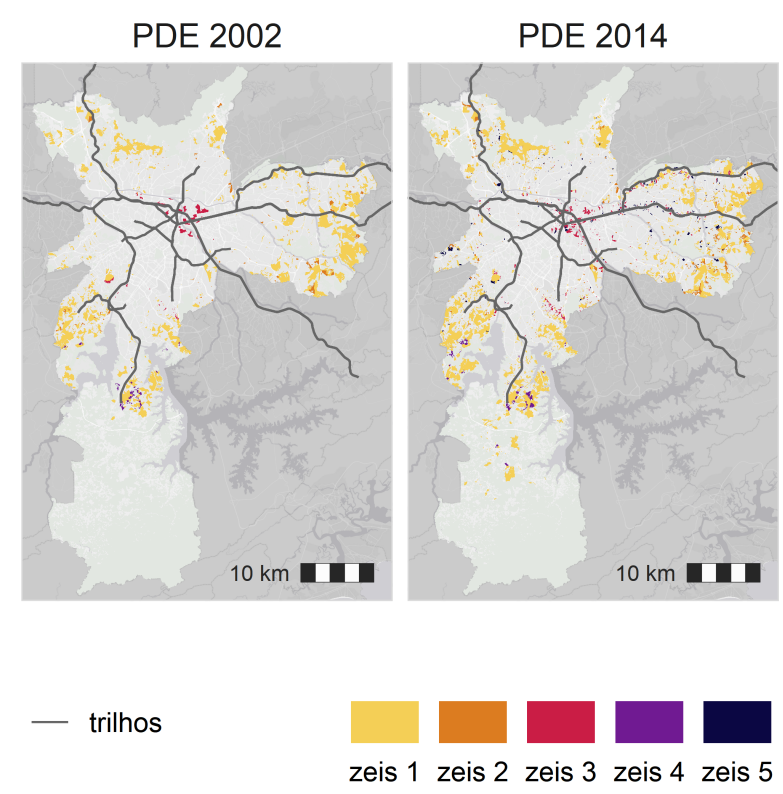

Esri, HERE, Garmin, INCREMENT P, @ OpenStreetMap contributors, and the GIS user community

Figura 2 - Mapas das Zonas Especiais de Interesse Social por PDE

Outra diferença entre os dois planos foi a definição de parâmetros para HIS e HMP, conforme o Quadro 2. Em 2002, HIS é a habitação destinada a famílias com renda menor ou igual a seis salários mínimos, com promoção pública, área útil máxima de $50 \mathrm{~m}^{2}$ e com no máximo um banheiro e uma vaga de garagem (São Paulo (cidade), 2002). Já em 2014, HIS também pode ser de promoção privada e é classificada em dois tipos: HIS-1, para famílias com renda até três salários mínimos; e HIS-2, famílias com renda de até 6 salários mínimos (São Paulo (cidade), 2014). No caso da HMP, a diferença está no limite da renda 
familiar; em 2002, o limite era de até dezesseis salários mínimos, enquanto que o plano atual limita a dez salários mínimos (São Paulo (cidade), 2002; São Paulo (cidade), 2014). Em ambos os planos a unidade habitacional de HMP pode ter até dois sanitários e uma vaga de garagem.

Quadro 2 - Parâmetros de HIS e HMP

\begin{tabular}{lcccc}
\hline \multirow{2}{*}{ Parâmetro } & \multicolumn{2}{c}{ HIS } & \multicolumn{2}{c}{ HMP } \\
\cline { 2 - 5 } & PDE 2002 & PDE 2014 & PDE 2002 & PDE 2014 \\
\hline \hline Renda familiar & até 6 SM & $\begin{array}{c}\text { HIS-1: até 3 SM } \\
\text { HIS-2: até 6 SM }\end{array}$ & até 16 SM & até 10 SM \\
\hline Área útil máxima & $50 \mathrm{~m}^{2}$ & - & $70 \mathrm{~m}^{2}$ & - \\
\hline Banheiro & 1 & 1 & 2 & 2 \\
\hline Vaga de garagem & 1 & 1 & 1 & 1 \\
\hline Promoção & $\begin{array}{c}\text { pública ou a } \\
\text { ela vinculada }\end{array}$ & $\begin{array}{c}\text { pública ou } \\
\text { privada }\end{array}$ & pública ou \\
privada
\end{tabular}

$\overline{\text { Fonte - Elaboração própria com base nos planos de São Paulo (cidade) (2014), São Paulo }}$ (cidade) (2002)

Nota - 1 SM em 2002 tinha valor de $\mathrm{R} \$ 200,00$ e equivale a $\mathrm{R} \$ 506,16$ em 12/2007; 1 SM em 2014 tinha valor de $\mathrm{R} \$ 724,00$ e equivale a $\mathrm{R} \$ 879,72$.

Além da definição dos parâmetros de HIS e HMP, os planos também definem o percentual mínimo da área construída que deve ser dedicada a HIS e a HMP nas ZEIS. No caso da São Paulo (cidade) (2004), no mínimo 80\% da área construída computável deve ser dedicada a construção de HIS e HMP em todas as ZEIS, com exceção da ZEIS 4. Este mínimo é dividido entre HIS e HMP, sendo $50 \%$ e 30\%, respectivamente, no caso das ZEIS 1 e 40\% para cada tipo no caso das ZEIS 2 e 3. Já para a ZEIS 4, a determinação é de que no mínimo $70 \%$ da área deve ser destinada à construção de HIS. Estes valores foram atualizados no São Paulo (cidade) (2014), o qual determinou o mínimo de $40 \%$ para HIS na ZEIS 5 e 60\% para as restantes. Apesar da determinação desses valores mínimos, na revisão do PDE 2002 verificou-se que eles não foram atendidos, conforme discutido na seção a seguir.

\subsection{O uso das ZEIS}

Para a revisão do PDE 2002, a então Secretaria Municipal de Desenvolvimento Urbano (SMDU) e a Secretaria Municipal de Habitação (SEHAB) avaliaram o uso das ZEIS demarcadas dentro do período (2002-2013) (São Paulo (cidade), 2013, p. 30). Em relação às ZEIS 2, apenas 38\% de sua área teve uso, sendo 41,9\% para uso institucional, como 
escolas, creches, parques, estação de tratamento de água e terminal de ônibus (previsto em lei (São Paulo (cidade), 2002, art. 171)), 33,4\% para a produção de HIS e HMP (tanto promoção pública, quanto privada), 17\% de assentamentos precários e moradias irregulares, e $6,8 \%$ foi usado para a produção de habitação de médio e alto padrão.

Já no caso das ZEIS 3, as áreas foram subdivididas entre: (i) lotes não utilizados / subutilizados; (ii) lotes em uso; (iii) lotes parte em uso / parte não utilizados / subutilizados; (iv) conjuntos de Quadras; e (v) edifícios. Dos lotes não utilizados ou subutilizados, apenas $51 \%$ (em área) foram consumidos, sendo $42 \%$ para produção de HIS e HMP (tanto por promoção pública, quanto privada), 29\% para uso institucional, $20 \%$ para produção de empreendimentos de alto padrão e $9 \%$ de outros usos, que não são descritos no relatório (São Paulo (cidade), 2013). O mesmo levantamento verificou que 88\% em área das ZEIS 4 se manteve desocupada, apesar de haver previsão de construção de habitação em 1,4\% da mesma (São Paulo (cidade), 2013). O restante das áreas se divide entre 7\% de assentamento informal e $5 \%$ de outros usos não descritos no relatório.

Focando na produção habitacional, o relatório não fornece a quantidade por unidade habitacional e nem a área utilizada no caso das ZEIS 3, dificultando a análise comparativa. Porém, pela Tabela 4, observa-se uma maior quantidade de empreendimentos de interesse social e para o mercado popular a partir da promoção privada (47 no total), mas é importante ressaltar que a produção pública foi exclusivamente para a população com renda de até seis salários mínimos.

Tabela 4 - Produção de habitação nas ZEIS no período entre 2002-2013

\begin{tabular}{ccccc}
\hline \multirow{2}{*}{ Tipo de produção } & \multicolumn{3}{c}{ ZEIS 2 } & ZEIS 3 \\
\cline { 2 - 5 } & Empreendimentos & $\mathbf{\%}$ & Empreendimentos & $\mathbf{\%}$ \\
\hline \hline $\begin{array}{c}\text { HIS promoção } \\
\text { pública }\end{array}$ & 18 & 40,0 & 24 & 44,4 \\
\hline $\begin{array}{c}\text { HIS/ HMP } \\
\text { promoção privada }\end{array}$ & 23 & 51,1 & 24 & 44,4 \\
\hline Alto padrão & 4 & 8,9 & 6 & 11,1 \\
\hline \hline Total & $\mathbf{4 5}$ & $\mathbf{1 0 0}$ & $\mathbf{5 4}$ & $\mathbf{1 0 0}$ \\
\hline
\end{tabular}

Fonte - Elaboração própria com base no relatório técnico de São Paulo (cidade) (2013)

Nota - A ZEIS 4 não foi incluída na tabela por não ter produção de HIS/HMP no período.

Santoro e Borrelli (2015) levantam que o mesmo relatório aponta que a quantidade em área de ZEIS vazias remanescentes não é suficiente para atender o déficit habitacional projetado no Plano Municipal de Habitação de 2009. Portanto o uso dessas áreas que 
não seja para a produção de HIS e HMP, como a produção de empreendimentos de alto padrão (cerca de 10\% da produção), devem ser coibidos, pois não cumprem a função social da propriedade. Outro uso dessas áreas que deve ser reduzido é para a produção de equipamentos públicos, além de diminuírem a possibilidade da redução do déficit, Ribeiro, Daniel e Abiko (2016) comentam que a sua produção em ZEIS 3 aumenta a atração do mercado imobiliário e possibilita a "expulsão da população mais vulnerável das regiões centrais da cidade".

Apesar da necessidade de aumento das áreas das ZEIS, a justificativa de um aumento menor do que o esperado pela participação da população na revisão foi a de que o preço para aquisição dos terrenos estava elevado, segundo a SEHAB (SANTORO; BORRELLI, 2015). Percebe-se, portanto, que mesmo havendo intervenções do poder público no uso e ocupação do solo para garantir o direito à moradia digna da população mais vulnerável, a mesma ainda se mantém refém do mercado imobiliário, reduzindo as suas possibilidades de acesso às oportunidades disponíveis na cidade. Para a avaliação da influência da localização das ZEIS com relação ao potencial de alcançar as oportunidades disponíveis na cidade, medidas de acessibilidade tem sido usadas e serão incorporadas na modelagem desse trabalho, por isso seguem melhor descritas a seguir. 


\section{Localização e possíveis medidas}

Para a análise da terra urbana, Villaça (2001) utiliza a definição de Lefebvre (1974 apud VILLAÇA, 2001), a qual diz que a terra urbana é composição entre o solo e o espaço produzido. Sendo o solo, a matéria que dá suporte ao que é construído na terra urbana e o espaço produzido, o que é construído no terreno e também no seu entorno (VILLAÇA, 2001). Deák (1985) também define o espaço produzido como o que torna o terreno útil e que possibilita ligações entre outros locais. É este espaço produzido que é considerado como a localização, a qual possibilita o deslocamento e o acesso à cidade (SINGER, 1982; DEÁK, 1985; VILLAÇA, 2001).

Por ser resultado da conjunção de diferentes trabalhos aplicados não só no próprio terreno, mas também no solo do restante da rede, a localização não pode ser replicada, ocorrendo o monopólio das localizações privilegiadas (SINGER, 1982; VILLAÇA, 2012; RIBEIRO, 2015a), ou seja, terrenos com melhor acesso à cidade. Entende-se, portanto, que uma das medidas que possibilitam o cálculo de localização, ou qualificá-la, é a acessibilidade. Acessibilidade, dentre muitas definições no contexto de transportes, é definida por Páez, Scott e Morency (2012) como o "potencial de alcançar oportunidades espacialmente distribuídas". Portanto, relaciona duas informações básicas: o custo da viagem, que fornece informações do sistema de transportes; e a quantidade ou qualidade das oportunidades, que fornece informações sobre o uso do solo (PÁEZ; SCOTT; MORENCY, 2012).

No contexto da habitação, como já discutido anteriormente, muitos autores criticam a alocação dos empreendimentos voltados para a baixa renda, por enfatizarem a estrutura espacial da cidade, aumentando a segregação urbana (CARDOSO; ARAGÃO; ARAUJO, 2011; CAMPOS; MENDONÇA, 2013; MARQUES; RODRIGUES, 2013; PEQUENO; FREITAS, 2013; BONDUKI, 2014; FERREIRA, 2015a; ROLNIK et al., 2015; Santo Amore; SHIMBO; RUFINO, 2015; SÍGOLO; SIGOLO, 2014). Maiores níveis de segregação, significam menor possibilidade de interação entre grupos diferentes, aumentando as chances de discriminação e reduzindo as de justiça social (RIBEIRO, 2007; MARICATO, 2009a; BARROS; FEITOSA, 2018). Feitosa et al. (2007), Marques e Rodrigues (2013) definem segregação urbana como um indicador do nível de separação entre grupos sociais no espaço. Podendo, portanto, auxiliar na avaliação do ambiente construído e a configuração social de um lugar.

A seguir, são discutidas as duas medidas que entende-se que permitem uma melhor inferência da localização: acessibilidade e segregação. 


\subsection{Acessibilidade}

Além das componentes de custo de transportes e atividades comentadas por Páez, Scott e Morency (2012), Geurs e Wee (2004) levantam outras que podem contribuir para a análise da acessibilidade real, são elas: temporal, que reflete a disponibilidade da oportunidade durante o dia; e individual, que reflete as características socioeconômicas do indivíduo que podem afetar o seu acesso. A partir da Figura 3, é possível entender as relações existentes entre cada componente e como a sua interação pode influenciar na acessibilidade real.

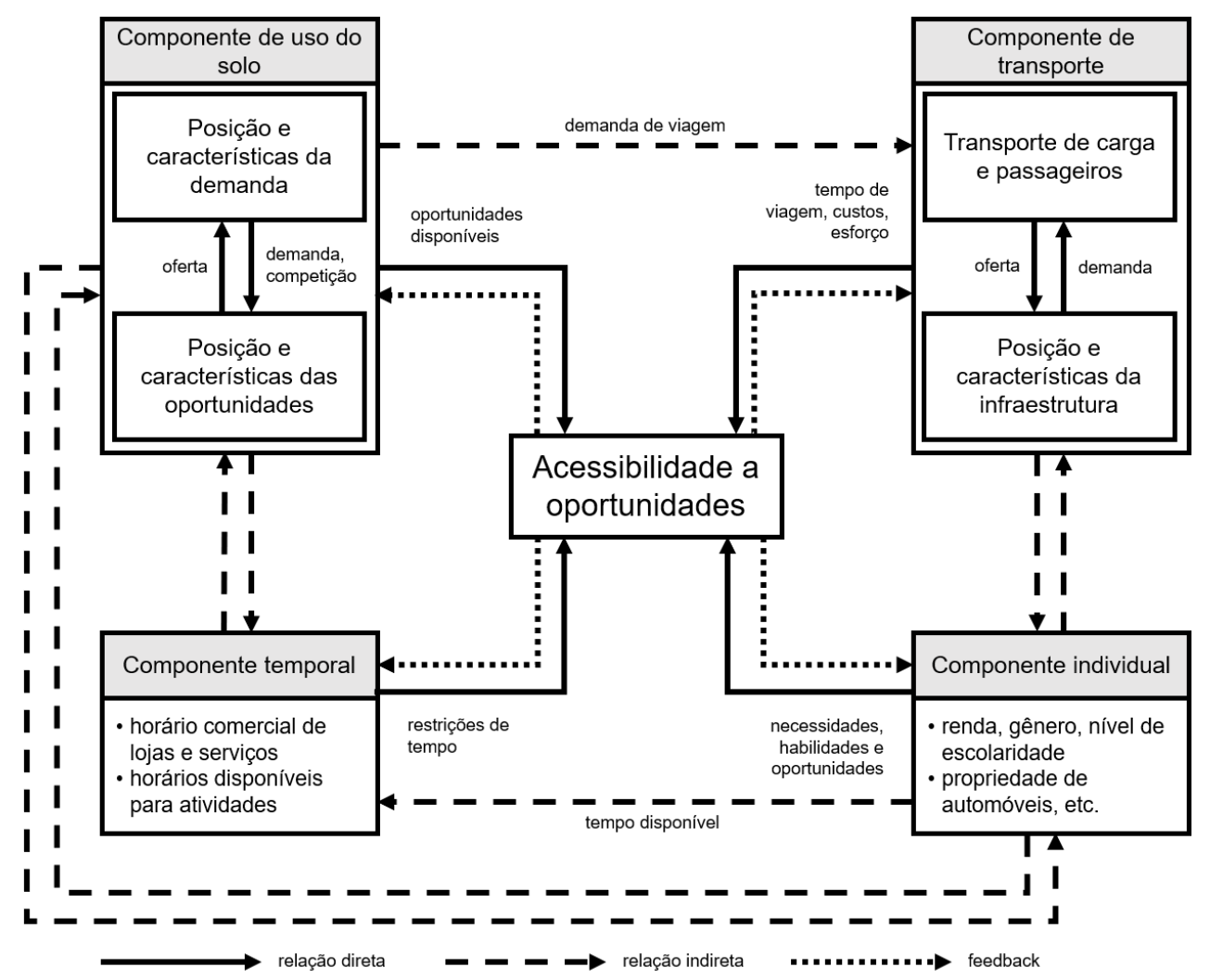

Figura 3 - Relações entre componentes de acessibilidade

Fonte - Adaptado de Geurs e Wee (2004, p. 129).

Outros estudos abordam elementos das componentes de transporte e individual de modo diferente ao considerar duas dimensões dicotômicas, sendo o eixo geográfico/social e o eixo potencial/revelado (JOSEPH; BANTOCK, 1982; KHAN, 1992; PÁEZ; SCOTT; MORENCY, 2012). A primeira dimensão é associada aos obstáculos presentes ao acesso às oportunidades, sendo eles obstáculos físicos (geográficos) presentes na infraestrutura de transporte ou sociais, que podem impedir que a pessoa possa exercer uma atividade, como renda e posse de automóveis (JOSEPH; BANTOCK, 1982; KHAN, 1992). Já o segundo eixo está relacionado ao uso dos dados. Enquanto o primeiro (potencial) infere comportamentos e oportunidades esperadas, o segundo utiliza os dados existentes para a análise, como o comportamento e disponibilidade de oportunidades reais (JOSEPH; 
BANTOCK, 1982; KHAN, 1992; PÁEZ; SCOTT; MORENCY, 2012).

Há duas medidas mais usadas para o cálculo da acessibilidade de um local: a acumulada e a gravitacional. Segundo Páez, Scott e Morency (2012), estas duas medidas são casos específicos da seguinte formulação geral:

$$
A_{i}^{p}=\sum_{j} W_{j, o} f\left(c_{i j}^{p}\right)
$$

A qual calcula a acessibilidade $A$ da origem $i$ para as oportunidades $W$ de tipo $o$ no destino $j$ para o indivíduo $p$. A função $f\left(c_{i j}\right)$ considera o custo generalizado de transportes $c_{i j}$ (ex: distância euclidiana, distância pela rede, tempo de viagem) e a diferença entre as duas medidas citadas acima está nesta função $f(\bullet)$, apresentada no Quadro 3. Para simplificar a formulação, iremos omitir os coeficientes $p$ e $o$ nas equações subsequentes.

Quadro 3 - Medidas de acessibilidade

\begin{tabular}{|c|c|c|c|c|}
\hline Medida & $f\left(c_{i j}\right)$ & & \multicolumn{2}{|c|}{ Formulação Geral } \\
\hline Acumulada & $f\left(c_{i j}\right)= \begin{cases}1, & \text { se } c_{i j} \leq \gamma_{i} \\
0, & \text { caso contrário. }\end{cases}$ & $(3.2)$ & $A_{i}=\sum_{j \in\left\{c_{i j} \leq \gamma_{i}\right\}} W_{j}$ & (3.3) \\
\hline$C$ revitorion & $f\left(c_{i j}\right)=c_{i j}^{-\beta}$ & $(3.4)$ & $A_{i}=\sum_{j}^{n} W_{j} c_{i j}^{-\beta}$ & $(3.5)$ \\
\hline & $f\left(c_{i j}\right)=e^{-\beta c_{i j}}$ & $(3.6)$ & $A_{i}=\sum W_{j} e^{-\beta c_{i j}}$ & (3.7) \\
\hline
\end{tabular}

Fonte - Elaboração própria.

Para a acessibilidade acumulada, a qual será a medida explorada neste trabalho, a $f(\bullet)$ depende de um limite de custo generalizado $\gamma_{i}$, o qual é determinado por quem está fazendo a análise, muitas vezes de modo arbitrário, conforme a Equação 3.2. Merlin e Hu (2017) consideram o resultado final é de fácil interpretação, pois resulta na quantidade de atividades de possível interação dentro do tempo limite determinado, como observado na Equação 3.3. No entanto, a métrica é criticada por não representar as possibilidades de decisão da realidade (SHEN, 1998; MERLIN; HU, 2017). Shen (1998), Merlin e Hu (2017) argumentam que, por ser uma métrica dicotômica, as oportunidades com $c_{i j}>\gamma_{i}$, mas próximas ao limite, não serão contabilizadas no indicador, enquanto que as oportunidades contabilizadas e próximas a esse limite são consideradas da mesma forma que as que estão mais próximas do ponto de interesse. Ou seja, as atividades que estão longe do ponto são tão atrativas quanto as que estão perto. 
Já a acessibilidade gravitacional, também conhecida como potencial, foi proposta por Hansen (1959) indicando a quantidade de atividades distribuídas no espaço, mas ponderando-as pela "habilidade e desejo"da população para superar as barreiras espaciais. Neste caso, a função $f\left(c_{i j}\right)$ não só considera o custo generalizado, mas também esta "habilidade e desejo"( $\beta$ ) descrita por Hansen (1959), como na Equação 3.4. Assim, todas as oportunidades de todas as zonas $n$ são contabilizadas para o cálculo de $A_{i}$, mas com diferentes pesos, ou seja, quanto mais distante de uma zona $i$, menor é a importância da área $j$ para $i$, sendo mais aderente à expectativa teórica (MERLIN; HU, 2017; MILLER, 2018). Atualmente, a função que depende do custo generalizado pode tomar a forma da Equação 3.6 (SHEN, 1998; GEURS; WEE, 2004; MERLIN; HU, 2017), resultando na Equação 3.7 de acessibilidade gravitacional.

Devido a esta ponderação, autores discutem a dificuldade de interpretar o resultado final da acessibilidade gravitacional, já que é a soma das oportunidades ponderadas de todas as regiões (BATTY, 2009). Outro problema levantado por Batty (2009, p. 192) é a diferença entre como as pessoas se comportam e como elas reagem em relação à infraestrutura, pois o cálculo de $\beta$ costuma utilizar os dados de viagens realizadas, portanto a representação do nível de acessibilidade pode ser diferente do real. Além disso, Joseph e Bantock (1982) já haviam levantado a ausência da análise da demanda das oportunidades para o cálculo da acessibilidade potencial, questão também existente para a acessibilidade acumulada. Não considerar a demanda no cálculo pode resultar em um nível de acessibilidade superestimado em áreas de alta concentração de médicos, mas também com alta concentração de população, por exemplo.

Para superar esta última dificuldade, Joseph e Bantock (1982) propuseram um cálculo adicional ao da acessibilidade potencial, o qual permite a análise de acessibilidade a saúde considerando a demanda (competição ${ }^{1}$ ) populacional tal como Shen (1998) propôs para a acessibilidade ao trabalho, resultando na Equação 3.9, onde $f\left(c_{i j}\right)$ pode ser igual às equações 3.4 ou 3.6 .

Outro segmento que levantou a necessidade de contabilizar a demanda na análise de acessibilidade foi o que discutia a defasagem espacial entre trabalho e população (PENG, 1997; WANG, 2000). Inicialmente, a análise de defasagem calculava a taxa de empregos de uma área $i$ pela população existente na mesma área. Apesar da facilidade de cálculo, Peng (1997), Wang (2000) levantam a aleatoriedade da análise, já que os limites administrativos não representam a realidade, pois um morador próximo a um limite pode trabalhar na zona vizinha. Portanto, os autores propuseram o Floating Catchment Area (FCA), computando, assim, não só a população contida na área geográfica, mas toda a população contida na área de influência (PENG, 1997; WANG, 2000; LUO; WANG, 2003).

\footnotetext{
1 Entende-se como competição a disputa da demanda pelo serviço oferecido.
} 
Quadro 4 - Medidas de acessibilidade com competição

\begin{tabular}{lccc}
\hline Medida & Demanda & \multicolumn{2}{c}{ Formulação Geral } \\
\hline \hline Shen & $D_{j}=\sum_{k}^{n} P_{k} f\left(c_{i j}\right)$ & $(3.8)$ & $A_{i}=\sum_{j}^{n} \frac{W_{j}}{D_{j}} f\left(c_{i j}\right)$ \\
\hline 2SFCA & $R_{j}=\frac{W_{j}}{\sum_{k} P_{k} f\left(c_{i j}\right)}$ & $(3.10)$ & $A_{i}^{p}=\sum_{j} R_{j}^{p} f\left(c_{i j}\right)$ \\
\hline
\end{tabular}

Fonte - Elaboração própria.

Em 2003, adaptando a proposta de Radke e Mu (2000), que calculavam a taxa de oportunidades por população a partir do provedor das oportunidades, Luo e Wang (2003) propuseram um avanço do FCA: o 2 Step Floating Catchment Area (2SFCA). A diferença entre as duas métricas é que além de calcular a taxa de emprego por população (1 $1^{\mathrm{a}}$ etapa análise de oferta, Equação 3.10) em relação ao provedor de serviço, a segunda etapa soma, a partir de pontos de demanda, as taxas calculadas na primeira etapa (Equação 3.11) (LUO; WANG, 2003).

Portanto, é possível reconhecer que há semelhanças entre as duas medidas que avaliam a competitividade do sistema. Enquanto a de Shen, a partir da $f\left(c_{i j}\right)$, pondera tanto a população quanto a taxa de oportunidades pelo comportamento, tal como a acessibilidade gravitacional. A acessibilidade 2SFCA tem a $f\left(c_{i j}\right.$ como uma função dicotômica dependente do limite pré-determinado por quem está fazendo a análise, como a acessibilidade acumulada.

Assim, a 2SFCA também considera as oportunidades com a mesma ponderação, já que a função que utiliza o custo generalizado é dicotômica. Do mesmo modo que a medida de Shen é parecida com a gravitacional, pois a função considera um fator de comportamento, dificultando a interpretação. Estas semelhanças e diferenças possibilitam a divisão das medidas entre os eixos de competição e ponderação, como na Figura 4.

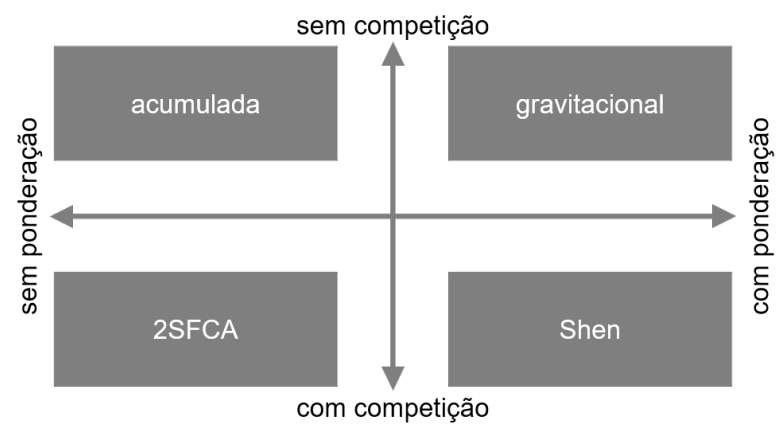

Figura 4 - Eixos de acessibilidade 
Outra dificuldade que é discutida por Neutens (2015) para a 2SFCA, mas que também aparece na medida de Shen é a superestimação da demanda. Podendo, portanto, dificultar a interpretação devido à taxa apresentada, pois um resultado baixo pode significar tanto a pequena quantidade de oportunidades que podem ser alcançadas, quanto a alta demanda. Enquanto que a acessibilidade acumulada resulta em um número absoluto de oportunidades alcançadas dentro do limite definido, não permitindo diferentes interpretações. Giannotti et al (2019, no prole) também verificaram que, no caso de São Paulo, os resultados da aplicação da acessibilidade acumulada e o 2SFCA são semelhantes, tanto na análise visual da distribuição espacial, quanto nos resultados de análise de desigualdades. Portanto, neste trabalho será aplicada a acessibilidade acumulada.

\subsection{Segregação espacial}

Diferente das medidas de acessibilidade, que têm como resultado significados semelhantes (relação do uso do solo com os transportes), as medidas de segregação, segundo a revisão feita por Reardon e O'Sullivan (2004), estão relacionadas a dois eixos: dispersão/agrupamento e exposição/isolamento (Figura 5). Enquanto o eixo dispersão/agrupamento refere-se ao quão equilibradamente distribuídos encontram-se os diferentes grupos no espaço residencial (REARDON; O'SULLIVAN, 2004), o segundo, exposição/isolamento, diz respeito à capacidade de encontro entre membros de grupos distintos (ou do mesmo grupo, no caso do isolamento) (REARDON; O'SULLIVAN, 2004).

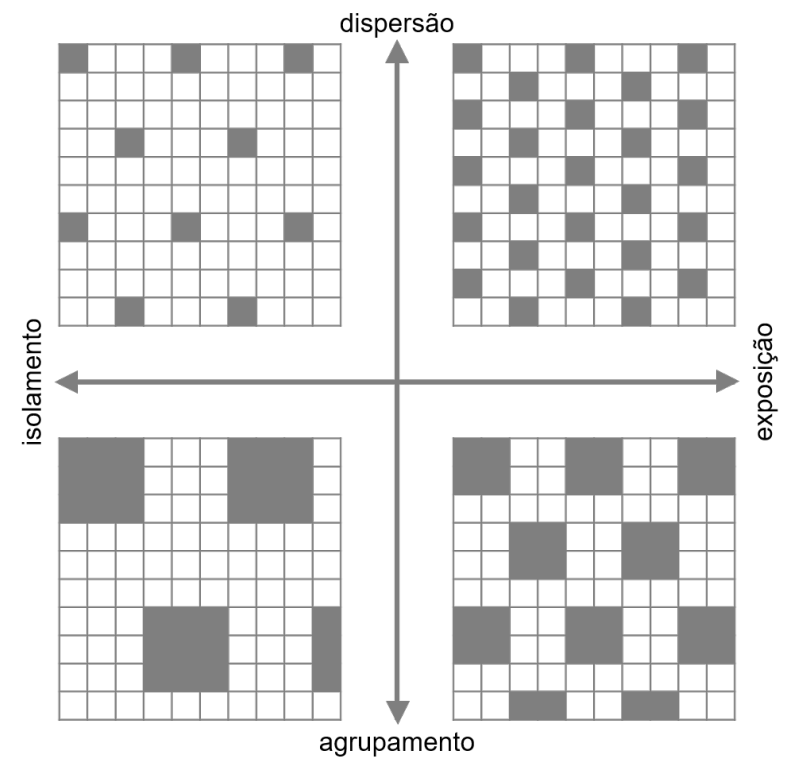

Figura 5 - Eixos de segregação urbana

Fonte - Adaptado de Feitosa et al. (2007) 
Desde a década de 1950, a segregação urbana é medida através de índices de segregação (FEITOSA; CÂMARA; MONTEIRO, 2007). Por representarem o grau de segregação de toda a área de estudo e não considerarem a espacialização dos diferentes gruos, estes índices iniciais, chamados de globais, receberam grandes críticas (FEITOSA et al., 2007; BARROS; FEITOSA, 2018). Desse modo, foram propostas alternativas de espacialização e de cálculo destes índices localmente. Assim, os índices locais, obtidos a partir de uma decomposição dos índices globais, permitem representar a segregação como um fenômeno que varia espacialmente e que pode ser apresentado na forma de mapas (FEITOSA et al., 2007).

Relacionando com a discussão de segregação urbana como efeito da má localização dos empreendimentos para classe de menor renda, iremos focar neste estudo o cálculo do índice de isolamento, o qual permite a medição da "experiência de segregação sentida pela minoria"Massey e Denton (1988, p. 287). Inicialmente discutido por Bell (1954), o índice de isolamento representa a probabilidade de um indivíduo de um determinado grupo encontrar outro membro do mesmo grupo. Portanto, Bell (1954) entende que este índice é composto por duas probabilidades:

1. a probabilidade de um indivíduo de um grupo $m$ encontrar alguém do mesmo grupo e na mesma localidade $i$; e

2. a probabilidade de um indivíduo de um grupo $m$ estar na localidade $i$.

Resultando na Equação 3.12, sendo $N$ a população, e o índice de isolamento $\left(Q_{m}\right)$ o produto entre a parte 1 , a primeira probabilidade, e a parte 2 , a segunda.

$$
Q_{m}=\sum_{i=1}^{I} \underbrace{\frac{N_{m i}}{N_{m}}}_{\text {parte } 1} * \underbrace{\frac{N_{m i}}{N_{i}}}_{\text {parte } 2}
$$

Como o foco da nossa análise é na espacialização, adotamos a abordagem de Feitosa et al. (2007), a qual decompõe o índice de isolamento global espacial $\left(\breve{Q}_{m}\right)$ através de índices locais espaciais $\left(\breve{q}_{i} m\right)$, os quais foram utilizados no estudo. A versão espacial considera a população além dos limites de uma localidade $i$, diferente do que ocorre na Equação 3.12. Essa flexibilidade é formalizada por uma função $\operatorname{Kernel}^{2}(k(\bullet))$, a qual é definida pelo analista e que permite análises multiescalares da segregação. Esta função $k(\bullet)$ é aplicada como fator de ponderação na intensidade populacional local $\left(\breve{L}_{i}\right)$ de cada unidade de área, resultando na média ponderada da população $N$ pela distância entre as unidades de área (FEITOSA et al., 2007). Desse modo, semelhante à acessibilidade potencial, quanto mais próximo da área analisada, maior é o peso da população.

Analisando a formulação de Feitosa et al. (2007) para o índice de isolamento global

2 Para mais informações sobre Kernel, ver Smith et al. (2018) 
espacial $\breve{Q}_{m}$ (Equação 3.13), verificamos que $Q_{m}$ proposto por Bell (1954) (Equação 3.12) se torna uma particularidade de $\breve{Q}_{m}$ quando a ponderação de Kernel é igual a 1 para todas as distâncias. Como discutido, o índice de isolamento global espacial é resultado da soma dos índices locais espaciais (compostos pelas partes 1 e 2) e pode variar de 0 (mínimo isolamento) a 1 (máximo isolamento) (FEITOSA et al., 2007).

$$
\begin{aligned}
\breve{Q}_{m} & =\sum_{i=1}^{I} \underbrace{\frac{N_{i m}}{N_{m}}}_{\text {parte1 }} * \underbrace{\frac{\breve{L}_{i m}}{\breve{L}_{i}} \text { onde, }}_{\text {parte2 }} \\
\breve{L}_{i} & =\sum_{j=1}^{J} k\left(N_{j}\right) \\
\breve{L}_{i m} & =\sum_{j=1}^{J} k\left(N_{j m}\right)
\end{aligned}
$$




\section{Decisões de pesquisa}

Para atender os objetivos da pesquisa, este trabalho adotou uma abordagem quantitativa baseada no cômputo do indicador de acessibilidade acumulada e índice de isolamento local espacial, discutidos no Capítulo 3. Para tanto, diferentes bases de dados foram utilizadas sendo, portanto, secundárias, ou seja, a sua coleta e seu tratamento foram feitos por institutos de pesquisa ou outras empresas. Foram utilizados: dados socioeconômicos, de oportunidades, de transportes e de produção habitacional, descritos nas seções abaixo em conjunto com decisões para a aplicação das métricas utilizadas.

Devido a diversidade desses dados e de suas escalas, foi adotada a biblioteca de hexágonos (H3) desenvolvida pela Uber (BRODSKY, 2018). O uso de grade estruturadas permite a comparabilidade entre estudos e a adição de novas análises para áreas vizinhas, usando a mesma escala e mantendo a continuidade do processamento. A biblioteca permite a escolha de diferentes escalas. A utilizada neste trabalho foi resolução 9, com área média de cada hexágono igual a $0.105 \mathrm{~km}^{2}$ (aproximadamente um quarteirão), resultando em 14.414 células para o município de São Paulo.

Reconhecemos que a análise da Região Metropolitana, principalmente no caso de São Paulo, é importante pois as relações de transporte, empregos e sociais não estão contidas em apenas um município. No entanto, devido a limitações de dados, discutidas a seguir, o recorte espacial será contido no município de São Paulo.

\subsection{Produção habitacional}

Na questão da produção habitacional foram utilizadas duas bases de dados: a de lançamentos imobiliários residenciais da RMSP sistematizados pela Empresa Brasileira de Patrimônio (Embraesp) entre o período de 1985 e 2013 aprimorados pelo CEM (CEM, 2014); e a de contratações de empreendimentos do PMCMV no Brasil entre 2009 e 2018.

Dentre as variáveis disponíveis na base da Embraesp, as utilizadas foram: área útil, quantidade de banheiros, de vagas por unidade e preço de venda da unidade. Vale ressaltar que o levantamento refere-se aos empreendimentos lançados pelas incorporadoras, portanto a base pode incluir tanto empreendimentos que não foram entregues, quanto que não foram totalmente vendidos (CEM, 2014).

O banco de dados (BD) de contratações do PMCMV está disponível na plata- 
forma de "Acesso a Informação"(Controladoria Geral da União, 2019). O processo de geocodificação dependeu dos campos de endereço e nome do empreendimento contidos no $\mathrm{BD}$, os quais permitiram a codificação de $82 \%$ do total de 701 empreendimentos no município de São Paulo. A falta de informação tem dois motivos: (i) alguns contratos são referentes a diferentes unidades habitacionais que podem estar espacialmente distribuídas e não concentradas em um empreendimento; (ii) os contratos estão protegidos pelo sigilo bancário, portanto empreendimentos de todas as faixas, exceto a Faixa 1, não são obrigados a apresentar as informações necessárias para fazer a geocodificação (Controladoria Geral da União, 2019).

\subsection{Acessibilidade no município de São Paulo}

Como já discutido na seção anterior, as medidas de acessibilidade apresentadas dependem de dois parâmetros: as oportunidades e o custo de viagem. No caso da acessibilidade acumulada, também deve-se determinar o limite do custo generalizado $\gamma$. Nas próximas subseções serão discutidos os dados utilizados e escolhas definidas para aplicação.

\subsubsection{Oportunidades}

A acessibilidade pode ser calculada para qualquer tipo de oportunidade como empregos, escola, equipamentos de saúde, equipamentos de lazer e até lojas de mercado. A partir da Pesquisa Origem e Destino de 2017 (Metro, 2019), observamos a predominância das viagens por motivo no destino trabalho (Figura 6). Para o ano de referência, excluindo as viagens com motivo no destino residência, quase $50 \%$ das viagens foram com motivo no destino trabalho, enquanto que viagens com motivo educação representam 27,9\% e viagens por outros motivos representam $22,4 \%$ do total. Portanto, a análise de acessibilidade para o município de São Paulo será a empregos.

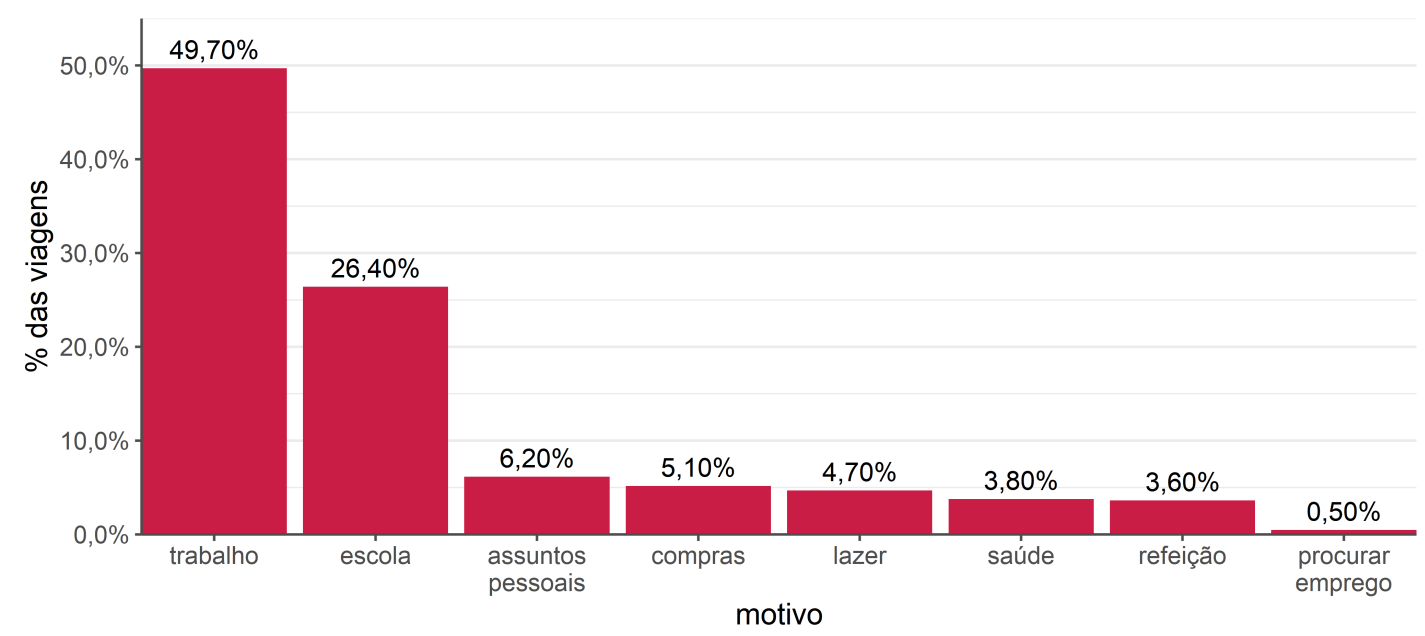

Figura 6 - Distribuição de viagens por motivo no destino 
Os dados de empregos formais usados para a análise provém da organização e geocodificação dos bancos de dados da Relação Anual de Informações Sociais (RAIS) pelo Núcleo de Economia Regional e Urbana da USP (NEREUS). Eles foram disponibilizados para o uso do Laboratório de Geoprocessamento da Escola Politécnica (LabGeo) em grade de $1 \mathrm{~km}^{2}$, para os anos de 2010 e 2014. Para complementar a análise, foi usada a base da RAIS 2017 organizada por CEP e georreferenciada pelo LabGeo.

Podemos observar na figura 7 que, com o decorrer do tempo, não há padrão espacial que evidencie as diferenças entre os anos. Olhando para a proporção de células para cada categoria (Figura 8) removendo as sem emprego, verificamos que há um aumento (10\%) de células com mais de 3.930 empregos (quinto percentil de 2010) ao longo dos anos. Vemos, também que em 2017 há um decréscimo (15\%) da quantidade de células da terceira classe, além do aumento de $8 \%$ na segunda categoria.



Figura 7 - Empregos formais em São Paulo

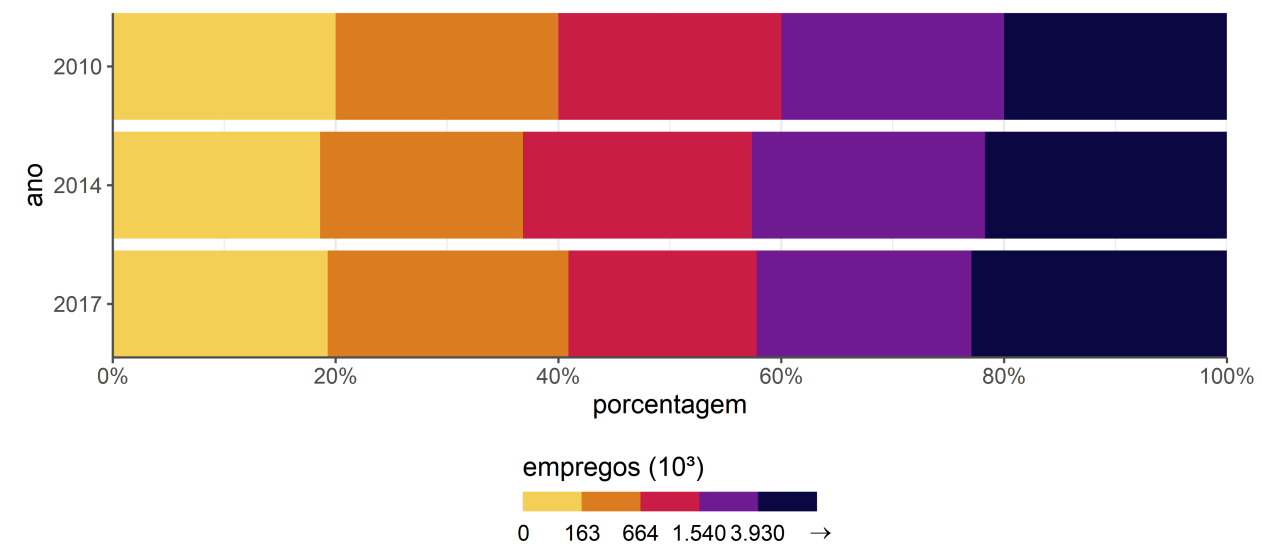

Figura 8 - Distribuição das células por célula 


\subsubsection{Transporte}

Já para a componente de transporte, foram usados os dados referentes ao sistema de transporte público do município de São Paulo fornecidos pela SPTrans. Dando continuidade ao recorte temporal de empregos, foram analisados os dados para os mesmos anos.

No entanto, os dados estão organizados segundo a Especificação Geral de Feeds de Transporte Público (GTFS) estática apenas a partir de 2012. A GTFS estática é um conjunto de arquivos em formato texto que contém informações de operação esperadas para o transporte público (Google, 2019). O uso do GTFS permite o cálculo de tempos de viagem entre pares de origem e destino usando o Open Trip Planner (OTP).

Para antes desse período, foram disponibilizadas as Ordens de Serviço Operacional e os itinerários georreferenciados de cada linha que operava em cada ano. Portanto, foi necessário organizar os dados fornecidos para o formato GTFS para o cálculo das matrizes de tempos de viagem para 2010. Porém, as seguintes questões foram encontradas neste processo: falta de informação de localização de pontos de ônibus, falta de trilhos e falta de velocidades.

Em relação ao último problema, a velocidade média esperada para cada linha foi calculada a partir da equação 4.1,

$$
V_{m_{i}}=\frac{e x t_{i}}{T C_{i}}, \text { tal que } T C_{i}=\text { headway }_{i} * \text { frota }_{i}
$$

sendo $V_{m_{i}}$ a velocidade média $(\mathrm{m} / \mathrm{s})$ da linha $i$, ext, a extensão total da linha (ida e volta, em m) e $T C$, o tempo de ciclo calculado a partir do headway e frota de cada linha $i$.

Em relação aos trilhos, foram levantadas as datas de inauguração de cada estação do sistema, com o objetivo de selecionar apenas os trechos em operação para cada data em de análise. Os trechos selecionados e usada como base os dados de 2014 e filtrando as estações existentes para cada ano de análise ${ }^{1}$. Já os pontos de ônibus foram obtidos a partir da GTFS mais antiga disponível (2012).

\subsubsection{Definição de limite de tempo}

Para o cálculo de acessibilidade acumulada, como discutido por Pereira (2019), é importante a análise usando diferentes limites de tempo de viagem. Como a análise é a partir do transporte público, foram escolhidos limites que possibilitem a variação e ainda

\footnotetext{
1 Tabela utilizada disponível em Apêndice A - Tabela 5
} 
captem a escala do modo analisado. Sendo eles $15 \mathrm{~min}, 30 \mathrm{~min}, 60 \mathrm{~min}$ e $120 \mathrm{~min}$ e aplicados para a rede de 2017 para quarta-feira às 7:00, como mostrado na Figura 9.

Para facilitar a interpretação, os valores de acessibilidade obtidos foram divididos pelo total de postos de trabalho existentes em 2017 (4.417.239), resultando na porcentagem do total de empregos. Vemos que, para o município de São Paulo, os limites de 15 e 30min não apresentam muita variabilidade de possibilidade de alcance das oportunidades, enquanto que para o de 120min praticamente todo o município tem um alto nível de acessibilidade, sugerindo que o limite de 60min é adequado para a análise.

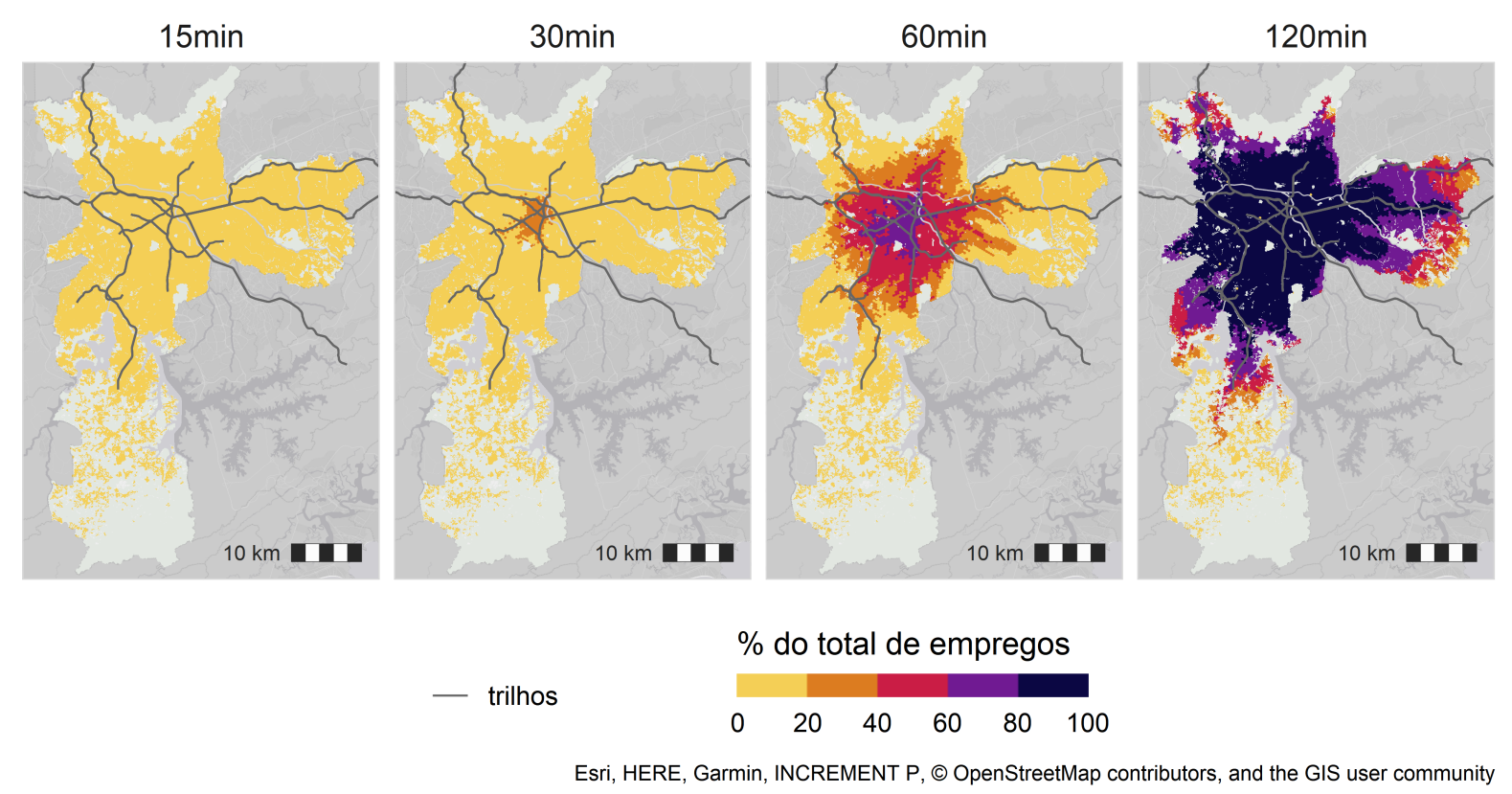

Figura 9 - Acessibilidade a empregos

Nota - Distribuição das células por acessibilidade e limite de tempo está no Apêndice A - Figura 33.

Tal sugestão é confirmada ao aplicarmos o método de definição de limite de tempo do Department for Transport Business Plan (2014). O método sugere a definição do limite através da mediana dos tempos de viagem de mesmo modo e motivo analisado. Utilizando novamente os dados da Pesquisa OD 2017, temos exatamente o limite de 60min.

\subsection{Segregação no município de São Paulo}

Para a aplicação do índice de isolamento, é necessário definir os grupos sociais a serem analisados. Abaixo, temos a descrição dos dados usados, os seus tratamentos e outras escolhas relacionadas à análise de segregação. 


\subsubsection{População e grupos}

Os dados socioeconômicos são do Censo demográfico de 2010 (Censo 2010), por ser o mais recente. A coleta dos questionários ocorreram entre $1^{\circ}$ de agosto de 2010 a 30 de outubro do mesmo ano (IBGE, 2011).

Os Censos Demográficos ocorrem a cada 10 anos e pesquisam todos os domicílios do país (IBGE, 2011). A pesquisa é dividida entre dois questionários: o questionário básico e o questionário da amostra. O questionário básico é aplicado em todos os domicílios, menos os selecionados para a amostra, investigando características socioeconômicas básicas do domicílio e dos moradores. Já o questionário da amostra contém as mesmas questões do questionário básico, mas também inclui as informações complementares, mas não é aplicado em todos os domicílios (IBGE, 2011).

Os dados resultantes das perguntas do questionário básico são chamados de Resultados do Universo e são agregados em setores censitários, os quais são áreas contíguas que respeitam limites administrativos e barreiras físicas (IBGE, 2011). Já os dados do questionário da amostra são chamados de Resultados Gerais da Amostra e estão agregados em área de ponderação, sendo elas resultados de agrupamentos de setores censitários (IBGE, 2010).

Para a definição dos grupos, foi utilizado o critério da primeira fase do PMCMV, que também se aproxima do PDE 2014, em que as famílias são classificadas por suas rendas. Comparando com o caso do PMCMV, em que as faixas 2 e 3 são comercializadas para o Mercado Popular, estas duas faixas foram agrupadas. Temos os grupos, divididos por renda familiar: 1, até três salários mínimos; 2, entre três a dez salários mínimos; e 3 acima de dez salários mínimos.

Assim, é necessária a informação da renda familiar bruta, mas está disponível apenas no questionário da amostra. Devido a esse problema, foi aplicada a microssimulação espacial a qual permite o processamento da representatividade de um indivíduo entrevistado em uma amostra em relação ao dado de um censo (LOVELACE; CHESHIRE, 2014; HUYNH; BARTHÉLEMY; PEREZ, 2016; LOVELACE; DUMONT, 2016). Melhor explicada por (LOVELACE; DUMONT, 2016), dentre os métodos possíveis, foi aplicado o Iterative Proportional Fitting (IPF), o qual, de modo iterativo, calcula o peso a partir de uma variável comum (chamada de restritiva) entre a amostra e o censo para obter uma variável presente apenas na escala menor (chamada de alvo).

Como o método fornece um número real e não inteiro para a ponderação do indivíduo, Lovelace e Ballas (2013) recomendam a aplicação do método Truncate, Replicate and Sample. A ferramenta permite transformar os pesos em inteiros sem que o total da 
área analisada seja alterado.

No caso deste trabalho, para conseguir os agrupamentos, foram usadas as variáveis de quantidade de domicílios com renda domiciliar per capita em salários mínimos, como restritiva, e domicílios com renda domiciliar em salários mínimos já classificados nos grupos acima como variável alvo (Quadro 5). Para a compatibilização entre as variáveis restritivas da amostra e universo, foi necessária a categorização dos domicílios da amostra usando como critério os cortes do universo. Através do teste $\chi^{2}$, verificou-se que há relação a entre as categorias ao nível de significância de 99,99\%. Entende-se, portanto, que é possível aplicar o método sem grandes perdas de informação.

Quadro 5 - Variáveis utilizadas.

\begin{tabular}{|c|c|c|c|}
\hline Tipo de variável & Categoria & $\begin{array}{l}\text { Variável } \\
\text { universo }\end{array}$ & $\begin{array}{l}\text { Variável } \\
\text { amostra }\end{array}$ \\
\hline \multirow{10}{*}{ Restritiva } & Sem rendimento & V014 & \multirow{10}{*}{ V6532 } \\
\hline & Renda per capita até 1/8 SM & V005 & \\
\hline & Renda per capita de $1 / 8 \mathrm{SM}$ até $1 / 4 \mathrm{SM}$ & V006 & \\
\hline & Renda per capita de $1 / 4 \mathrm{SM}$ até $1 / 2 \mathrm{SM}$ & V007 & \\
\hline & Renda per capita de $1 / 2 \mathrm{SM}$ até $1 \mathrm{SM}$ & V008 & \\
\hline & Renda per capita de 1 SM até 2 SM & V009 & \\
\hline & Renda per capita de $2 \mathrm{SM}$ até $3 \mathrm{SM}$ & V010 & \\
\hline & Renda per capita de $3 \mathrm{SM}$ até $5 \mathrm{SM}$ & V011 & \\
\hline & Renda per capita de 5 SM até 10 SM & V012 & \\
\hline & Renda per capita de acima de $10 \mathrm{SM}$ & V013 & \\
\hline \multirow{3}{*}{ Alvo } & G1: domicílio com renda até $3 \mathrm{SM}$ & \multirow{3}{*}{-} & \multirow{3}{*}{ V6530 } \\
\hline & G2: domicílio com renda de $3 \mathrm{SM}$ a $10 \mathrm{SM}$ & & \\
\hline & G3: domicílio com renda acima de $10 \mathrm{SM}$ & & \\
\hline
\end{tabular}

Fonte - Elaboração própria.

Dos 3.576.307 domicílios particulares registrados no Censo de 2010 no município de São Paulo, apenas 0,05\% não foi computado na microssimulação. Destes domicílios, 41,3\% foi classificado como parte do G1, 40,7\% do G2 e 18,0\% do G3. A distribuição espacial dos grupos está apresentada na Figura 10, que mostra o quanto o grupo é predominante dentro de uma célula. A partir desses mapas, vemos que os grupos extremos têm predominância em áreas distintas. Enquanto o G1 (mais pobres) predomina nas células nas franjas do município, o G3 (mais ricos) se destaca nas células do centro expandido, conhecido como quadrante sudoeste por Villaça (2011). 


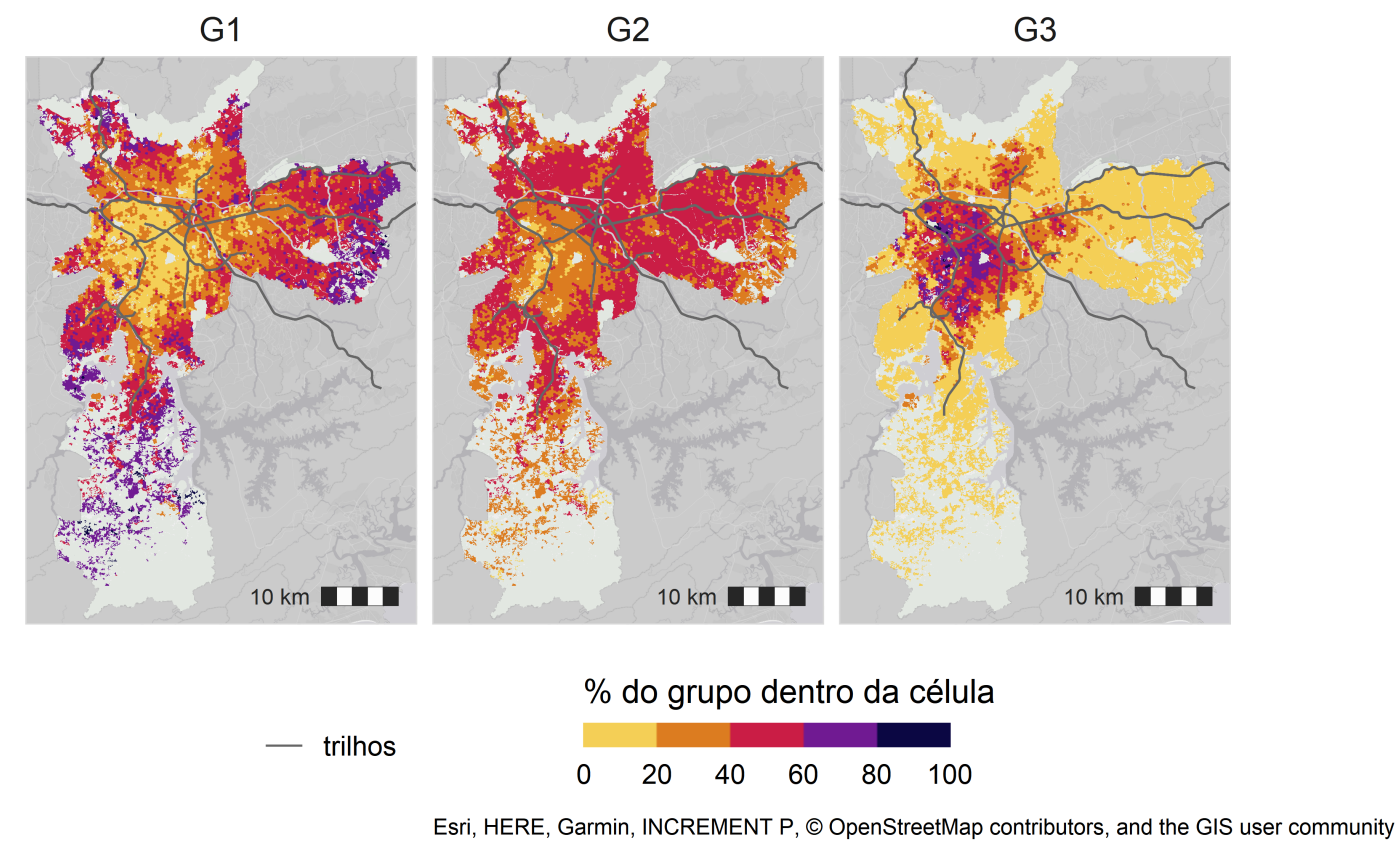

Figura 10 - Distribuição e predominância espacial dos grupos

\subsubsection{Definição de limite de vizinhança}

Para a aplicação do índice de isolamento local espacial, inicialmente é necessário selecionar a função de kernel. Como não é objetivo deste trabalho discutir os métodos de definição de vizinhança, escolhemos a função gaussiana, comumente aplicada nas análise de segregação.

Tal como a acessibilidade acumulada, é necessário definir uma largura de banda para o cálculo de segregação espacial. O'sullivan e Wong (2007) também recomendam a análise usando diferentes valores de banda, já que larguras maiores tendem a suavizar o resultado e menores enfatizam as particularidades locais. No caso deste trabalho, foram usados os limites de $500 \mathrm{~m}, 1.500 \mathrm{~m}, 5.000 \mathrm{~m}$ e $10.000 \mathrm{~m}$.

Podemos verificar a suavização a partir dos resultados dos valores globais. Enquanto para a largura de $500 \mathrm{~m}$ o $\breve{Q}_{G 1}$ é igual a 0,477 , este valor reduz com o aumento das bandas $(0,464,0,433,0,406$, respectivamente). Esta redução também pode ser observada espacialmente (Figura 11) e a análise da distribuição na escala, que divide a distribuição dos resultados para a banda de 500m em cinco percentis (Figura 12). A quantidade de células com os valores mais altos (azul escuro) diminui, enquanto aumenta a quantidade de células com valores intermediários. Considerando a discussão proposta por O'sullivan e Wong (2007), selecionamos a banda de $1.500 \mathrm{~m}$ para a análise. 

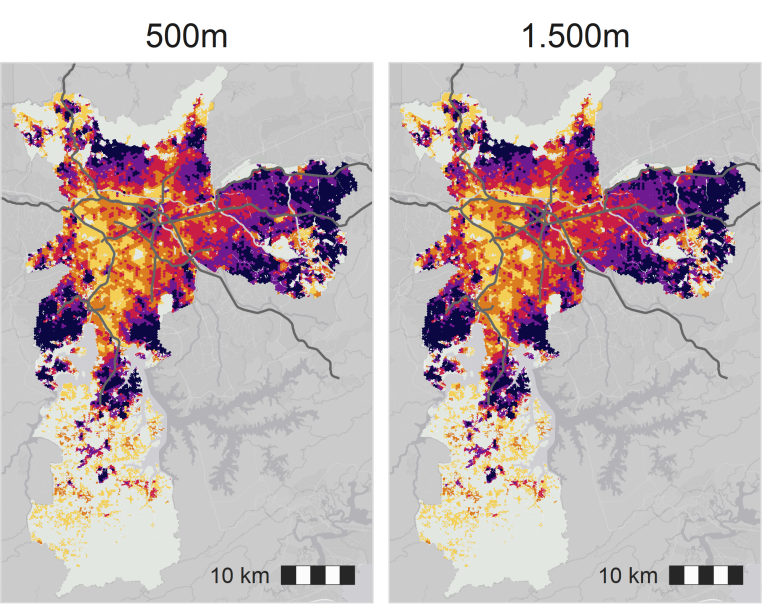

$10 \mathrm{~km}$

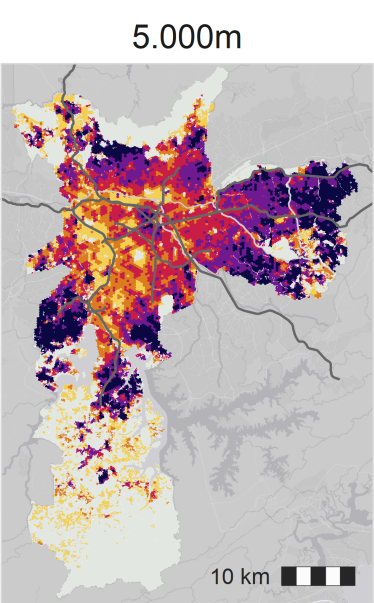

$10 \mathrm{~km}$

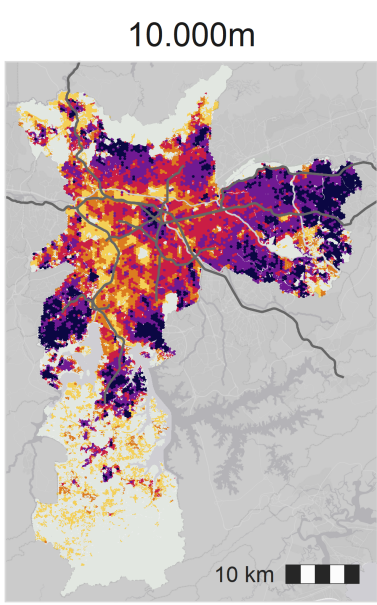

isolamento local (quantil)

- trilhos

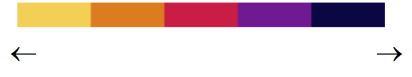

Esri, HERE, Garmin, INCREMENT P, ( ) OpenStreetMap contributors, and the GIS user community Legenda baseada na distribuiÃßÃ £o da banda de $500 \mathrm{~m}$.

Figura 11 - Isolamento de G1

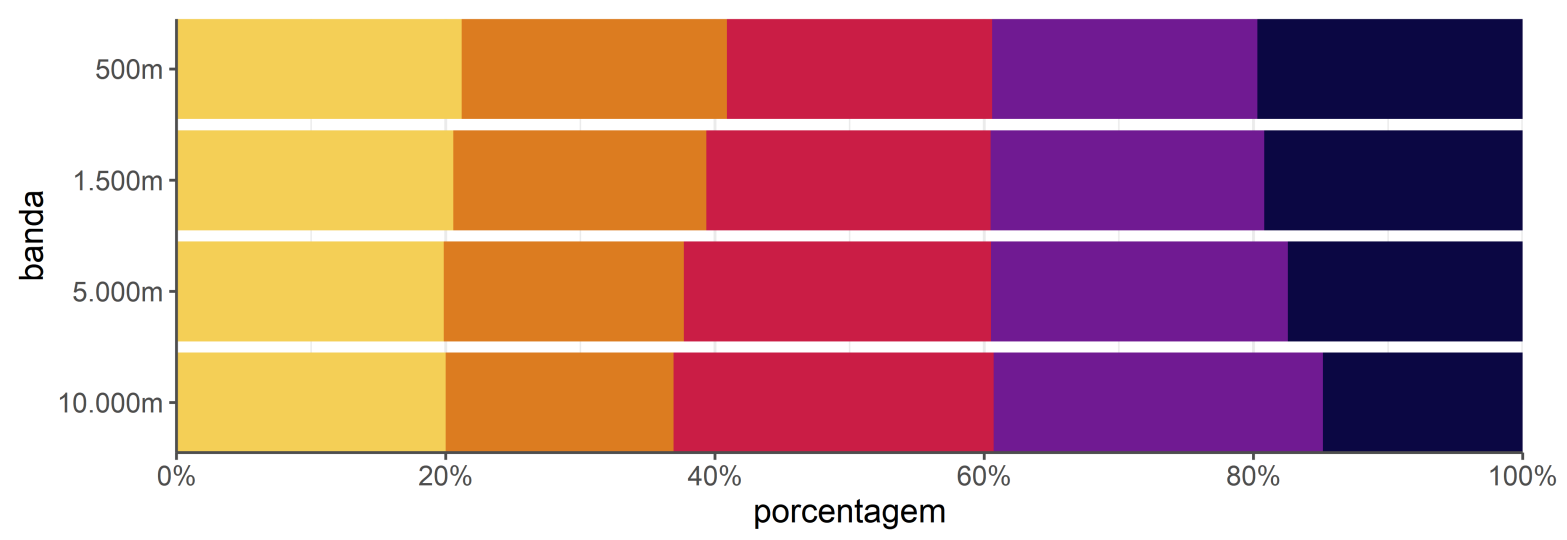

isolamento local (quantil)

$\leftarrow$

Figura 12 - Distribuição do isolamento por largura de banda 


\section{Estudos de caso}

O trabalho é constituído por duas análises: a relação da acessibilidade e segregação a partir do estudo de caso dos empreendimentos propostos em São Paulo, tanto os promovidos pelo Programa Minha Casa Minha Vida, quanto os pelo mercado imobiliário, além da variação de acessibilidade no município dentro do período; e a de localizações das Zonas Especiais de Interesse Social e seu uso.

\subsection{A relação entre acessibilidade e segregação e a localização dos empreendimentos}

Com os limites de tempo de viagem para o cálculo de acessibilidade e de largura de banda para o processamento de segregação definidos (60min e $1.500 \mathrm{~m}$, respectivamente), podemos iniciar a análise de relação das métricas. Ao dividir a distribuição de acessibilidade em intervalos iguais a partir do valor máximo obtido ( $81 \%$ do total de empregos), temos a figura 13 - acessibilidade na qual vemos que os maiores níveis de acessibilidade (verde escuro) estão concentrados no conhecido quadrante sudoeste (VILLAÇA, 2011).

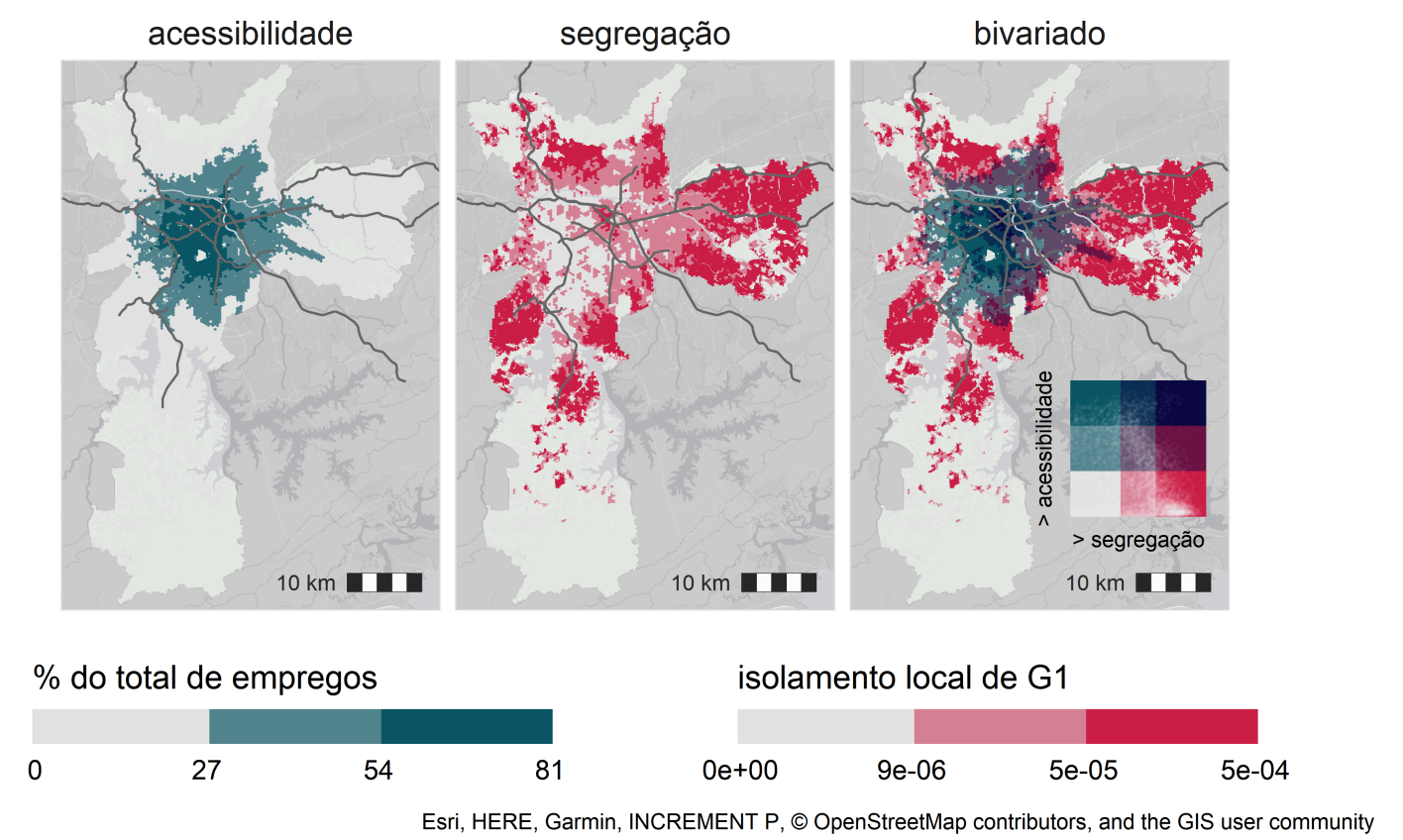

Figura 13 - Mapas de acessibilidade, isolamento e bivariado

No caso do isolamento do grupo de baixa renda (Figura 13 - segregação), a escala foi dividida em três percentis. A partir dele observamos um mapa que se assemelha ao 
"negativo"do mapa de acessibilidade, onde maiores valores de segregação (vermelho) estão localizados em áreas de menor acessibilidade (cinza).

Esta relação está melhor representada pelo mapa bivariado (Figura 13 - bivariado). Neste terceiro mapa, quanto mais saturada a cor (menos acinzentada), maior é o valor do indicador. Desse modo, vemos que são poucos os casos $(0,4 \%)$ com alto valor de segregação e acessibilidade (azul escuro), enquanto há a predominância (30,4\%) das células com alto isolamento e baixa acessibilidade, seguida por baixos valores dos indicadores (19,5\%). Este resultado é refletido na correlação simples das células(-0,282).

Aprofundando a análise e calculando a autocorrelação espacial bivariada pelo Moran I, vemos que há relação espacial entre as variáveis e que, quanto maior a acessibilidade, menor o isolamento (Moran I = -0,285). Espacializando esta relação a partir do índice local de associação espacial (LISA) de Moran (Figura 14), verificamos que o quadrante sudoeste, com exceção da região central, se destaca com altos níveis de acessibilidade, mas baixo isolamento (alto - baixo). Enquanto que as franjas do município, como zona leste, área dos mananciais, mas fora das áreas de proteção, e próximo a Serra da Cantareira, são áreas com baixa acessibilidade e alto isolamento (baixo - alto).

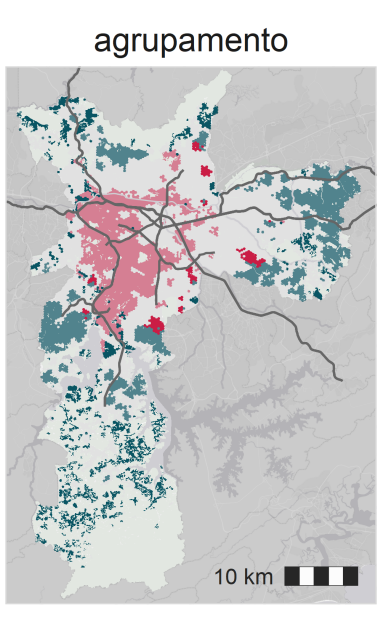

agrupamento

- trilhos



alto - alto alto - baixo não significante baixo - alto baixo - baixo

Esri, HERE, Garmin, INCREMENT P, $\odot$ OpenStreetMap contributors, and the GIS user community

Figura 14 - Mapas LISA de Moran, agrupamentos e significância

\subsubsection{As localizações do PMCMV}

Durante os dez anos do programa Minha Casa Minha Vida em São Paulo, foram contratados 701 empreendimentos, totalizando 134.676 unidades habitacionais, das quais $51 \%$ foram entregues. Ao final de 2018, a terceira fase corresponde 50\% das UH contratadas, 
seguida pela segunda fase (29\%) e então pela primeira (21\%). Em relação ao total de UH contratadas por faixa de renda e fase, a maioria é da Faixa 2 durante a terceira fase $(34,93 \%$ e $15,75 \%$, respectivamente), enquanto a que foi menos contratada, foi a Faixa 1,5, com apenas 3 empreendimentos e correspondendo a 0,43\% de todas as unidades contratadas. Pela baixa quantidade e impossibilidade de comparação com as outras fases, desconsideraremos a Faixa 1,5 para as próximas análises.

Em relação à distribuição espacial dos empreendimentos, a partir da figura $15^{1}$, vemos que os empreendimentos da Faixa 1 estão nas franjas do município independente da fase, como já apontado em diversos trabalhos Marques e Rodrigues (2013), Rolnik et al. (2015), Siqueira-Gay, Gallardo e Giannotti (2019). Ferreira et al. (2019), Shimbo (2019) argumentam que isso ocorre pois, como a maioria dos produtores são incorporadoras do mercado imobiliário, as escolhas para o gasto com localização são direcionadas às faixas 2 e 3, por estes grupos terem maior poder de compra. Enquanto que, como as famílias da Faixa 1 são alocadas pelo poder público e não tem poder de escolha sobre onde morar, as incorporadoras selecionam localizações mais baratas e que são mais rentáveis (ACOLIN; HOEK-SMIT; ELOY, 2019).

No entanto, de forma contra-intuitiva ao argumento apresentado, já que a faixa 3 teria poder de compra maior que a faixa 2 , poucas são as contratações dos empreendimentos destinados a esse grupo dentro do centro expandido do município. Enquanto que as da Faixa 2 estão espalhadas pela cidade, mas com uma concentração maior no centro.

$\overline{1}$ Para o mapa de calor, foi aplicada a função kernel com banda constante igual a $5 \mathrm{~km}$. 


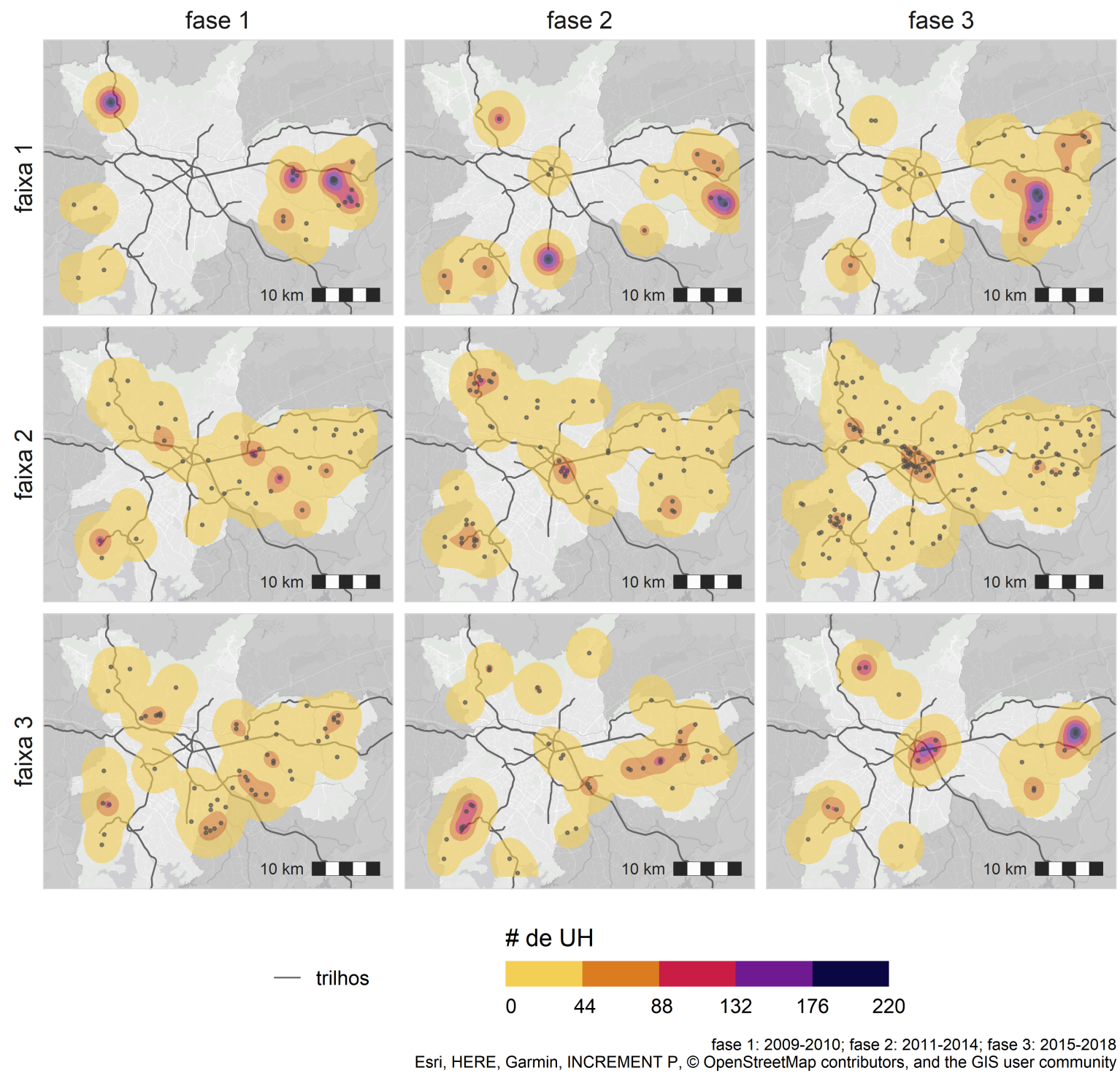

Figura 15 - Localização dos empreendimentos do PMCMV em São Paulo

Usamos os resultados apresentados na Figura 13 para avaliar a localização do PMCMV (Figura 16) e comparamos com o restante do município (pontos em cinza) e com as medianas dos indicadores (retas), que indicam que metade das células atingem apenas 9,7\% dos empregos do município e têm um nível de isolamento de 2e-05. Na figura, vemos que a maioria dos empreendimentos da Faixa 1 (65,2\%), independente da fase, estão em lugares com baixos níveis de acessibilidade e alto isolamento em relação às medianas. Discretizando esses empreendimentos por fase, eles correspondem a 82,2\% dos contratados na fase $1,66,7 \%$ na fase 2 e 50,0\% na fase 3 . Apesar dessa redução, sua localização se mantém predominantemente em regiões com baixa acessibilidade ( $87 \%$ na fase $1,66,7 \%$ na fase 2 e 67,9\% na fase 3), estando, portanto, em locais com menor isolamento.

No caso da faixa 2, observa-se que a maioria dos empreendimentos contratados (36,11\% na fase 1 e 36,67\% na fase 2) também estão em áreas com níveis mais baixos de 
acessibilidade e mais altos de segregação. No entanto, 39,55\% dos empreendimentos da fase 3 desta mesma faixa estão no quadrante alto-alto, ou seja, em lugares com maiores níveis de acessibilidade e de segregação. O mesmo ocorre para a faixa 3 na fase 1, em que $39,62 \%$ estão no quadrante alto-alto. Enquanto isso, cerca de 50,0\% dos empreendimentos propostos nas fases seguintes para o mesmo grupo foram alocados em áreas de baixa acessibilidade e alta segregação.

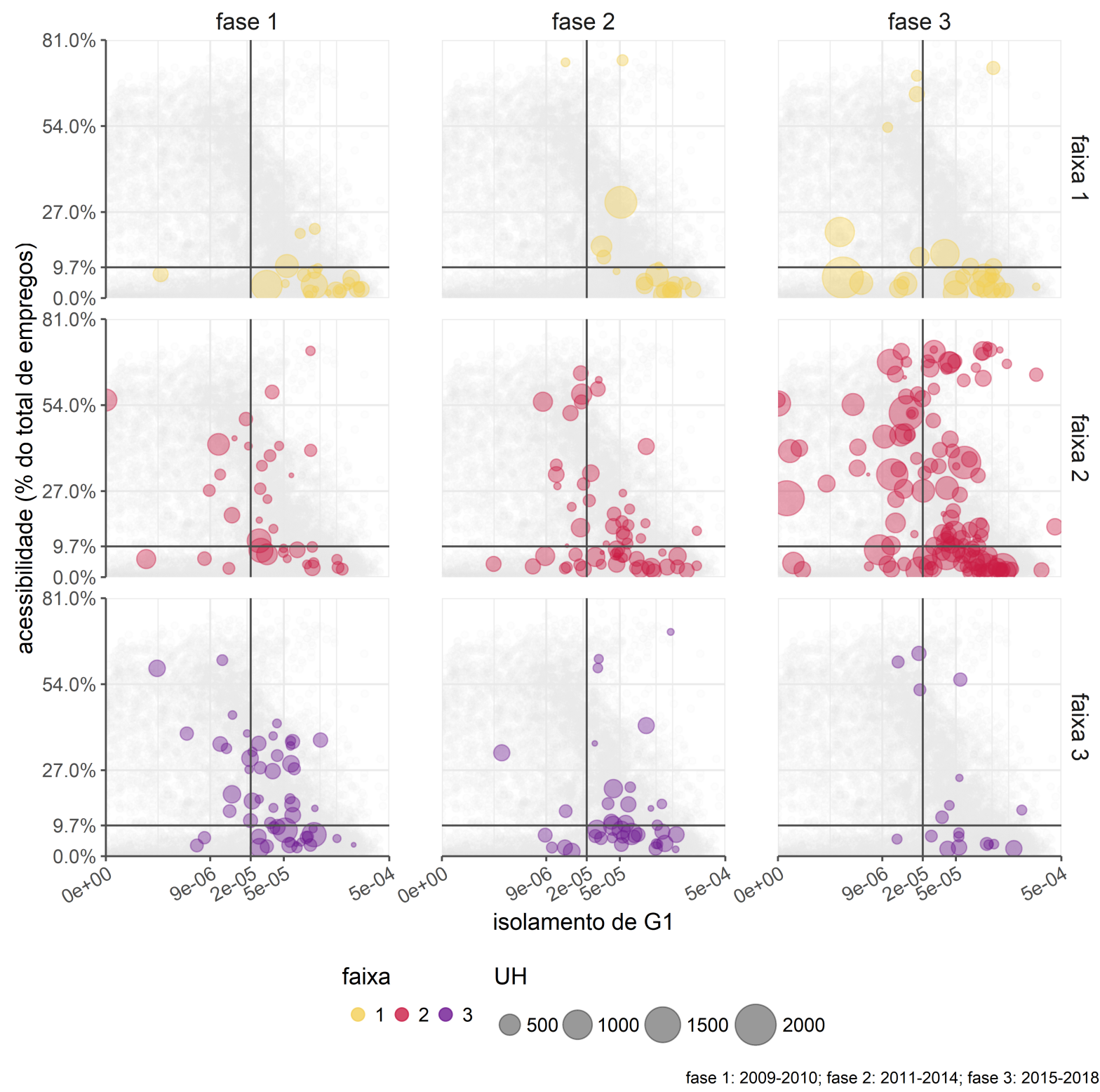

Figura 16 - Gráficos de acessibilidade por segregação, divididos por fase e faixa.

\subsubsection{A localização dos empreendimentos do mercado imobiliário}

A produção habitacional pelo mercado imobiliário, como discutido no Capítulo 1, foi marcada pelo direcionamento dos produtos para as camadas de alta renda, além da má localização dos poucos empreendimentos para baixa renda. Nesta seção, iremos analisar 
os lançamentos imobiliários pela iniciativa privada dentro do período do Plano Diretor Estratégico de 2002 e que intersecciona com o PMCMV (2009-2013), para comparação.

Durante esse período, foram lançados 3.064 empreendimentos, totalizando 169.727 $\mathrm{UH}$, resultando em uma média menor de UH por empreendimentos $(55,4)$ que o PMCMV $(180,4)$, para o mesmo período. Ao analisar em conjunto os gráficos da Figura 17, vemos que as distribuições das áreas das UH lançadas pelo mercado imobiliário se mantém constante ao longo dos anos. Enquanto que o gráfico da direita mostra que, com o passar dos anos, houveram mais lançamentos com maior relação entre preço e área útil.
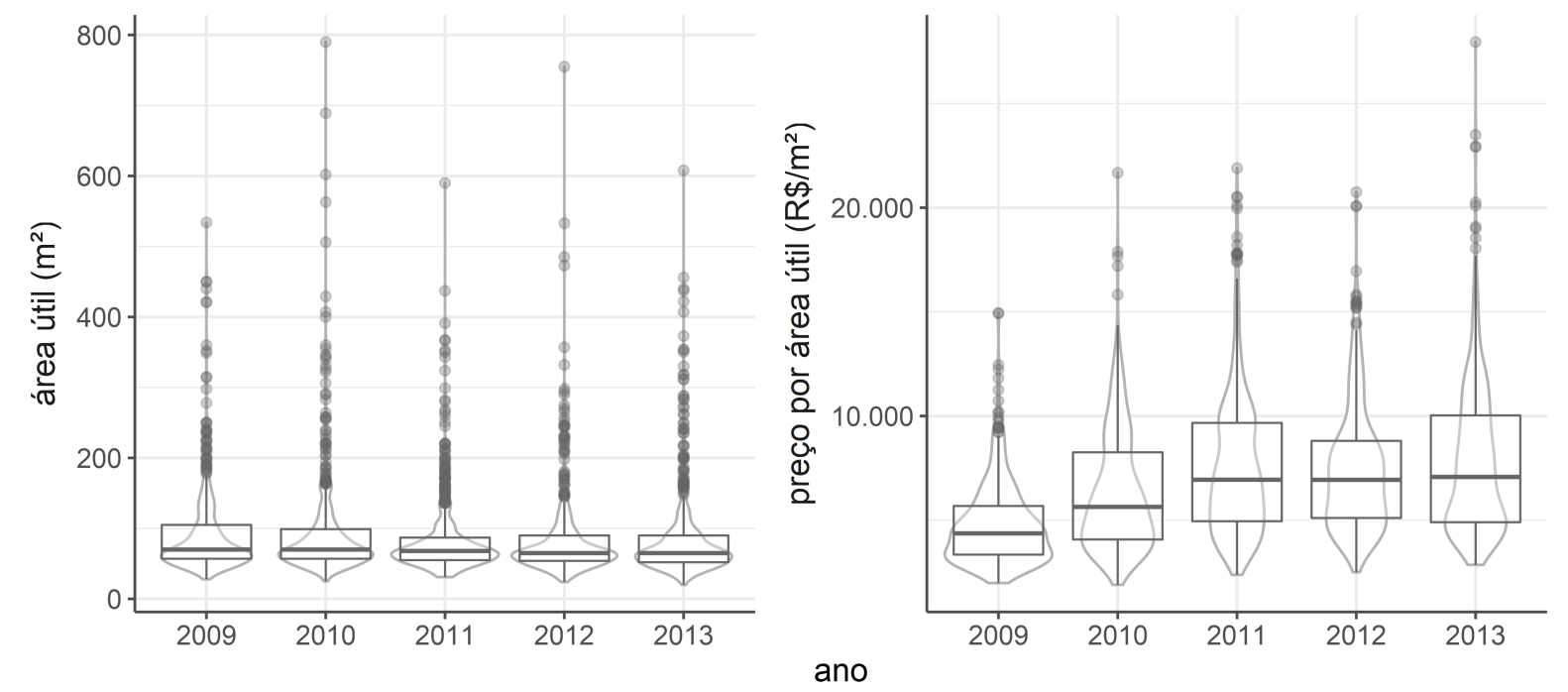

Figura 17 - Boxplots da área útil da $\mathrm{UH}$ e preço por $\mathrm{m}^{2}$ de área útil da $\mathrm{UH}$

Nota - O preço por $\mathrm{m}^{2}$ de área útil da UH foi atualizado em valores de dezembro de 2013 pelo IGP-DI (CEM, 2014, p. 7).

Os empreendimentos foram classificados adotando os critérios de HIS e HMP do PDE 2002 (Quadro 2) e os limites de valores determinados pelo PMCMV para cada período, para possibilitar a comparação. No caso da primeira fase, foi usado R $\$ 52.000,00$ para HIS, limite da faixa 1, e R\$130.000,00 para HMP, limite da faixa 3 (Santo Amore, 2015). Já para a segunda fase, os critérios foram $\mathrm{R} \$ 76.000$ para HIS e $\mathrm{R} \$ 190.000$ para HMP. Todos os limites foram atualizados para dezembro de 2013 usando IGP-DI, correspondendo à atualização feita na base de dados utilizada, sendo $\mathrm{R} \$ 68.429,16$ e $\mathrm{R} \$ 171.072,90$, para a primeira fase, e $\mathrm{R} \$ 86.707,06$ e $\mathrm{R} \$ 216.767,66$, para a segunda.

Analisando o total de unidades produzidas por tipo de empreendimento (Figura 18), o primeiro destaque é a falta de lançamentos classificados como HIS no período analisado. Outro padrão evidente é a constante de propostas de UH de HMP (em torno de 25\%) em relação ao que foi proposto para alta renda (em torno de 75\%) durante todo o período. Este resultado em conjunto com a distribuição espacial do G2 (Figura 10) retoma a discussão 
apresentada por Abramo (2007a) da cidade caleidoscópica, em que as incorporadoras produzem mais empreendimentos para a alta renda, induzindo a demanda, e os grupos de classe média ocupam os vazios deixados pela renda alta.

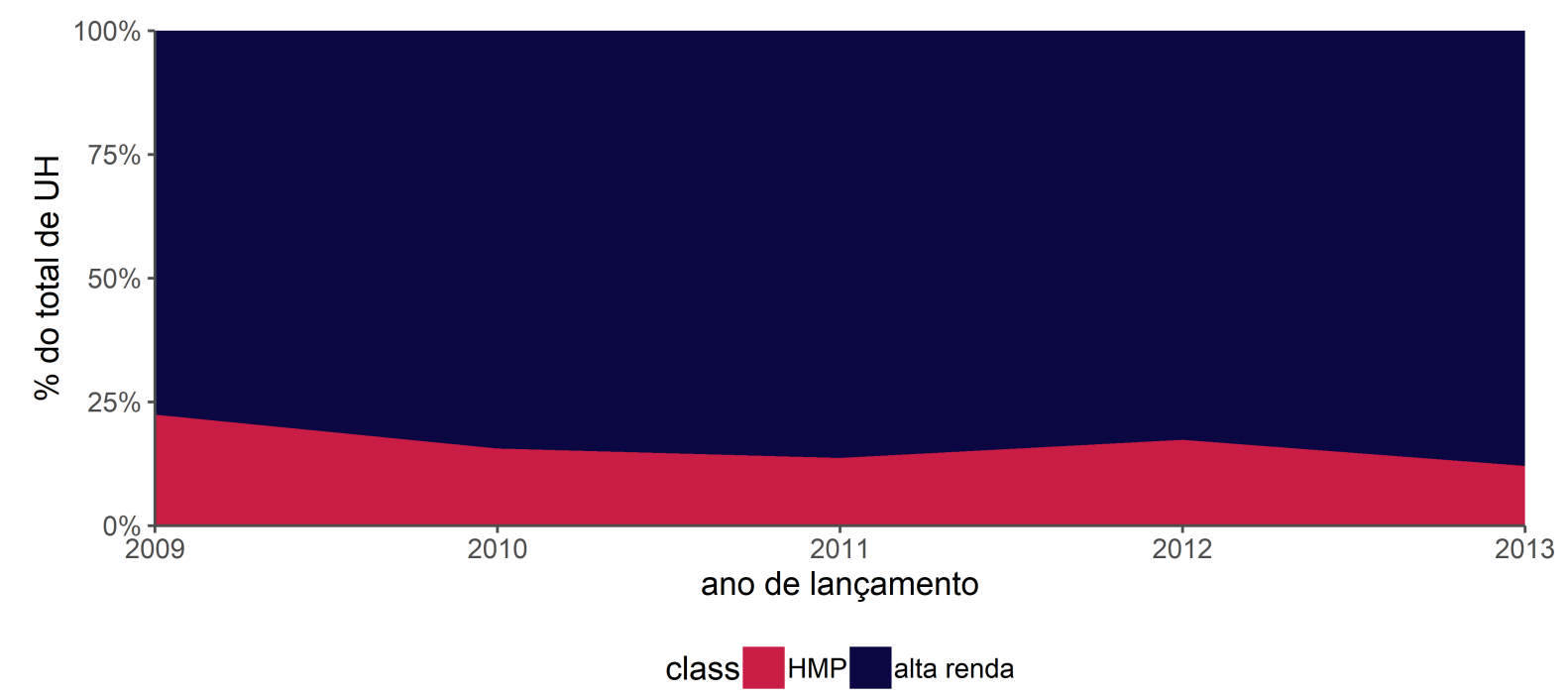

Figura 18 - Total de unidades (\%) lançadas por tipo de empreendimento

Em relação a distribuição espacial (Figura 19²), dividimos o período entre as duas fase do PMCMV. De modo geral, vemos a concentração dos empreendimentos destinados a alta renda no quadrante sudoeste e uma maior dispersão dos de padrão médio na zona leste para ambos os períodos. Para HMP, observa-se que na primeira fase os lançamentos foram principalmente na região do Parque do Carmo (área em roxo), seguida da região da avenida Jacu-Pêssego (área em laranja). Já na segunda, as mesmas regiões mantém destaque, mas vemos uma maior concentração no entorno do rio Tamanduateí; os lançamentos na Zona Norte se distanciam do centro, quando comparados aos propostos na primeira fase; e aumenta a quantidade de unidades de HMP no entorno da Linha Lilás do Metrô na Zona Sul.

Enquanto isso, observamos mais lançamentos de UH de empreendimentos destinados a alta renda no primeiro período na região da Vila Andrade, de Santo Amaro e da Água Branca (áreas em roxo e vermelho). Ainda nesse período, vemos que também há uma concentração no entorno da Linha Vermelha do Metrô até a região do Tatuapé e também na região do Ipiranga até a estação de Metrô Sacomã (áreas em laranja). Já no segundo período, vemos uma expansão dessas áreas, com destaque para as regiões: da Vila Andrade, Brooklin, Santa Cruz e Centro.

2 Para o mapa de calor, foi aplicada a função kernel com banda constante igual a 5km. 



fase 1: 2009-2010; fase 2: 2011-2014
Esri, HERE, Garmin, INCREMENT P @ O OpenStreetMap contributors

Figura 19 - Mapa de concentração de unidades habitacionais por período e tipo

Aplicando a mesma análise feita para as contratações do PMCMV ao usar os resultados da Figura 13, obtemos os gráficos da Figura 20. Em relação à Habitação de Mercado Popular, verificamos que a maioria dos empreendimentos, independente de período (44,6\% da fase 1 e 57,2\% da fase 2), estão em locais com baixa acessibilidade e alto isolamento, apresentando um padrão similar aos empreendimentos do MCMV. Já no caso dos destinados à alta renda, observa-se que o resultado é oposto, sendo $60,1 \%$ dos propostos da primeira fase e $57,4 \%$ dos da segunda fase estão em locais de alta acessibilidade e baixo isolamento do G1. 


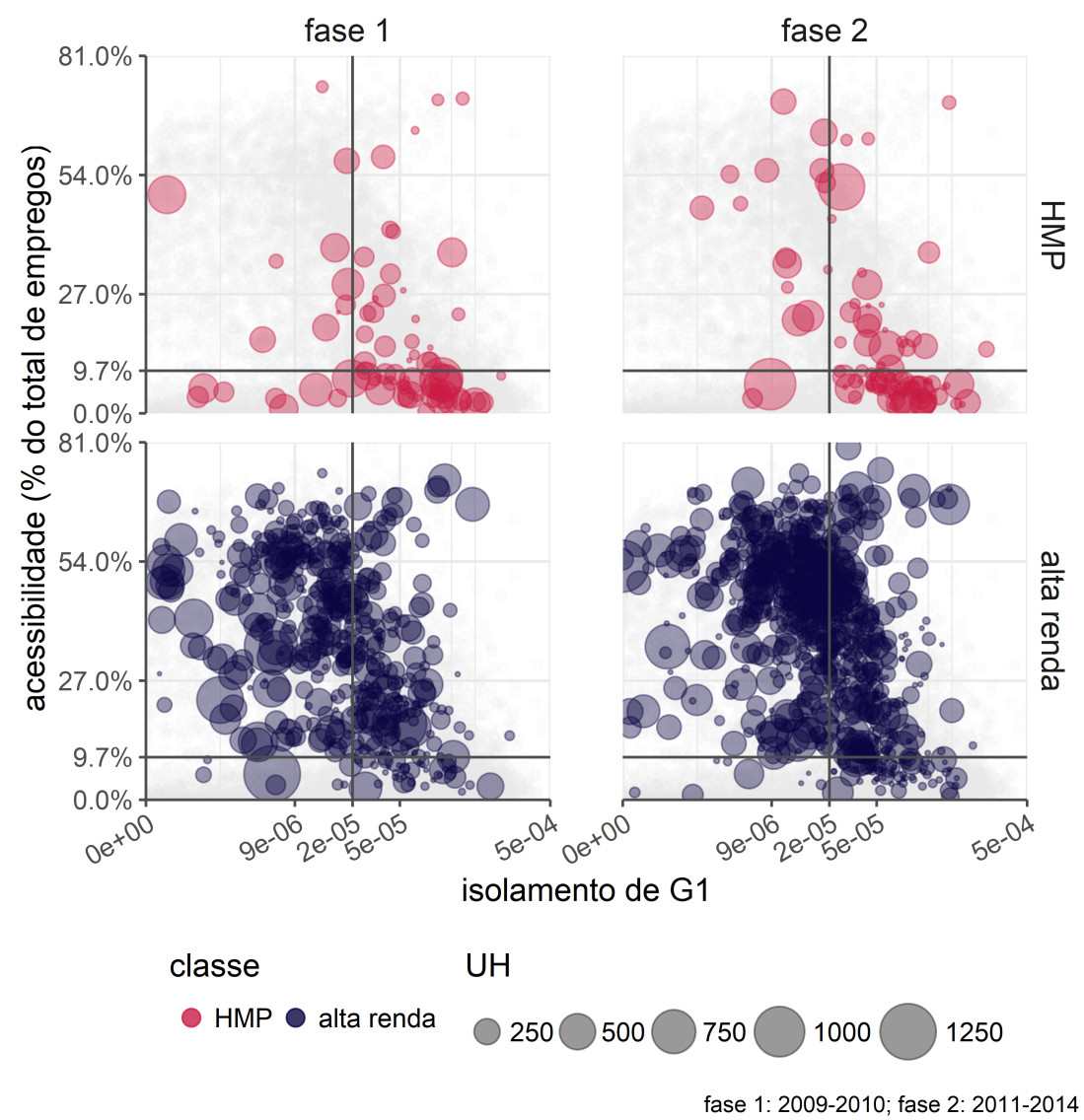

Figura 20 - Gráficos de acessibilidade por segregação, divididos por fase e classe

\subsubsection{Comparação entre mercado imobiliário e PMCMV}

Para a comparação entre os empreendimentos propostos pelo mercado imobiliário e pelo PMCMV, trabalhamos apenas com a acessibilidade acumulada, devido a falta de dados que possibilitaria a análise da variação do isolamento dentro do período. Portanto, trabalhamos com acessibilidade acumulada a empregos com limite de tempo de 60min para os anos de 2010 e 2014, mostradas na Figura 21. A partir do terceiro mapa, vemos que há uma redução generalizada dos níveis de acessibilidade relativos ao total de empregos de cada ano. Como não há diferença significativa entre as médias da distribuição de emprego dos anos analisados (Teste t com p-valor $>0,05$ ), essa redução sugere que a reestruturação do sistema de ônibus implementada no ano de 2013 no município reduziu a mobilidade da população e, portanto, o acesso da população à cidade. 


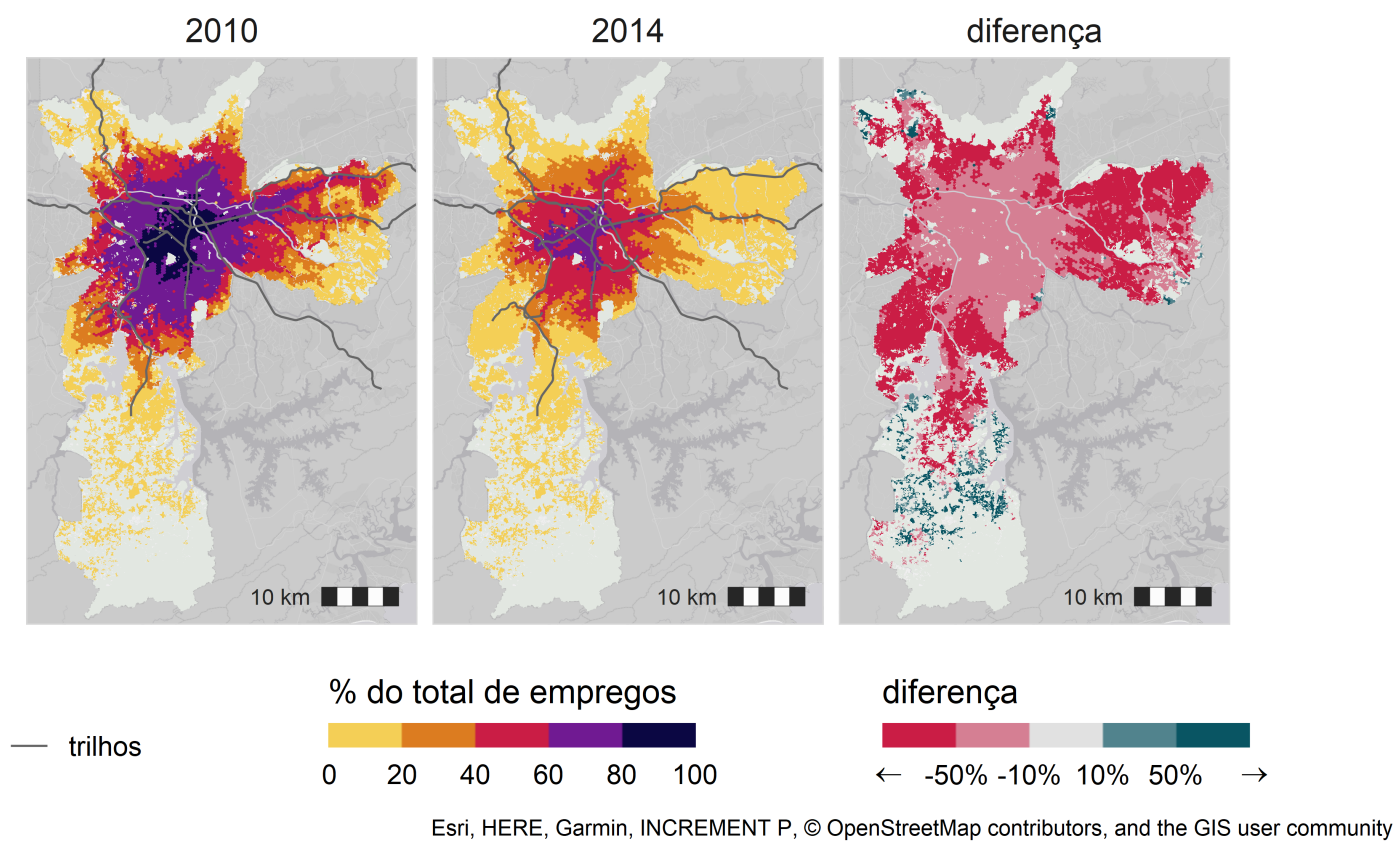

Figura 21 - Mapas de acessibilidade de 2010 e 2014, escala relativa ao total de empregos por ano

Nota - Mapa em escala de cinco percentis por ano está no Apêndice B - Figura 35

Para a comparação entre os empreendimentos lançados presentes no banco de dados da Embraesp e os contratados pelo PMCMV, os empreendimentos das faixas 2 e 3 do MCMV foram agrupados como HMP. Temos então três classes de empreendimentos (HIS, HMP e alta renda) com duas origens de banco de dados (MCMV e Embraesp) e mantivemos a divisão dos períodos (fase 1 de 2009 a 2010 e fase 2 de 2011 a 2014).

Analisando a distribuição da acessibilidade dos empreendimentos (Figura 22), vemos que os empreendimentos destinados a baixa renda têm menores níveis de acessibilidade (piores localizações) que os outros. Também podemos observar nos gráficos a melhor localização dos empreendimentos de alta renda, não só apresentando uma maior mediana, mas os mostrando que pelo menos $75 \%$ dos empreendimentos (acima do primeiro quartil) estão melhores que a maioria do restante, com exceção dos HMP do MCMV da primeira fase. A respeito deste último, quando comparado com a mesma classe lançada diretamente pelo mercado imobiliário, vemos que seus níveis de acessibilidade são maiores.

Para auxiliar a análise das diferenças, foi construída a curva de Lorenz. Usualmente esta curva é usada para análises de equidade na economia, relacionando a distribuição de renda com população. No caso da análise de exclusão social relacionada a transportes, podemos relacionar a acessibilidade com população, como proposto por Lucas, Wee e Maat (2016). Em nossa análise, para avaliar a diferença entre os empreendimentos, o eixo $x$ é resultado da soma acumulada das unidades habitacionais ordenadas pela acessibilidade, 


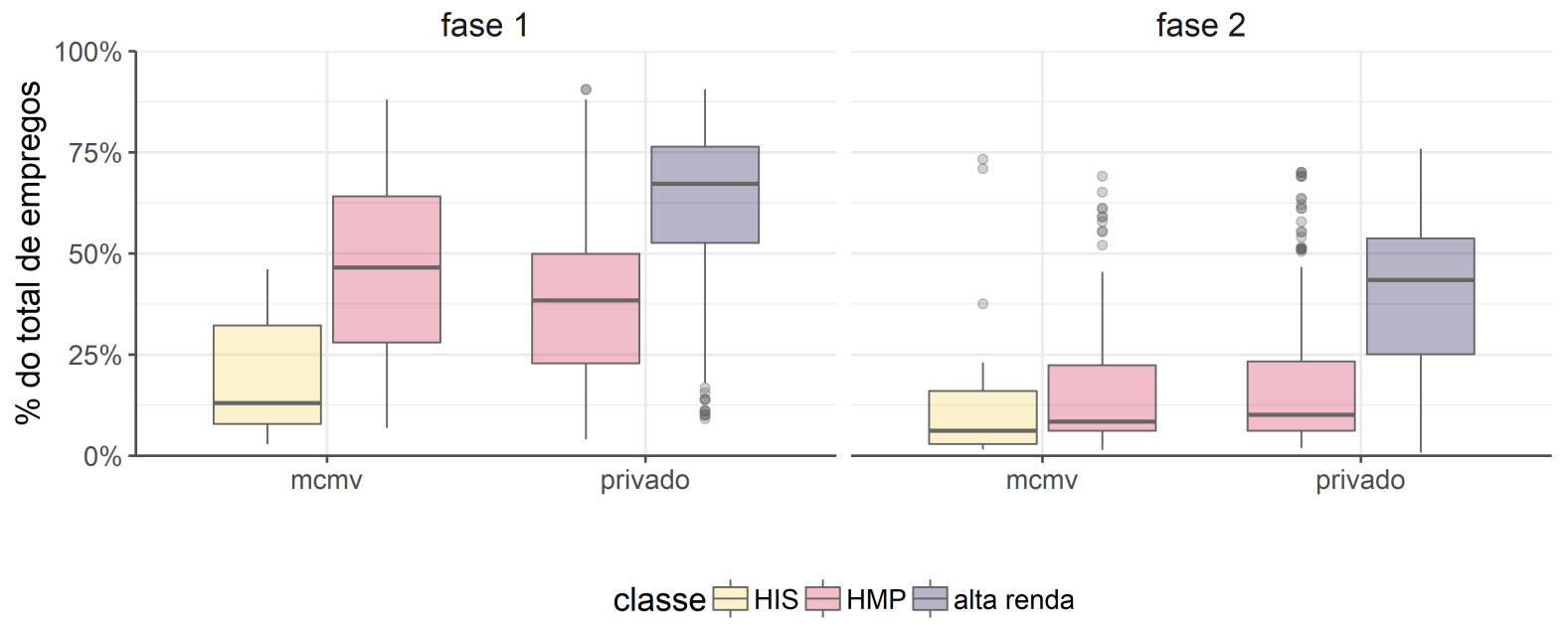

fase 1: 2009-2010; fase 2: 2011-2014

Figura 22 - Boxplot de acessibilidade por classe e origem de produção

como mostrado na Figura 23. Olhando apenas para as curvas de cada período, observamos uma diferença, que também aparece no índice de $\mathrm{Gini}^{3}$, em que há mais UHs com baixa acessibilidade na segunda fase, resultando em um maior índice.

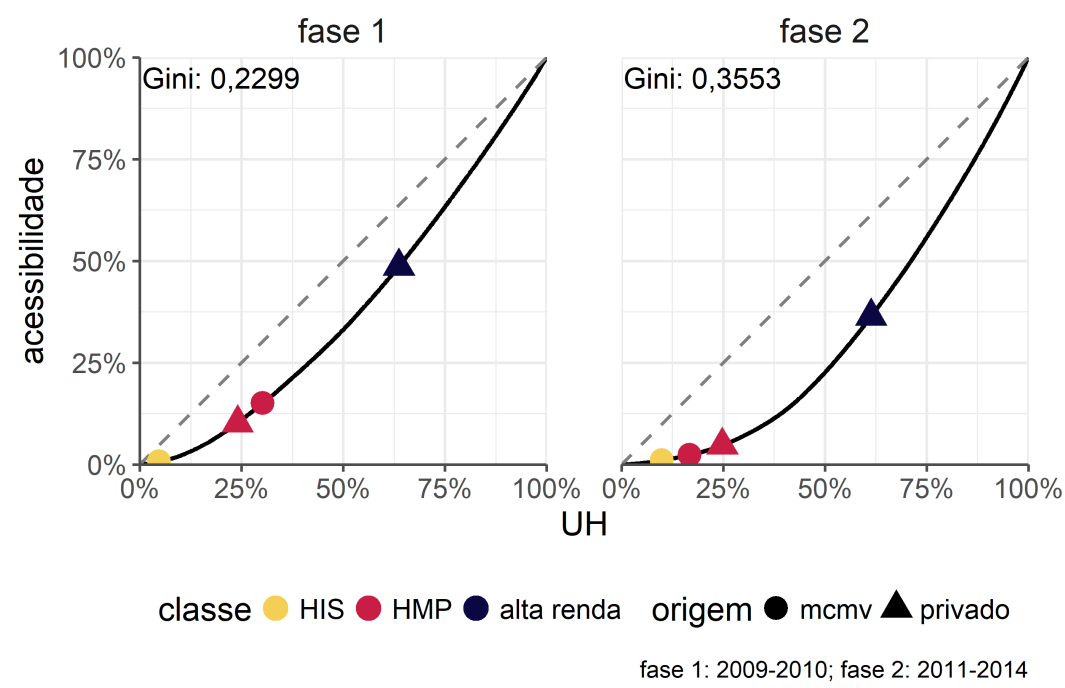

Figura 23 - Lorenz de acessibilidade por unidades habitacionais

Os pontos apresentados na mesma figura apresentam as medianas ponderadas por UH relativas à curva para cada tipo de empreendimento. Como já mostrado na Figura 22, as unidades habitacionais contratadas pelo PMCMV destinadas a baixa renda estão piores localizadas nos dois períodos, enquanto que os lançamentos de alta renda estão melhor posicionados. No entanto, vemos que há diferenças entre as contratações e lançamentos das HMP. Enquanto no primeiro período as HU contratadas pelo MCMV têm melhores 3 Para maiores explicações, ver Lucas, Wee e Maat (2016). 
níveis de acessibilidade em relação aos lançamentos; no segundo período esses valores se aproximam entre si e das HIS.

Além disso, apesar de haver uma redução de acessibilidade generalizada entre os dois períodos (apresentada na Figura 35), vemos que há um aumento de desigualdade no segundo período (aumento do índice de Gini). Este resultado também mostra não haver uma diferença significativa entre as localizações de HIS e HMP no segundo período, devido a proximidade entre as medianas de acessibilidade das UHs desses tipos.

O resultado obtido evidencia a discussão apresentada no Capítulo 1, em que incorporadores investem preferencialmente em empreendimentos de alta renda. Desse modo, políticas habitacionais para a melhoria do acesso à cidade para baixa renda se tornam necessárias. Portanto, a próxima seção apresenta a análise de localização das ZEIS propostas no período em que estamos estudando e as possibilidades de redução de desigualdades do acesso à cidade, caso essa política fosse efetivamente implementada.

\subsection{A localização das ZEIS e seu uso}

Como esperado pela definição das próprias ZEIS, ao analisarmos a distribuição das médias de acessibilidade de cada ZEIS para os anos calculados (Figura 24), vemos que as ZEIS 3 têm os melhores resultados. Tendo $75 \%$ delas valores maiores que $75 \%$ das ZEIS 2 e $100 \%$ maiores que as ZEIS 4.

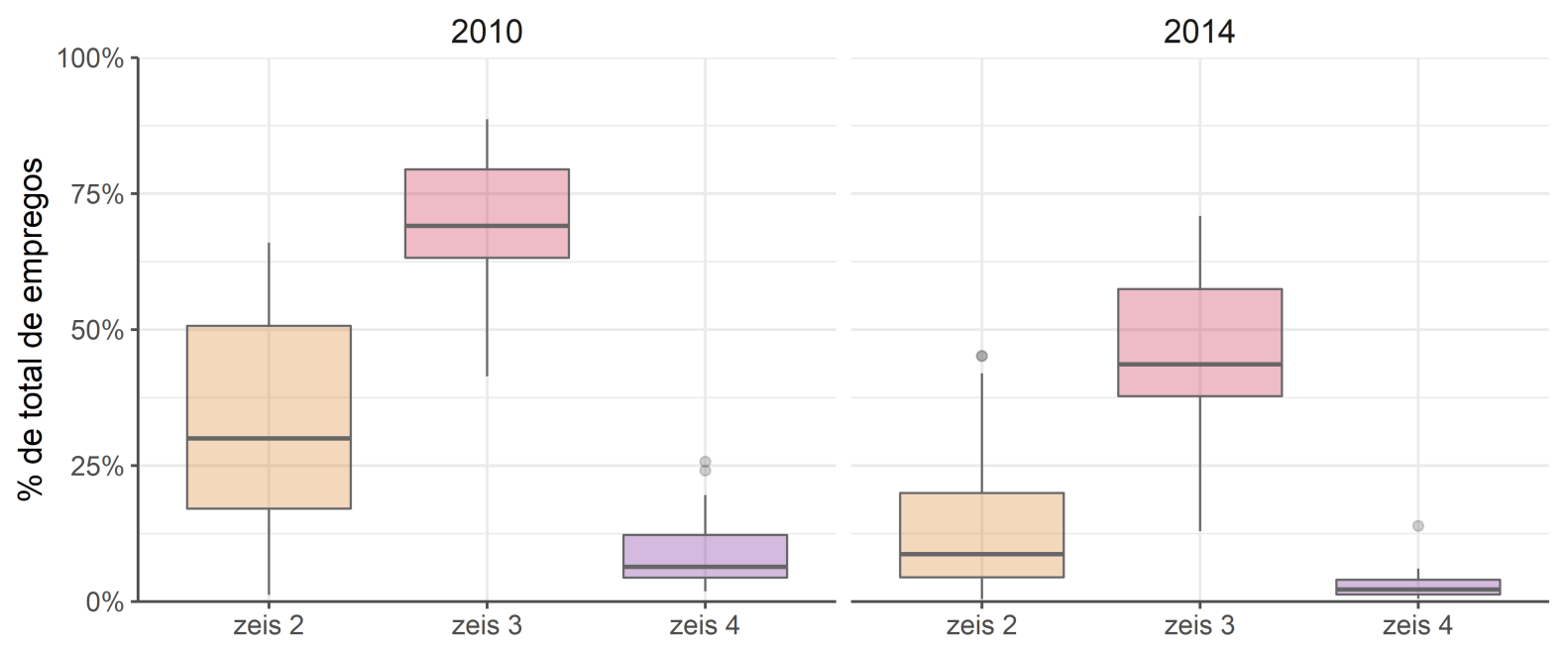

Figura 24 - Distribuição de acessibilidade por ZEIS e ano

Ao cruzarmos essas ZEIS com os empreendimentos analisados, verificou-se que apenas $7 \%$ das ZEIS foram utilizadas, equivalente a $21 \%$ em área das mesmas. Discretizando por tipo, a ZEIS 3 foi a mais usada (63\% do total de sua área, equivalente a $3,2 \mathrm{~km}^{2}$ ), 
seguida da ZEIS 2 (7\% de sua área, equivalente a $0,8 \mathrm{~km}^{2}$ ) e depois, ZEIS 4 (4\% da área, $\left.0,1 \mathrm{~km}^{2}\right)$.

No caso da ZEIS 3, foram propostos 38 empreendimentos, sendo tanto contratações do PMCMV quanto lançamentos diretos pelo mercado imobiliário, desses empreendimentos, $51 \%$ das UH são HMP (Figura 25) e o restante, destinadas a alta renda, ou seja, as áreas destinadas para a produção de habitação de interesse social foram usadas para outros produtos. Também encontramos a predominância de HMP e habitações destinadas a alta renda nas propostas para as ZEIS 2, enquanto apenas 10\% das UH propostas são de HIS. Somente as ZEIS 4 apresentaram proposta predominante de HIS, no entanto, é resultado de um empreendimento com $192 \mathrm{UH}$, indicando, portanto, que as ZEIS não atenderam o seu propósito de favorecer as classes mais vulneráveis.

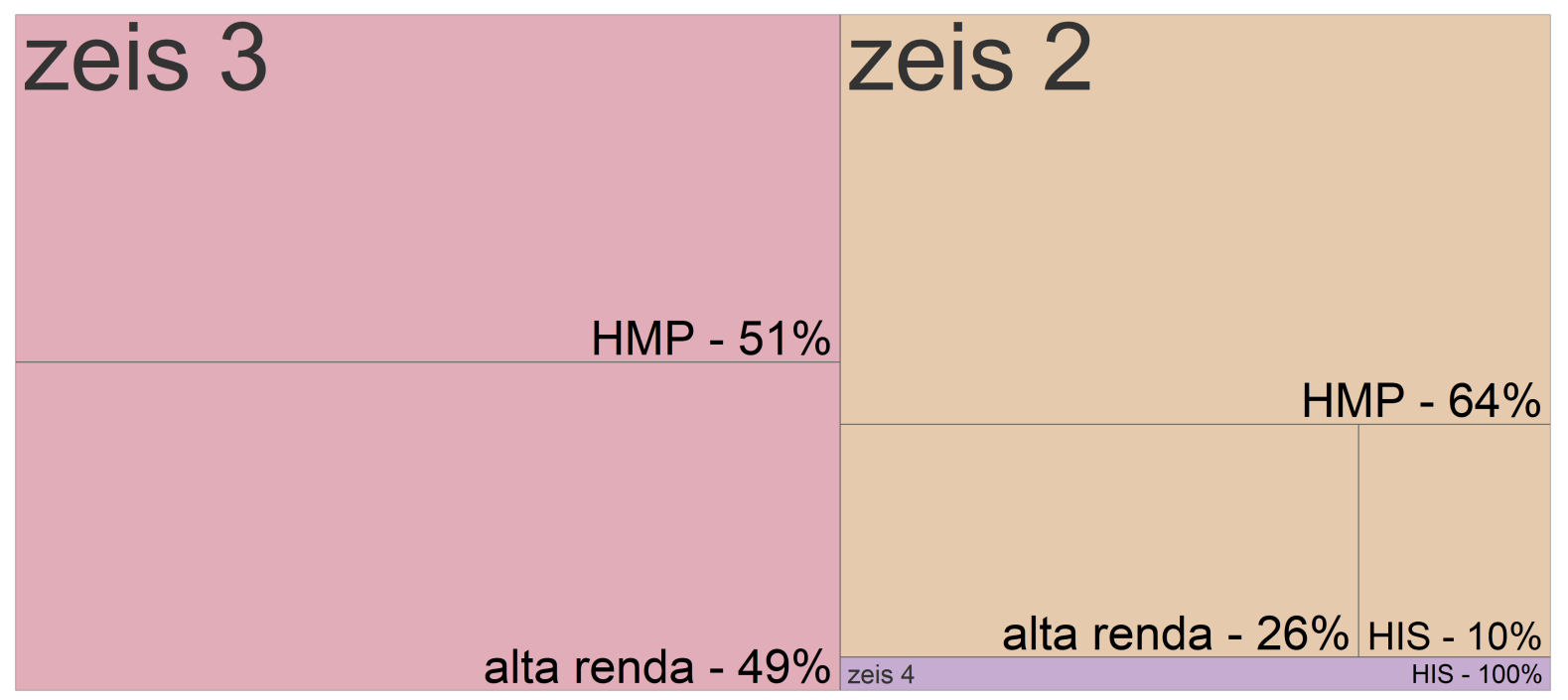

Figura 25 - Distribuição de UHs por ZEIS e padrão de construção

Comparando as distribuições dos empreendimentos propostos fora de ZEIS e as ZEIS não usadas (Figura 26), vemos que há possibilidade de melhora dos níveis de acessibilidade para as HIS de ambos os períodos. Já no caso das HMP, vemos que a distribuição do primeiro período é parecida com a das ZEIS não usadas, enquanto que também é possível melhorar os valores das HMP propostas durante o segundo. 


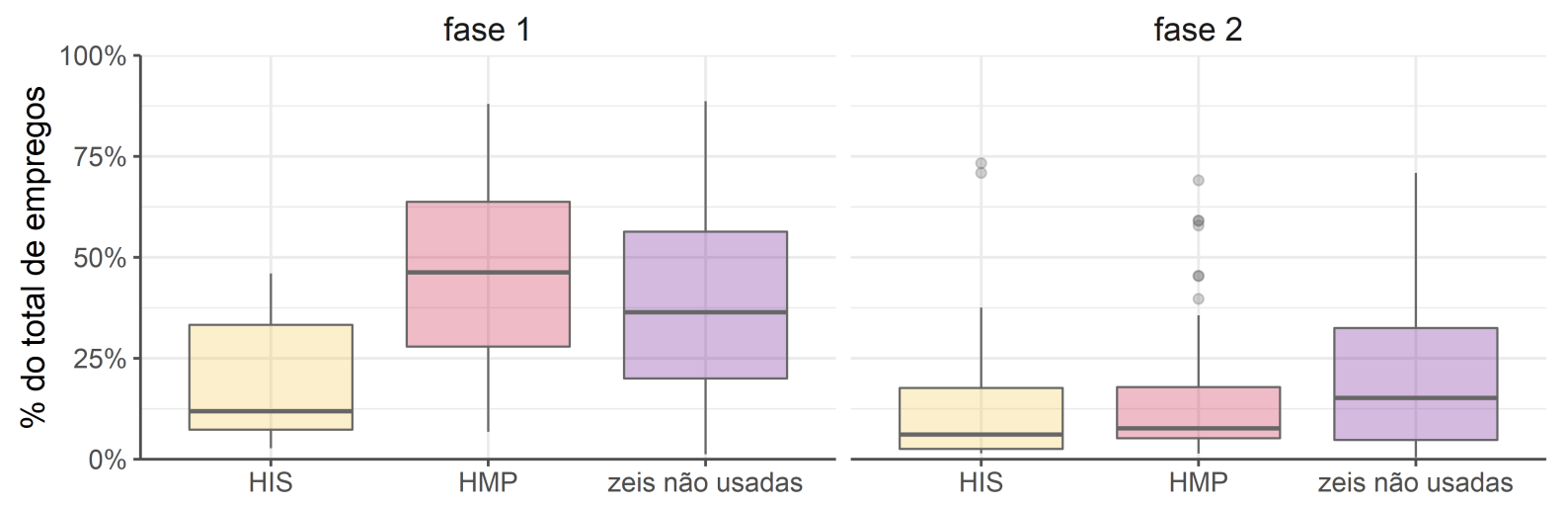

穴HIS

fase 1: 2009-2010; fase 2: 2011-2014

Figura 26 - Distribuição de acessibilidade por HIS, HMP e ZEIS não usadas

\subsubsection{Simulação de realocação dos empreendimentos}

Para avaliar se o uso efetivo das ZEIS reduziria a desigualdade entre as UHs propostas nos dois períodos (2009-2010 e 2011-2014) foram simulados 7 cenários (Quadro 6) nos quais são analisadas novas localizações para as UHs avaliadas acima. Os cenários foram definidos a partir da variação de dois parâmetros: o potencial construtivo do lote e a distribuição de como esta área seria usada.

O potencial de construtivo do lote é resultado da multiplicação do coeficiente de aproveitamento e a área do terreno (Potencial construtivo $=C A * A_{\text {terreno }}$ ), conforme São Paulo (cidade) (2002). Como discutido no Capítulo 2, o coeficiente de aproveitamento (CA) varia para cada tipo de ZEIS e também pode ser adotado o básico, ou o máximo. Sabendo a área que poderá ser construída no lote, é necessário definir o quanto dessa área será área útil total, para aproximar a quantidade de UHs que poderiam ser efetivamente construídas. Na nossa análise, foi adotado que $60 \%{ }^{4}$ do potencial construtivo será destinado a construção de UHs ( $A_{\text {útil total }}=0.6 *$ Potencial construtivo).

O outro parâmetro que varia entre os cenários entra nesta etapa da simulação. Tendo a área total de área útil, precisamos saber como essa área será dividida entre cada tipo de habitação (HIS, HMP, alta renda), tal que $A_{\text {tipo }}=\%$ tipo $* A_{\text {útil total }}$. Para tanto, definimos três possibilidades:

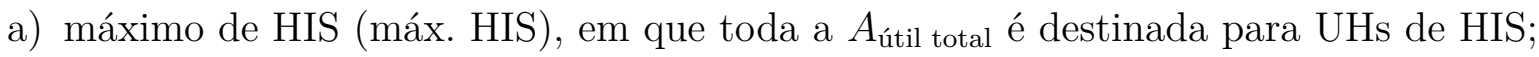

b) máximo possível de HMP (máx. HMP), em que parte da $A_{\text {útil total é destinada para }}$

$\overline{4}$ Esse valor é uma aproximação a partir das médias (58\% para alta renda e $64 \%$ para HMP) da relação entre total de área útil do empreendimento por total de área construída do empreendimento obtida pela base da Embraesp. 
UHs de HIS (respeitando o mínimo exigido pelo São Paulo (cidade) (2002)) e o restante é para UHs de HMP;

c) máximo possível para alta renda (máx. alta renda), em que parte da $A_{\text {útil total }}$ é destinada para UHs de HIS e HMP (respeitando o mínimo exigido pelo São Paulo (cidade) (2002)) e o restante é para UHs para alta renda.

Desse modo, temos nossos seis cenários construídos Quadro 6

Quadro 6 - Cenários simulados

\begin{tabular}{|c|c|c|c|}
\hline \multirow{2}{*}{ CA } & \multicolumn{3}{|c|}{ Distribuição por tipo } \\
\hline & máx. HIS & máx. HMP & $\begin{array}{l}\text { máx. alta } \\
\text { renda }\end{array}$ \\
\hline básico & cenário 1 & cenário 3 & cenário 5 \\
\hline máximo & cenário 2 & cenário 4 & cenário 6 \\
\hline \multicolumn{4}{|c|}{$\begin{array}{ll}\text { Nota: } & \text { CA básico }=1 \text {, para todas as ZEIS; } \\
& \text { CA máx.: ZEIS } 1=2,5 \text {; ZEIS } 2=2,5 \text {; ZEIS } 3=4 \text {; ZEIS } 4= \\
& 1 ; \\
& \text { min. de área construída para HIS: ZEIS } 1=50 \% \text {; ZEIS } 2= \\
& 40 \% \text {; ZEIS } 3=40 \% \text {; ZEIS } 4=70 \% \text {; } \\
& \text { min. de área construída para HIS + HMP: } 80 \% \text { todas as ZEIS, } \\
& \text { exceto ZEIS } 4=70 \% \text { (São Paulo (cidade), } 2004 \text { ). }\end{array}$} \\
\hline
\end{tabular}

Seguindo os cálculos para chegar na quantidade de UHs potenciais em cada ZEIS e cenário $\left(U H_{\text {potencial }}^{\text {tipo }}\right)$, adotamos as seguintes áreas úteis por $\mathrm{UH}\left(A_{U H}^{t i p o}\right)$ :

a) $37 \mathrm{~m}^{2}$ para HIS, mínimo para empreendimentos faixa 1 (Caixa Econômica Federal, 2008);

b) $46 \mathrm{~m}^{2}$ para HMP, valor próximo à media para esse tipo e período pela base da Embraesp, 46,2 $\mathrm{m}^{2}$;

c) $90 \mathrm{~m}^{2}$ para alta renda, valor próximo à media para esse tipo e período pela base da Embraesp, $90.3 \mathrm{~m}^{2}$.

Portanto, a quantidade potencial de UHs dentro de uma ZEIS é resultado da expressão $U H_{\text {potencial }}^{\text {tipo }}=A_{\text {tipo }} / A_{U H}^{\text {tipo }}$.

Para permitir a comparação entre os resultados da simulação e o cenário base, o que de fato ocorreu, foi utilizada como restrição a quantidade de HIS que foram contratadas para cada fase (5.548 na primeira e 5.926 na segunda). Desse modo, nem todas as ZEIS serão usadas e foi usado o indicador de acessibilidade de cada período como pontuação para selecionar quais serão as ZEIS ocupadas primeiro. Assim, em para todos os cenários as UHs de HIS serão realocadas e: 
a) se \%HIS for máximo (cenários 1 e 2):

- nenhuma UH de HMP e para alta renda será realocada;

b) se \%HMP for máximo (cenários 3 e 4):

- as UHs de HMP serão realocadas apenas para ZEIS em que há HIS, priorizando os empreendimentos para renda média propostos no cenário base com menor acessibilidade e mantendo os com melhor índice, para manter o total que foi contratado e lançado;

- nenhuma UH para alta renda será realocada;

c) se \%alta renda for máximo (cenários 5 e 6):

- as UHs de HMP e para alta renda terão o mesmo procedimento das HMP do caso anterior.

\subsubsection{Comparação entre os empreendimentos}

Inicialmente, vamos analisar as diferenças de acessibilidade entre os tipos de unidades habitacionais propostas pela simulação. A partir da Figura 27, em que mostra o percentual de UHs que foram realocadas em relação ao cenário base e para qual tipo de ZEIS, vemos que todas as UHs foram realocadas para a ZEIS 3, por terem um maior nível de acessibilidade. No caso de HMP, cerca de $23 \%$ e $28 \%$ das 61.743 UH foram realocadas nos cenários 3 e 4 e $15 \%$ e $18 \%$ nos cenários 5 e 6 . Nestes últimos cenários, quase $2 \%$ das 141.976 UH para alta renda mudaram de localização.

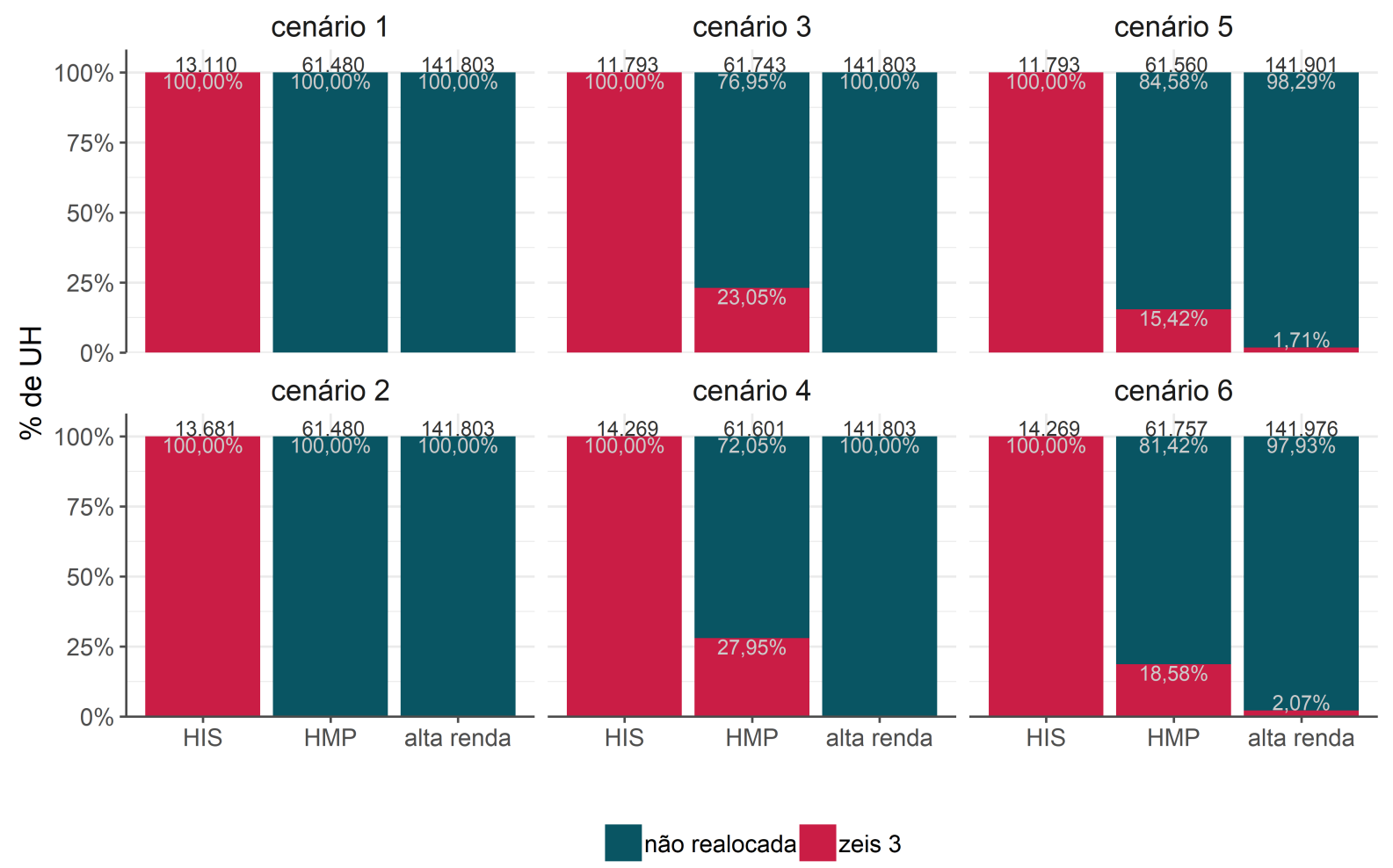

Figura 27 - Realocação das unidades habitacionais por cenário 
Estas porcentagens estão refletidas na mudança das distribuições de acessibilidade entre os tipos de empreendimentos e os cenários (Figura 28). Como todas as unidades habitacionais de HIS mudaram de localização, devido a uma restrição imposta no modelo, seus níveis de acessibilidade são os que obtiveram maior mudança, em comparação ao cenário base. Já para a HMP, quando olhamos os cenários em que há realocação e comparamos com o cenário base, verifica-se que a distribuição também se desloca para níveis mais altos. No entanto, como mais de $70 \%$ não se altera (cenários 3 e 4), vemos que a mediana se mantém próxima da do cenário base. Situação semelhante acontece com a distribuição de acessibilidade dos empreendimentos para alta renda. Por ter apenas $2 \%$ de realocação (cenário 5 e 6), sua distribuição não se altera.

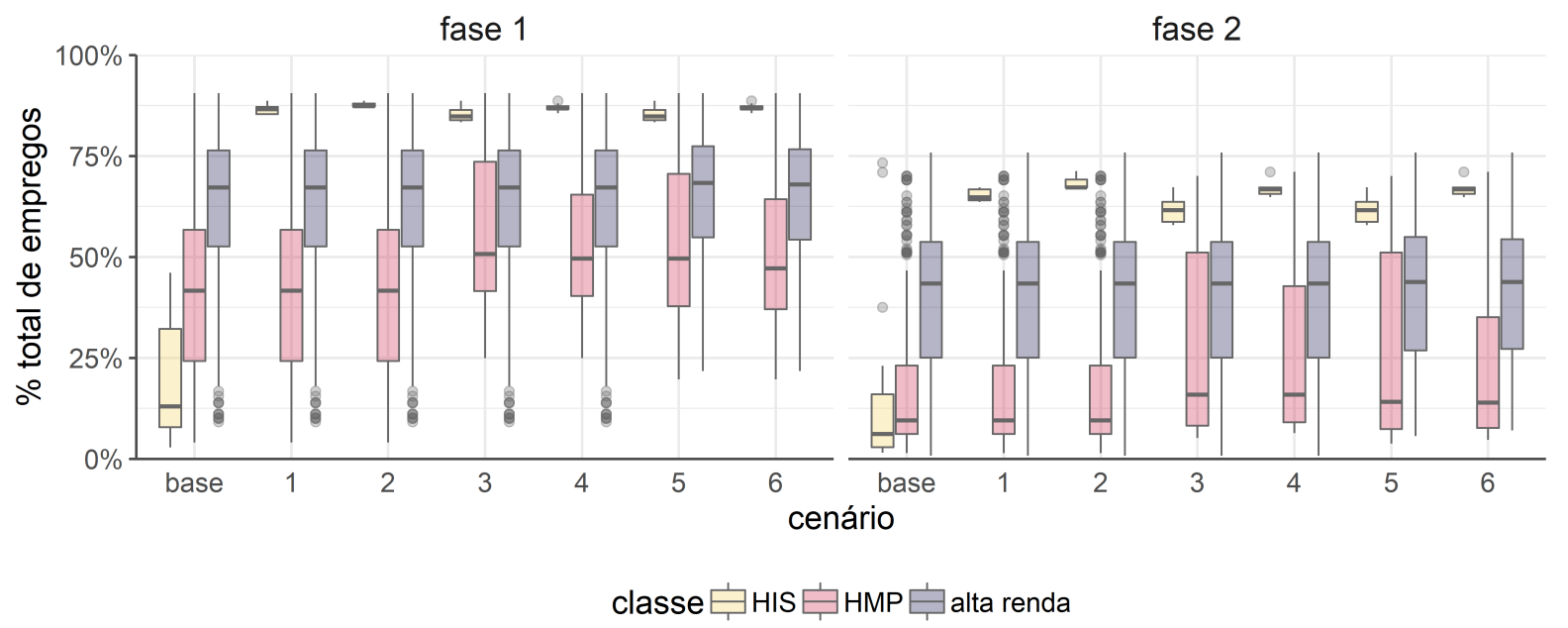

fase 1: 2009-2010; fase 2: 2011-2014

Figura 28 - Distribuição de acessibilidade por tipo de empreendimento e cenário

Ao analisarmos as desigualdades entre os cenários para os dois períodos (Figura 29), vemos que todos os cenários propostos têm melhores resultados que o cenário base analisado anteriormente. Como esperado, quando comparamos os períodos entre si, verificamos que há um aumento no índice entre os empreendimentos propostos para a segunda fase, já que a primeira fase tem a possibilidade de alocação dos empreendimentos em ZEIS com melhores níveis de acessibilidade, enquanto a segunda pode realocar nas ZEIS restantes. Também dentro do esperado, ao compararmos a adoção do coeficiente de aproveitamento básico ou máximo, os cenários que adotaram os valores máximos (cenários 2, 4 e 6) obtiveram menor valor do índice na segunda fase, já que há um melhor aproveitamento das ZEIS com melhores localizações.

Através dos índices de Gini, também verificamos que as desigualdades entre os empreendimentos são menores quando apenas são realocadas as HIS e HMP (cenários 3 e 4). O fato dos cenários 5 e 6 terem maiores índices de Gini é devido a redução da restrição de uso nas ZEIS que possibilita a construção de UHs para alta renda, as quais, 
como apresentado na Figura 23, já possuem maiores níveis de acessibilidade em relação aos outros tipos de empreendimento. Podemos perceber esta relação quando avaliamos as medianas de cada tipo em relação à curva de Lorenz para cada cenário (Figura 30).

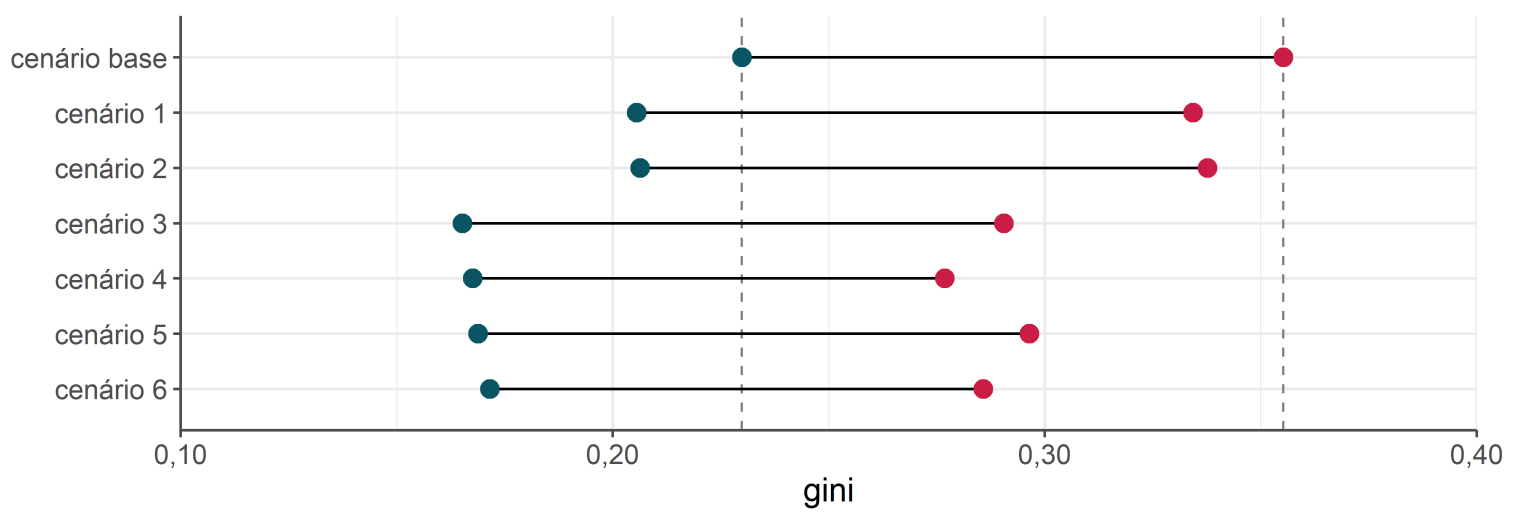

fase 1 fase 2

fase 1: 2009-2010; fase 2: 2011-2014

Figura 29 - Índices de Gini para os cenários simulados

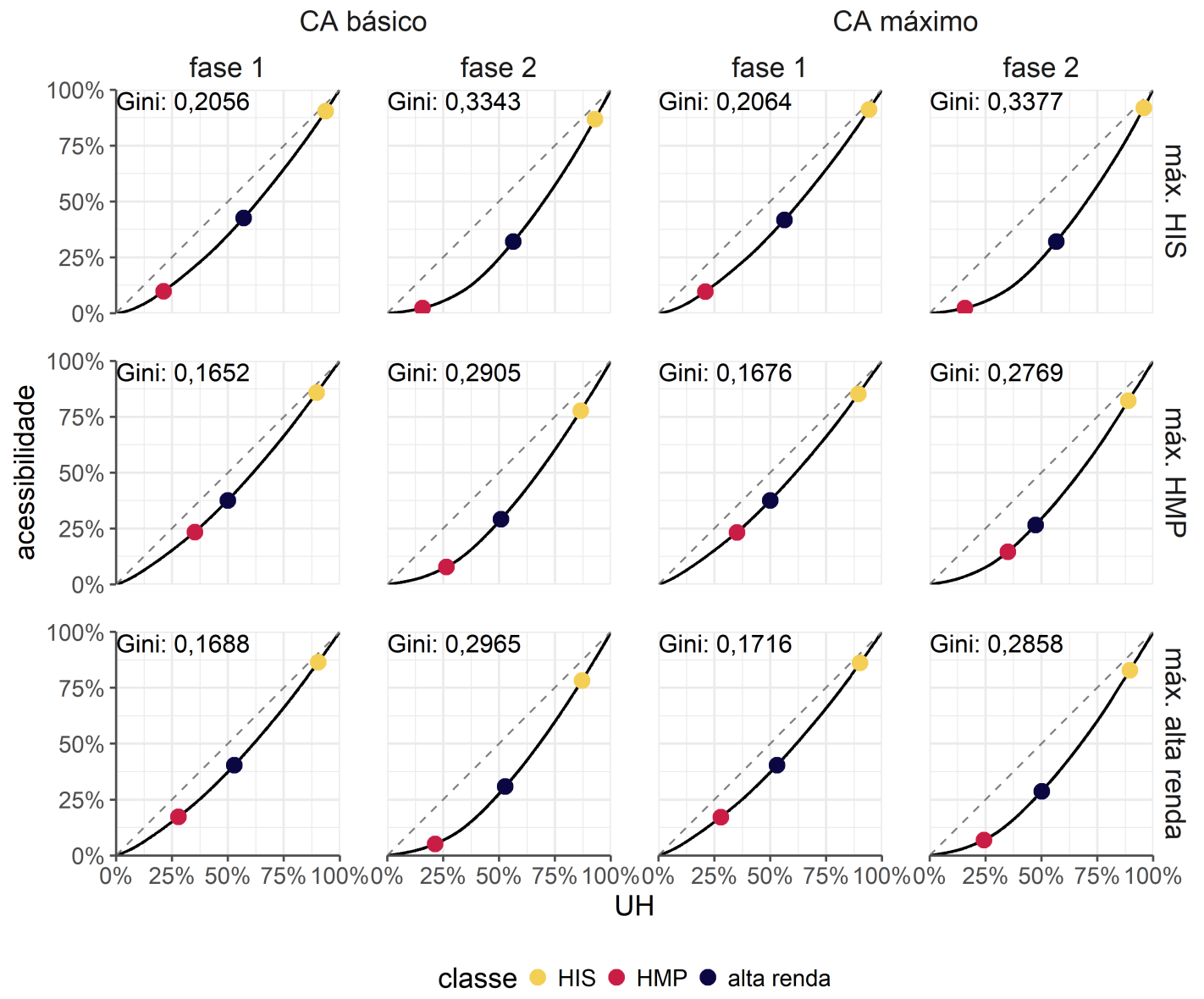

fase 1: 2009-2010; fase 2: 2011-2014

Figura 30 - Lorenz de acessibilidade por UH dos cenários simulados 
Na Figura 30, a tabela de gráficos foi preenchida na ordem dos cenários e por linha, ou seja, a primeira linha apresenta as curvas Lorenz para os cenários 1 e 2, a segunda, para os cenários 3 e 4, e a terceira, para os cenários 5 e 6 . Nela, vemos que nos cenário 3 e 4 as medianas da HMP estão mais próximas das de habitação para alta renda e, no caso do cenário 4, a mediana na fase 2 mostra que há mais unidades habitacionais de HMP com maior nível de acessibilidade que as para alta renda.

\subsubsection{Comparação com o município}

Para compreender qual seria o impacto nas desigualdades caso o cenário fosse implementado, adicionamos à base para o cálculo do índice de Gini os domicílios divididos em grupos, que foram usadas para o cálculo de segregação, discutido no Capítulo 4, e consideramos cada UH proposta nos cenários como um domicílio do grupo alvo do tipo de empreendimento ${ }^{5}$. Nesta análise, temos os 7 cenários discutidos previamente (cenário base e cenários de 1 a 6) e um cenário adicional, o qual chamamos de original. Este cenário não considera a implementação dos empreendimentos propostos, presentes no cenário base, ou seja, são considerados apenas os domicílios classificados.

Avaliando as diferenças do coeficiente de Gini em relação ao cenário original (Figura 31), vemos que todos os cenários, inclusive o cenário base, o qual considera a localização inicial dos empreendimentos propostos, têm menores valores de Gini. Pela figura, observa-se que a implementação de coeficiente de aproveitamento básico ou máximo não altera substancialmente os resultados, enquanto que uma menor restrição de construção de outros tipos de UHs além de HIS dentro das ZEIS possibilita uma maior redução da desigualdade em relação ao município.

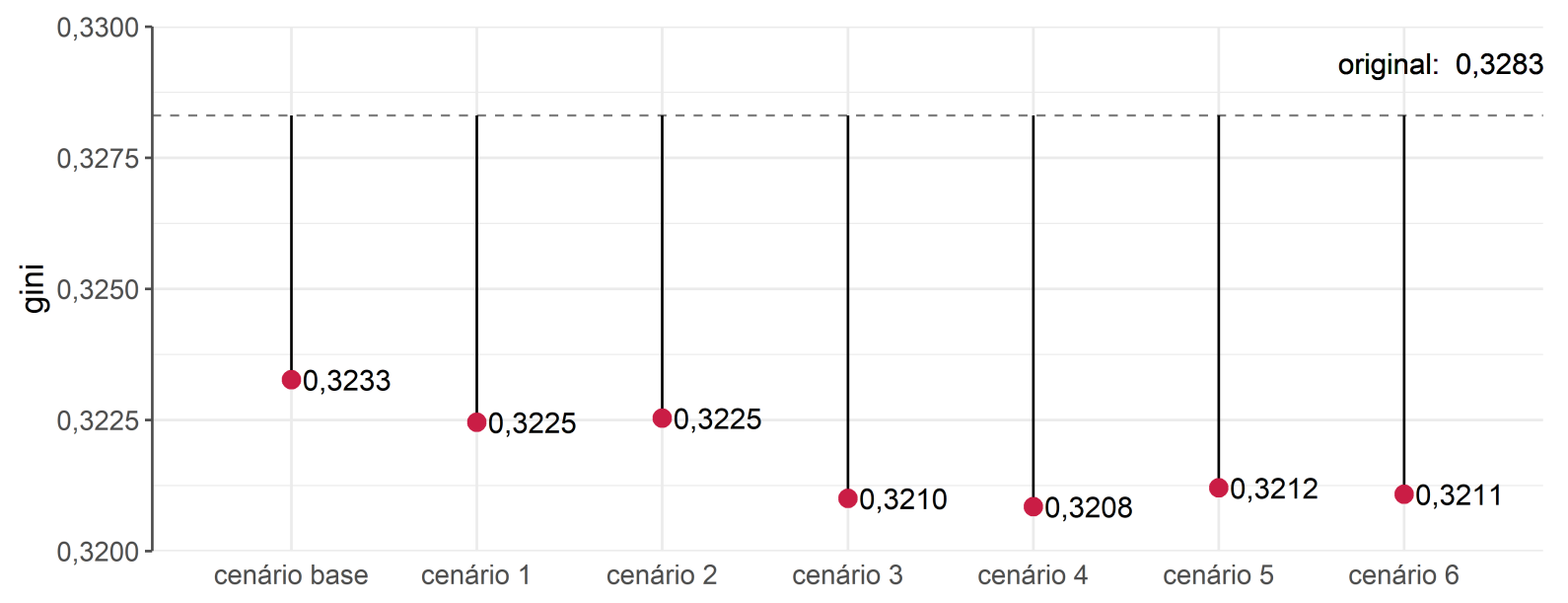

Figura 31 - Comparação entre os Ginis dos cenários simulados e o cenário original

5 Unidades habitacionais de HIS como domicílios do g1, UHs de HMP como domicílio do g2 e UHs para alta renda como domicílios do g3 
Como verificado pelos valores de Gini, que mudam na casa do décimo de milésimos, as curvas de Lorenz e as medianas por grupo (indicadas por círculo) não são afetadas pelas novas localizações propostas com as simulações Figura 32. No entanto, ao compararmos as medianas que consideram os domicílios da situação original e as UHs propostas (círculo) de cada grupo com as que consideram apenas unidades habitacionais propostas (triângulos), vemos a diferença entre o cenário original e os cenários simulados.

No caso do cenário base, a mediana das UHs de HIS propostas tem um valor menor do que a que considera o grupo como um todo, indicando que os empreendimentos alocados estavam em localizações piores que metade dos domicílios de g1. O mesmo ocorre para a mediana de acessibilidade das UHs de HMP propostas em relação aos domicílios existentes do g2, sendo que a mediana das propostas se aproxima do valor da mediana dos domicílios originais de g1. Vemos que esta situação se altera nos cenário 3 a 6 , sendo que nos cenários 3 e 4 as medianas das HMP propostas se aproximam das medianas para alta renda; e nos cenário 5 e 6 estão mais próximas das do g2, como seria o esperado. Já no caso do terceiro grupo, os cenários simulados e as propostas no cenário base não alteram a sua mediana.
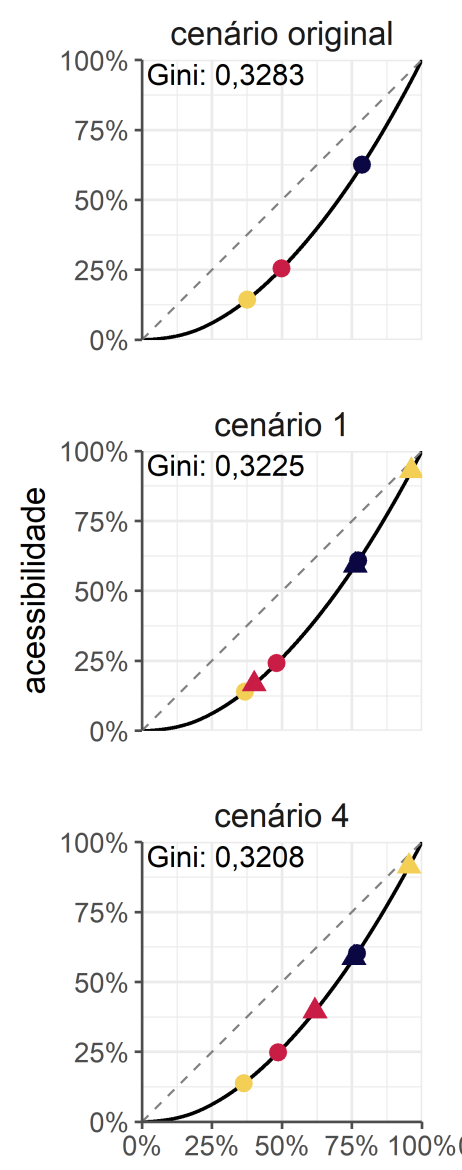

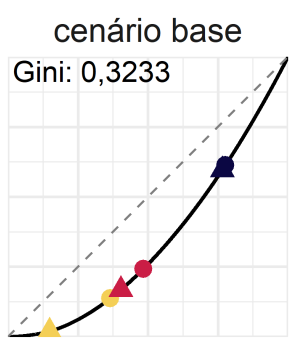

cenário 2

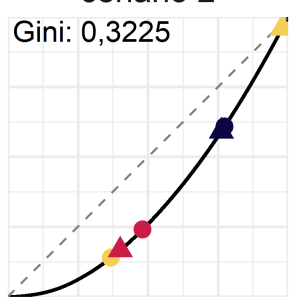

cenário 5

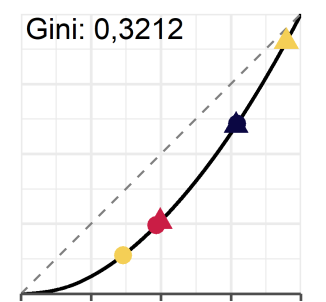

grupo

g1

g2

- g3

domicílio

- todos $+\mathrm{UHs}$

$\Delta$ UHs propostas

cenário 3

Gini: 0,3210

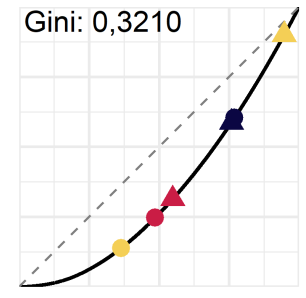

cenário 6

Gini: 0,3211

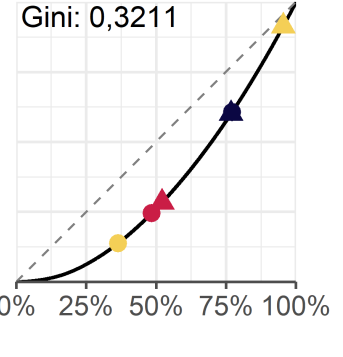

domicílio

Figura 32 - Lorenz de acessibilidade por famílias dos cenários simulados em relação ao município 


\section{Discussões finais}

O trabalho apresenta diferentes análises espaciais que contribuem para um melhor entendimento da dinâmica do município de São Paulo. Também contribui no avanço do planejamento urbano, possibilitando discussões sobre políticas públicas sobre o território embasadas em dados e indicadores.

A partir da análise da localização dos empreendimentos contratados pelo PMCMV, verificamos a existência da relação entre acessibilidade e segregação no município de São Paulo. O que reforça as discussões sobre a localização dos empreendimentos voltados para baixa renda em geral, e não só do PMCMV, as quais afirmam que esses tipos unidades habitacionais costumam estar em piores lugares e reforçam os padrões estruturais de segregação urbana.

Já na comparação entre os empreendimentos contratados do PMCMV e dos lançados pelo mercado imobiliário, como esperado a partir da revisão bibliográfica, os empreendimentos para alta renda têm melhores localizações que todos os outros segmentos. Ainda nesta análise, encontramos HMP contratados pelo PMCMV com melhores níveis de acessibilidade que os lançados pelo mercado imobiliário, sugerindo que as melhores condições de financiamento oferecidas pelo PMCMV possibilitaram tomadas de decisão (escolha por terrenos melhor localizados e, portanto, mais caros) mais arriscadas por parte dos incorporadores.

No entanto, ao compararmos os níveis de acessibilidade dos empreendimentos contratados e lançados por período relativos entre si, vemos pela curva de Lorenz que os níveis de acessibilidade das HIS e das HMP estão próximos entre si. Nesse sentido, retornamos à discussão presente no trabalho de Abramo (2007a), sobre a cidade caleidoscópica, na qual o mercado imobiliário foca nos estratos mais ricos da sociedade e negligencia o restante do mercado consumidor na expectativa de que o mesmo consuma os imóveis vazios do mercado alvo.

Por fim, após verificar que a ZEIS 3 foi a mais usada e principalmente para a produção de empreendimentos dedicados para a alta renda, simulamos novas localizações para as UHs propostas durante o período caso houvesse a restrição para a construção de empreendimentos de HIS e HMP dentro das ZEIS. Vimos que o uso efetivo das ZEIS, é capaz de reduzir as diferenças de acessibilidade entre os empreendimentos analisados. No entanto, a quantidade contratada, mesmo que fosse localizada em locais com melhores níveis de acessibilidade, não seria o suficiente para reduzir a desigualdade no município. 
Ainda sobre a simulação, sabemos que há espaço para outros cenários e possibilidade de refinamento, que sugerimos que sejam avançadas em próximos trabalhos, como adicionar empreendimentos de promoção pública e decisões de produção que podem reduzir o custo do empreendimento (restringir quantidade de andares para evitar uso de elevador, priorizar terrenos com maior área ou com menor dificuldade de implementação, etc) e também uma análise de sensibilidade para os diferentes parâmetros e para rever a quantidade necessária para a redução da desigualdade.

Também sugerimos para trabalhos futuros aprofundar a análise dos empreendimentos do PMCMV em relação à melhor localização de empreendimentos da faixa 2 em relação a faixa 3 , à maior contratação de empreendimentos desse primeiro segmento, na terceira fase do programa. Como esta fase está fora do período do PDE 2002, não nos aprofundamos na análise do motivo desse destaque. Sugerimos olhar as mudanças do PDE, além de regras de contratação nesta fase, que podem ter influenciado esta diferença.

Finalizando, reforçamos as discussões existentes sobre a localização dos empreendimentos destinados a baixa renda, já debatido acima, e também sobre as aplicações das leis. Nossos resultados sugerem que as leis são instrumentos de manutenção de poder e concentração de privilégios, além de serem aplicadas arbitrariamente, tal como argumentado por Ermínia (2003) para o século XX, mas que entendemos que podemos estender para a presente análise. 


\section{Referências}

ABRAMO, P. A cidade caleidoscópica: coordenação espacial e convenção urbana: uma perspectiva heterodoxa para a economia urbana. 1. ed. Rio de Janeiro: Bertrand Brasil, 2007. 368 p.

ABRAMO, P. A cidade COM-FUSA: a mão inoxidável do mercado e a produção da estrutura urbana nas grandes metrópoles latino-americanas. Revista Brasileira de Estudos Urbanos e Regionais, v. 9, n. 2, p. 25, 11 2007. ISSN 2317-1529. Disponível em: $<$ http://rbeur.anpur.org.br/rbeur/article/view/181>.

ACOLIN, A.; HOEK-SMIT, M. C.; ELOY, C. M. High delinquency rates in Brazil's Minha Casa Minha Vida housing program: Possible causes and necessary reforms.

Habitat International, Elsevier, v. 83, n. December 2018, p. 99-110, 2019. ISSN 01973975. Disponível em: <https://doi.org/10.1016/j.habitatint.2018.11.007>.

Agência CBIC. Governo Federal prepara anúncio da retomada das contratações da Faixa 1 do Programa Minha Casa, Minha Vida. 2017. Disponível em: < https://cbic.org.br/ governo-federal-prepara-anuncio-da-retomada-das-contratacoes-da-faixa-1-do-programa- $\backslash$ minha-casa-minha-vida/> .

ALVES, M. R. Incompleto, Minha Casa Minha Vida deixa de gerar $R \$ 70$ bi. 2016. Disponível em: <https://exame.abril.com.br/brasil/ incompleto-minha-casa-minha-vida-deixa-de-gerar-r-70-bilhoes $/>$.

BARROS, J.; FEITOSA, F. F. Uneven geographies: Exploring the sensitivity of spatial indices of residential segregation. Environment and Planning B: Urban Analytics and City Science, v. 45, n. 6, p. 1073-1089, 11 2018. ISSN 2399-8083. Disponível em: $<$ http://journals.sagepub.com/doi/10.1177/2399808318760572>.

BATTY, M. Accessibility: In Search of a Unified Theory. Environment and Planning B: Planning and Design, v. 36, n. 2, p. 191-194, 4 2009. ISSN 0265-8135. Disponível em: $<$ http://journals.sagepub.com/doi/10.1068/b3602ed $>$.

BELL, W. A Probability Model for the Measurement of Ecological Segregation. Social Forces, v. 32, n. 4, p. 357-364, 5 1954. ISSN 0037-7732. Disponível em: <https://academic.oup.com/sf/article-lookup/doi/10.2307/2574118>.

BONDUKI, N. Os pioneiros da habitação social: volume 01. 1. ed. São Paulo: Editora Unesp: Edições Sesc São Paulo, 2014.

Brasil. Estatuto da cidade. 3. ed. Brasília: Senado Federal, Subsecretaria de Edições Técnicas, 2001. 102 p. ISSN 1098-6596. ISBN 8573651687.

Brasil. Plano Nacional de Habitação. Versão para debates. Brasília, 2010. 212 p.

Brasil. Decreto no 7.499, de 16 de junho de 2011. Brasília: [s.n.], 2011. 7-8 p.

Brasil. Relatório Anual de Avaliação do PPA 2012-2015: ano base 2013. Brasília, 2014. II, $144 \mathrm{p}$. 
Brasil. Lei no 13.249 de 13 de Janeiro de 2016. Institui o Plano Plurianual da União para o período de 2016 a 2019. Brasília: [s.n.], 2016. 1 p. Disponível em: < http: //portal.imprensanacional.gov.br/destaques/ppa/2016_01_14_p_suplementoppa.pdf $>$.

BRODSKY, I. H3: Uber's Hexagonal Hierarchical Spatial Index. 2018. Disponível em: $<$ https://eng.uber.com/h3/>.

Caixa Econômica Federal. Cartilha Minha casa minha vida. Brasília, DF: [s.n.], 2008. 1-49 p. Disponível em: <http://downloads.caixa.gov.br/_arquivos/habita/mcmv/ CARTILHACOMPLETA.PDF $>$.

CALDAS, N. M. P. Os Novos Instrumentos da Política Urbana: Alcance e Limitações das ZEIS. 260 p. Tese (Doutorado) — Universidade de São Paulo, 2009.

CAMPOS, P. R.; MENDONÇA, J. G. d. Estrutura socioespacial e produção habitacional na Região Metropolitana de Belo Horizonte: novas tendências. In: CARDOSO, A. L. (Ed.). O Programa Minha Casa Minha Vida e seus Efeitos Territoriais. Rio de Janeiro: Letra Capital, 2013. p. 67-91.

CARDOSO, A. L. (Ed.). O Programa Minha Casa Minha Vida e seus Efeitos Territoriais. Rio de Janeiro: Letra Capital, 2013. 322 p. ISBN 9788577851713.

CARDOSO, A. L.; ARAGÃO, T. A. Do fim do BNH ao Programa Minha Casa Minha Vida: 25 anos da política habitacional no Brasil. In: CARDOSO, A. L. (Ed.). O Programa Minha Casa Minha Vida e seus Efeitos Territoriais. online. Rio de Janeiro: Letra Capital, 2013. cap. 1, p. 17-65. ISBN 978-85-7785-171-3. Disponível em: <http: //www.observatoriodasmetropoles.net/images/abook_file/mcmv_adauto2013.pdf $>$.

CARDoso, A. L.; ARAGÃO, T. A.; ARAuJO, F. D. S. Habitação De Interesse Social: Política Ou Mercado? Reflexos Sobre a Construção Do Espaço Metropolitano. Rio de Janeiro: [s.n.], 2011. 1-21 p. Disponível em: <papers3://publication/uuid/ AE17045C-60F0-45FA-8D31-F3F4812355D5>.

CEM. Dicionário da Base de Lançamentos Imobiliários Residenciais na Região Metropolitana de São Paulo (1985-2013). São Paulo, 2014. 9 p.

Controladoria Geral da União. Dados sobre o Programa Minha Casa Minha Vida - Pedido 59017000222201912. 2019. Disponível em: <http://www.consultaesic.cgu.gov.br/busca/ dados/Lists/Pedido/Item/displayifs.aspx?List=0c839f31-47d7-4485-ab65-ab0cee9cf8fe\& $\mathrm{ID}=752303 \& W e b=88 \mathrm{cc5f44}-8 \mathrm{cfe}-4964-8 \mathrm{ff} 4-376 \mathrm{~b} 5 \mathrm{ebb} 3 \mathrm{bef}>$.

CYMBALISTA, R.; TSUKUMO, I. L. Terra urbana para habitação social: alternativas à desapropriação na experiência brasileira. In: FERNANDES, E.; ALFONSIN, B. (Ed.). Revisitando o Instituto da Desapropriação. Belo Horizonte: Editora Fórum, 2009. p. 85-118.

DEÁK, C. Rent Theory and the Price of Urban Land - Spatial organization in a capitalist economy. 289 p. Tese (Doutorado) - Cambridge, 1985.

Department for Transport Business Plan. Accessibility Statistics : Guidance. 2014. Disponível em: < https://www.gov.uk/government/uploads/system/uploads/attachment data/file/230789/accessibility-statistics-guidance.pdf $>$. 
ERMÍNIA, M. Metrópole, legislação e desigualdade. Estudos Avançados, v. 17, n. 48, p. 151-166, 2003. ISSN 0103-4014.

FADUL, A. "Temos muito que trabalhar", diz na Fiesp a secretária Nacional de Habitação. 2016. Disponível em: <https://www.fiesp.com.br/noticias/ temos-muito-que-trabalhar-diz-na-fiesp-a-secretaria-nacional-de-habitacao/ > .

FEITOSA, F. F.; CÂMARA, G.; MONTEIRO, A. M. V. De Conceitos a Medidas Territoriais: A Construção de Índices Espaciais de Segregação Urbana. [s.n.], 2007. 86-105 p. Disponível em: <http://www.dpi.inpe.br/ flavia/articles/Segreg2007.pdf>.

FEITOSA, F. F. et al. Global and local spatial indices of urban segregation. International Journal of Geographical Information Science, v. 21, n. 3, p. 299-323, 2007. ISSN $1365-8816$.

FERREIRA, G. G. et al. Política habitacional no Brasil: uma análise das coalizões de defesa do Sistema Nacional de Habitação de Interesse Social versus o Programa Minha Casa, Minha Vida. urbe. Revista Brasileira de Gestão Urbana, v. 11, p. 1-15, 2019. ISSN 2175-3369.

FERREIRA, J. S. W. Minha Casa, Minha Vida: Notas sobre a Responsabilidade Coletiva de um Desastre Urbano. In: XVI ENANPUR. Belo Horizonte: [s.n.], 2015. p. 1-11.

FERREIRA, J. S. W. Minha Casa, Minha Vida: Notas sobre a Responsabilidade Coletiva de um Desastre Urbano. In: ENANPUR. [S.l.: s.n.], 2015. p. 1-11.

Fundação João Pinheiro. Déficit habitacional no Brasil 2009. Belo Horizonte, 2012. 200 p.

Fundação João Pinheiro. Déficit habitacional no Brasil 2011-2012. Belo Horizonte, 2015. 126 p. Disponível em: <http://www.fjp.mg.gov.br/index.php/docman/cei/ 559-deficit-habitacional-2011-2012/file $>$.

Fundação João Pinheiro. Déficit habitacional no Brasil 2013-2014. Belo Horizonte, 2016. $92 \mathrm{p}$.

GEURS, K. T.; WEE, B. van. Accessibility evaluation of land-use and transport strategies: Review and research directions. Journal of Transport Geography, v. 12, n. 2, p. 127-140, 2004. ISSN 09666923.

Google. Visão geral da GTFS estática. 2019. Disponível em: <https://developers.google. com/transit/gtfs/>.

HADDAD, E.; MEYER, J. F. P. Condições Habitacionais e distribuição de renda: evidências no caso de São Paulo. In: VII LARES. São Paulo: [s.n.], 2007. p. 1-11.

HADDAD, E. et al. O mercado imobiliário antecipa as alterações na estrutura dos bairros ? Evidências do caso de São Paulo. In: V LARES. São Paulo: [s.n.], 2005. p. 1-10.

HANSEN, W. G. How Accessibility Shapes Land Use. Journal of the American Institute of Planners, v. 25, n. 2, p. 73-76, 1959.

HOYLER, T. Produção Habitacional via Mercado: Quem produz, como e onde? Novos Estudos, v. 35, n. 1, p. 138-157, 2016. 
HUYNH, N.; BARTHÉLEMY, J.; PEREZ, P. A heuristic combinatorial optimisation approach to synthesising a population for agent-based modelling purposes. Jasss, v. 19, n. 4, 2016. ISSN 14607425.

IBGE. Censo Demográfico 2010: notas metodológicas. [S.l.], 2010. 167 p.

IBGE. Base de informações do Censo Demográfico 2010 : Resultados do Universo por setor censitário. Rio de Janeiro, 2011. 211 p.

JOSEPH, A. E.; BANTOCK, P. R. Measuring potential physician accessibility to general practitioners in rural areas: a method and case study. Social Science Ef Medicine, v. 16, n. 1, p. 85-90, 1982. ISSN 0277-9536. Disponível em: <http: //www.ncbi.nlm.nih.gov/pubmed/7100960>.

KHAN, A. A. An integrated approach to measuring potential spatial access to health care services. Socio-Economic Planning Sciences, Pergamon, v. 26, n. 4, p. 275-287, 101992. ISSN 0038-0121. Disponível em: <https://www.sciencedirect.com/science/article/pii/ 003801219290004O > .

LEFEBVRE, H. La production de l'espace. L'Homme et la société, Éditions Anthropos, Mayenne, v. 31, n. 1, p. 15-32, 1974. ISSN 0018-4306. Disponível em: <http://www.persee. $\mathrm{fr} /$ web/revues/home/prescript/article/homso_0018-4306_1974_num_31_1_1855>.

LIMA, J. J. et al. Estratégias de produção habitacional de interesse social através do PMCMC na Região Metropolitana de Belém e no sudeste do Pará. In: Santo Amore, C.; SHIMBO, L. Z.; RUFINO, M. B. C. (Ed.). Minha casa... e a cidade? Avaliação do programa minha casa minha vida em seis estados brasileiros. 1. ed. Rio de Janeiro: Letra Capital, 2015. cap. 13, p. 353-390.

LOVELACE, R.; BALLAS, D. 'Truncate, replicate, sample': A method for creating integer weights for spatial microsimulation. Computers, Environment and Urban Systems, Elsevier Ltd, v. 41, p. 1-11, 2013. ISSN 01989715. Disponível em: <http://dx.doi.org/10.1016/j.compenvurbsys.2013.03.004>.

LOVELACE, R.; CHESHIRE, J. Introduction to visualising spatial data in R. National Centre for Research Methods Working Paper 08/14, v. 14, n. 03, p. 1-30, 2014. Disponível em: < http://eprints.ncrm.ac.uk/3295/>.

LOVELACE, R.; DUMONT, M. Spatial microsimulation with R. CRC Press, 2016. Disponível em: <http://robinlovelace.net/spatial-microsim-book/>.

LUCAS, K.; WEE, B. van; MAAT, K. A method to evaluate equitable accessibility: combining ethical theories and accessibility-based approaches. Transportation, Springer US, v. 43, n. 3, p. 473-490, 2016. ISSN 15729435. Disponível em: <http://dx.doi.org/10.1007/s11116-015-9585-2>.

LUO, W.; WANG, F. Measures of spatial accessibility to health care in a GIS environment: Synthesis and a case study in the Chicago region. Environment and Planning B: Planning and Design, v. 30, n. 6, p. 865-884, 2003. ISSN 02658135.

MARICATO, E. Informalidade Urbana no Brasil: a Lógica da Cidade Fraturada. In: WANDERLEY, L. E.; RAICHELIS, R. (Ed.). A Cidade de São Paulo: Relações Internacionais e Gestão Pública. 1. ed. São Paulo: EDUC, 2009. cap. Posfácio, p. 267-292. 
MARICATO, E. Por um novo enfoque teórico na pesquisa sobre habitação. Cadeternos Metrópole, v. 21, p. 33-52, 2009. ISSN 2236-9996.

MARQUES, E.; RODRIGUES, L. O Programa Minha Casa Minha Vida na metrópole paulistana: atendimento habitacional e padrões de segregação. Revista Brasileira de Estudos Urbanos e Regionais, v. 15, n. 2, p. 159-177, 2013.

MASSEY, D. S.; DENTON, N. A. The dimensions of residential segregation. Social Forces, v. 67, n. 2, p. 281-315, 12 1988. ISSN 15347605. Disponível em: <https://academic.oup.com/sf/article-lookup/doi/10.1093/sf/67.2.281>.

MATOSO, F. Governo lança terceira fase do programa Minha Casa, Minha Vida. 2016. Disponível em: < http://g1.globo.com/politica/noticia/2016/03/ governo-lanca-terceira-fase-do-programa-minha-casa-minha-vida.html> .

MERLIN, L. A.; HU, L. Does competition matter in measures of job accessibility? Explaining employment in Los Angeles. Journal of Transport Geography, Pergamon, v. 64, p. 77-88, 10 2017. ISSN 09666923. Disponível em: < https://www.sciencedirect.com/ science/article/pii/S0966692317302405?via\%3Dihub>.

Metro. Pesquisa Origem Destino 2017. São Paulo, 2019. 136 p.

MILLER, E. J. Accessibility: measurement and application in transportation planning. Transport Reviews, v. 38, n. 5, p. 551-555, 2018. ISSN 14645327.

Ministério das Cidades. Apresentação do Ministério das Cidades para a Câmara dos Deputados. Brasília, 2018. 50 p.

NASCIMENTO, D. M. et al. Programa Minha Casa Minha Vida: desafios e avanços na Região Metropolitana de Belo Horizonte. In: Santo Amore, C.; SHIMBO, L. Z.; RUFINO, M. B. C. (Ed.). Minha casa... e a cidade? Avaliação do programa minha casa minha vida em seis estados brasileiros. 1. ed. Rio de Janeiro: Letra Capital, 2015. cap. 8, p. 195.

NEUTENS, T. Accessibility, equity and health care: Review and research directions for transport geographers. Journal of Transport Geography, Elsevier Ltd, v. 43, p. 14-27, 2015. ISSN 09666923. Disponível em: <http://dx.doi.org/10.1016/j.jtrangeo.2014.12.006>.

O'SULLIVAN, D.; WONG, D. W. S. A surface-based approach to measuring spatial segregation. Geographical Analysis, v. 39, n. 2, p. 147-168, 2007. ISSN 00167363.

PÁEZ, A.; SCOTT, D. M.; MORENCY, C. Measuring accessibility: Positive and normative implementations of various accessibility indicators. Journal of Transport Geography, Elsevier Ltd, v. 25, p. 141-153, 2012. ISSN 09666923. Disponível em: $<$ http://dx.doi.org/10.1016/j.jtrangeo.2012.03.016>.

PENG, Z.-R. The Jobs-Housing Balance and Urban Commuting. Urban Studies, Sage PublicationsSage UK: London, England, v. 34, n. 8, p. 1215-1235, 7 1997. ISSN 0042-0980. Disponível em: <http://journals.sagepub.com/doi/10.1080/0042098975600>.

PEQUENO, R.; FREITAS, C. Programa Minha Casa Minha Vida em Fortaleza: Primeiros Resultados. In: Adau (Ed.). O Programa Minha Casa Minha Vida e seus Efeitos Territoriais. Rio de Janeiro: Letra Capital, 2013. p. 115-142. 
PEQUENO, R.; ROSA, S. V. Inserção urbana e segregação espacial: análise do Programa Minha Casa Minha Vida em Fortaleza. In: Santo Amore, C.; SHIMBO, L. Z.; RUFINO, M. B. C. (Ed.). Minha casa... e a cidade? Avaliação do programa minha casa minha vida em seis estados brasileiros. 1. ed. Rio de Janeiro: Letra Capital, 2015. cap. 6, p. 131-164.

PEREIRA, R. H. Future accessibility impacts of transport policy scenarios: Equity and sensitivity to travel time thresholds for Bus Rapid Transit expansion in Rio de Janeiro. Journal of Transport Geography, Pergamon, v. 74, p. 321-332, 1 2019. ISSN 09666923. Disponível em: <https://www.sciencedirect.com/science/article/pii/S0966692318302047>.

RADKE, J.; MU, L. Spatial decompositions, modeling and mapping service regions to predict access to social programs. Geographic Information Sciences, v. 6, n. 2, p. 105-112, 2000. ISSN 10824006.

REARDON, S. F.; O’SUlLIVAN, D. Measures of Spatial Segregation. Sociological Methodology, v. 34, n. 1, p. 121-162, 2004. ISSN 1467-9531. Disponível em: <http://onlinelibrary.wiley.com/doi/10.1111/j.0081-1750.2004.00150.x/abstract>.

RIBEIRO, L. C. d. Q. A produção capitalista da moradia. In: Dos cortiços aos condomínios fechados: as formas de produção da moradia na cidade do Rio de Janeiro. 2. ed. Rio de Janeiro: Letra Capital, 2015. cap. 3, p. 79 - 101.

RIBEIRO, L. C. d. Q. Dos cortiços aos condominios fechados: as formas de produção da moradia na cidade do Rio de Janeiro. 2. ed. Rio de Janeiro: Letra Capital, 2015. recurso digital p. ISBN 9788577853861. Disponível em: < http://www.observatoriodasmetropoles. net/new/images/abook_file/dos_corticos_aos_condominios_fechados.pdf $>$.

RIBEIRO, L. C. Q. Desafios da construção da cidadania na metrópole brasileira. Sociedade e Estado, v. 22, n. 3, p. 525-544, 12 2007. ISSN 0102-6992. Disponível em: $<$ http://www.scielo.br/scielo.php?script=sci_arttext\&pid=S0102-69922007000300003\& $\operatorname{lng}=\mathrm{pt} \& \mathrm{tlng}=\mathrm{pt}>$.

RIBEIRO, S. C. L.; DANIEL, M. N.; ABIKO, A. ZEIS maps: Comparing areas to be earmarked exclusively for social housing in São Paulo city. Land Use Policy, Elsevier Ltd, v. 58, n. 44667, p. 445-456, 2016. ISSN 02648377. Disponível em: <http://dx.doi.org/10.1016/j.landusepol.2016.08.010>.

ROLNIK, R. et al. Inserção urbana no PMCMV e a efetivação do direito à moradia adequada: uma avaliação de sete empreendimentos no estado de São Paulo. In: Minha casa... e a cidade? Avaliação do programa minha casa minha vida em seis estados brasileiros. 1. ed. Rio de Janeiro: Letra Capital, 2015. cap. 14, p. 391 - 416.

ROLNIK, R.; SANTORO, P. F. Zonas Especiais de Interesse Social (ZEIS) em Cidades Brasileiras: Trajetória Recente de Implementação de um Instrumento de Política Fundiária. Lincoln Institute of Land Policy, p. 30, 2013.

RUFinO, M. B. C. et al. A produção do Programa PMCMV na Baixada Santista: habitação de interesse social ou negócio imobiliário? In: Santo Amore, C.; SHIMBO, L. Z.; RUFIN, M. B. C. (Ed.). Minha casa ... e a cidade? Avaliação do programa minha casa minha vida em seis estados brasileirosa. 1. ed. Rio de Janeiro: Letra Capital, 2015. cap. 5, p. $103-130$. 
São Paulo (cidade). Plano Diretor Estratégico do Município de São Paulo, Lei $n^{o}$ 13.340/02. 2002.

São Paulo (cidade). Lei $n^{\circ}$ 13.885, de 25 de agosto de 2004. São Paulo: [s.n.], 2004. Disponível em: <https://www.prefeitura.sp.gov.br/cidade/secretarias/urbanismo/ legislacao/planos_regionais/index.php? $\mathrm{p}=822>$.

São Paulo (cidade). Plano Municipal da Habitação Social da Cidade de São Paulo: PMH 2009 - 2024. São Paulo: Secretaria de Habitação, 2011. 234 p. ISSN 1098-6596. ISBN 9788578110796.

São Paulo (cidade). Revisão do Plano Diretor Estratégico Habitação. São Paulo: [s.n.], 2013. Disponível em: <https://www.prefeitura.sp.gov.br/cidade/secretarias/upload/ desenvolvimento_urbano/arquivos/plano_diretor/revisao-pde-habitacao.pdf $>$.

São Paulo (cidade). Plano Diretor Estratégico do Município de São Paulo, Lei $n^{o}$ 16.050/14 - Texto da lei ilustrado. 2014. 229 p. Disponível em: < https://gestaourbana. prefeitura.sp.gov.br/marco-regulatorio/plano-diretor/texto-da-lei-ilustrado/>.

São Paulo (cidade). Parcelamento, Uso e Ocupação do Solo do Município de São Paulo - Lei no16.402/2016. São Paulo: [s.n.], 2016. 177 p. Disponível em: <http://gestaourbana.prefeitura.sp.gov.br/wp-content/uploads/2016/03/ GEST $\sim \mathrm{AO} 2$-smdu-zoneamento_ilustrado.pdf $>$.

São Paulo (cidade). Plano Municipal de Habitação de São Paulo - Projeto de Lei no 619/16. São Paulo: [s.n.], 2016.

Santo Amore, C. Entre o nó e o fato consumado, o lugar dos pobres na cidade: um estudo sobre as ZEIS e os impasses da Reforma Urbana na atualidade. 276 p. Tese (Doutorado) Universidade de São Paulo, 2013.

Santo Amore, C. "Minha Casa Minha Vida" para iniciantes. In: Santo Amore, C.; SHIMBO, L. Z.; RUFIN, M. B. C. (Ed.). Minha casa... e a cidade? Avaliação do programa minha casa minha vida em seis estados brasileiros. 1. ed. Rio de Janeiro: Letra Capital, 2015. cap. 1, p. 11-27.

Santo Amore, C.; SHIMBO, L. Z.; RUFINO, M. B. C. Minha casa... e a cidade? Avaliação do programa minha casa minha vida em seis estados brasileiros. 1. ed. Rio de Janeiro: Letra Capital, 2015. 428 p. ISSN 1098-6596. ISBN 9788577853779.

SANTORO, P. F.; BORRELLI, J. Os desafios de produzir habitação de interesse social em São Paulo: da reserva de terra no zoneamento às contrapartidas obtidas a partir do desenvolvimento imobiliário ou das ZEIS à Cota de Solidariedade. In: ENANPUR. Belo Horizonte: [s.n.], 2015. p. 1-19.

SHEN, Q. Location characteristics of inner-city neighborhoods and employment accessibility of low-wage workers. Environment and Planning B: Planning and Design, SAGE PublicationsSage UK: London, England, v. 25, n. 3, p. 345-365, 11 1998. ISSN 02658135. Disponível em: <http://epb.sagepub.com/lookup/doi/10.1068/b250345>.

SHIMBO, L. An unprecedented alignment : state, finance, construction and housing production in Brazil since the 2000s since the 2000s. International Journal of Housing Policy, Routledge, v. 19, n. 3, p. 337-353, 2019. ISSN 1949-1247. Disponível em: <https://doi.org/10.1080/19491247.2019.1573960>. 
SÍGOLO, L. M.; SIGOLO, L. M. O Boom Imobiliário Redesenhando a Cartografia da Segregação Socioespacial na Metrópole Paulistana. 1-21 p. Tese (Doutorado) — FAUUSP, São Paulo, 2014.

SINGER, P. O Uso do Solo Urbano da Economia Capitalista. In: MARICATO, E. (Ed.). A produção capitalista da casa (e da cidade) no Brasil industrial. 2. ed. São Paulo: Alfa-Omega, 1982. cap. 1, p. 21-36.

SIQUEIRA-GAY, J.; GALLARDO, A. L. C. F.; GIANNOTTI, M. Integrating socioenvironmental spatial information to support housing plans. Cities, v. 91, p. 106-115, 8 2019. ISSN 02642751. Disponível em: <https://www.sciencedirect.com/science/article/pii/ S0264275118304645https://linkinghub.elsevier.com/retrieve/pii/S0264275118304645>.

SMITH, M. J. de et al. Geospatial Analysis: a comprehensive guide to principles techniques and software tools. [S.l.]: Troubador publishing ltd, 2018. 602 p.

VILLAÇA, F. Espaço intra-urbano no Brasil. São Paulo: Studio Nobel:FAPESP:Lincoln Institute, 2001. 391 p.

VILLAÇA, F. São Paulo: segregação urbana e desigualdade. Estudos Avançados, v. 25, n. 71, p. 37-58, 2011.

VILLAÇA, F. A terra como Capital (ou A Terra-Localização). In: Reflexões sobre as cidades brasileiras. São Paulo: Studio Nobel, 2012. cap. Parte I: R, p. 25-40. ISBN 978-979-044-446-1.

WANG, F. Modeling Commuting Patterns in Chicago in a GIS Environment: A Job Accessibility Perspective. The Professional Geographer, Wiley/Blackwell (10.1111), v. 52, n. 1, p. 120-133, 2 2000. ISSN 0033-0124. Disponível em: <http://www.tandfonline.com/doi/abs/10.1111/0033-0124.00210>. 
Apêndices 


\section{APÊNDICE A - Decisões de pesquisa}

Tabela 5 - Datas das inaugurações das estações de Metrô e Trem de São Paulo

\begin{tabular}{|c|c|c|c|c|c|}
\hline Estação & Linha & Sentido & Sistema & Operadora & Inauguração \\
\hline Jabaquara & 1 & 0 & Metrô & Metrô & $14 / 09 / 1974$ \\
\hline Conceição & 1 & 0 & Metrô & Metrô & $14 / 09 / 1974$ \\
\hline São Judas & 1 & 0 & Metrô & Metrô & $14 / 09 / 1974$ \\
\hline Saúde & 1 & 0 & Metrô & Metrô & $14 / 09 / 1974$ \\
\hline Praça da Árvore & 1 & 0 & Metrô & Metrô & $14 / 09 / 1974$ \\
\hline Santa Cruz & 1 & 0 & Metrô & Metrô & $14 / 09 / 1974$ \\
\hline Vila Mariana & 1 & 0 & Metrô & Metrô & $14 / 09 / 1974$ \\
\hline Ana Rosa & 1 & 0 & Metrô & Metrô & $17 / 02 / 1975$ \\
\hline Paraíso & 1 & 0 & Metrô & Metrô & $17 / 02 / 1975$ \\
\hline Vergueiro & 1 & 0 & Metrô & Metrô & $17 / 02 / 1975$ \\
\hline São Joaquim & 1 & 0 & Metrô & Metrô & $17 / 02 / 1975$ \\
\hline Liberdade & 1 & 0 & Metrô & Metrô & 26/09/1975 \\
\hline Sé & 1 & 0 & Metrô & Metrô & $17 / 02 / 1978$ \\
\hline São Bento & 1 & 0 & Metrô & Metrô & $26 / 09 / 1975$ \\
\hline Luz & 1 & 0 & Metrô & Metrô & $26 / 09 / 1975$ \\
\hline Tiradentes & 1 & 0 & Metrô & Metrô & 26/09/1975 \\
\hline Armênia & 1 & 0 & Metrô & Metrô & 26/09/1975 \\
\hline Portuguesa-Tietê & 1 & 0 & Metrô & Metrô & 26/09/1975 \\
\hline Carandiru & 1 & 0 & Metrô & Metrô & $26 / 09 / 1975$ \\
\hline
\end{tabular}


Tabela 5 - continuação

\begin{tabular}{|c|c|c|c|c|c|}
\hline Estação & Linha & Sentido & Sistema & Operadora & Inauguração \\
\hline Santana & 1 & 0 & Metrô & Metrô & $26 / 09 / 1975$ \\
\hline Jardim São Paulo & 1 & 0 & Metrô & Metrô & 29/04/1998 \\
\hline Parada Inglesa & 1 & 0 & Metrô & Metrô & $29 / 04 / 1998$ \\
\hline Tucuruvi & 1 & 0 & Metrô & Metrô & $29 / 04 / 1998$ \\
\hline Tucuruvi & 1 & 1 & Metrô & Metrô & $29 / 04 / 1998$ \\
\hline Parada Inglesa & 1 & 1 & Metrô & Metrô & $29 / 04 / 1998$ \\
\hline Jardim São Paulo & 1 & 1 & Metrô & Metrô & 29/04/1998 \\
\hline Santana & 1 & 1 & Metrô & Metrô & $26 / 09 / 1975$ \\
\hline Carandiru & 1 & 1 & Metrô & Metrô & $26 / 09 / 1975$ \\
\hline Portuguesa-Tietê & 1 & 1 & Metrô & Metrô & $26 / 09 / 1975$ \\
\hline Armênia & 1 & 1 & Metrô & Metrô & $26 / 09 / 1975$ \\
\hline Tiradentes & 1 & 1 & Metrô & Metrô & $26 / 09 / 1975$ \\
\hline Luz & 1 & 1 & Metrô & Metrô & $26 / 09 / 1975$ \\
\hline São Bento & 1 & 1 & Metrô & Metrô & 26/09/1975 \\
\hline Sé & 1 & 1 & Metrô & Metrô & $17 / 02 / 1978$ \\
\hline Liberdade & 1 & 1 & Metrô & Metrô & $26 / 09 / 1975$ \\
\hline São Joaquim & 1 & 1 & Metrô & Metrô & $17 / 02 / 1975$ \\
\hline Vergueiro & 1 & 1 & Metrô & Metrô & $17 / 02 / 1975$ \\
\hline Paraíso & 1 & 1 & Metrô & Metrô & $17 / 02 / 1975$ \\
\hline Ana Rosa & 1 & 1 & Metrô & Metrô & $17 / 02 / 1975$ \\
\hline Vila Mariana & 1 & 1 & Metrô & Metrô & $14 / 09 / 1974$ \\
\hline Santa Cruz & 1 & 1 & Metrô & Metrô & $14 / 09 / 1974$ \\
\hline
\end{tabular}


Tabela 5 - continuação

\begin{tabular}{|c|c|c|c|c|c|}
\hline Estação & Linha & Sentido & Sistema & Operadora & Inauguração \\
\hline Praça da Árvore & 1 & 1 & Metrô & Metrô & $14 / 09 / 1974$ \\
\hline Saúde & 1 & 1 & Metrô & Metrô & $14 / 09 / 1974$ \\
\hline São Judas & 1 & 1 & Metrô & Metrô & $14 / 09 / 1974$ \\
\hline Conceição & 1 & 1 & Metrô & Metrô & $14 / 09 / 1974$ \\
\hline Jabaquara & 1 & 1 & Metrô & Metrô & $14 / 09 / 1974$ \\
\hline Vila Madalena & 2 & 0 & Metrô & Metrô & $21 / 11 / 1998$ \\
\hline Sumaré & 2 & 0 & Metrô & Metrô & $21 / 11 / 1998$ \\
\hline Clínicas & 2 & 0 & Metrô & Metrô & 12/09/1992 \\
\hline Consolação & 2 & 0 & Metrô & Metrô & 25/01/1991 \\
\hline Trianon-MASP & 2 & 0 & Metrô & Metrô & 25/01/1991 \\
\hline Brigadeiro & 2 & 0 & Metrô & Metrô & $25 / 01 / 1991$ \\
\hline Paraíso & 2 & 0 & Metrô & Metrô & $25 / 01 / 1991$ \\
\hline Ana Rosa & 2 & 0 & Metrô & Metrô & $12 / 09 / 1992$ \\
\hline Chácara Klabin & 2 & 0 & Metrô & Metrô & $09 / 05 / 2006$ \\
\hline Santos-Imigrantes & 2 & 0 & Metrô & Metrô & $30 / 03 / 2006$ \\
\hline Alto do Ipiranga & 2 & 0 & Metrô & Metrô & $30 / 06 / 2007$ \\
\hline Sacomã & 2 & 0 & Metrô & Metrô & $30 / 01 / 2010$ \\
\hline Tamanduateí & 2 & 0 & Metrô & Metrô & $21 / 09 / 2010$ \\
\hline Vila Prudente & 2 & 0 & Metrô & Metrô & $21 / 08 / 2010$ \\
\hline Vila Prudente & 2 & 1 & Metrô & Metrô & $21 / 08 / 2010$ \\
\hline Tamanduateí & 2 & 1 & Metrô & Metrô & $21 / 09 / 2010$ \\
\hline Sacomã & 2 & 1 & Metrô & Metrô & $30 / 01 / 2010$ \\
\hline
\end{tabular}


Tabela 5 - continuação

\begin{tabular}{|c|c|c|c|c|c|}
\hline Estação & Linha & Sentido & Sistema & Operadora & Inauguração \\
\hline Alto do Ipiranga & 2 & 1 & Metrô & Metrô & $30 / 06 / 2007$ \\
\hline Santos-Imigrantes & 2 & 1 & Metrô & Metrô & $30 / 03 / 2006$ \\
\hline Chácara Klabin & 2 & 1 & Metrô & Metrô & $09 / 05 / 2006$ \\
\hline Ana Rosa & 2 & 1 & Metrô & Metrô & 12/09/1992 \\
\hline Paraíso & 2 & 1 & Metrô & Metrô & 25/01/1991 \\
\hline Brigadeiro & 2 & 1 & Metrô & Metrô & 25/01/1991 \\
\hline Trianon-MASP & 2 & 1 & Metrô & Metrô & 25/01/1991 \\
\hline Consolação & 2 & 1 & Metrô & Metrô & 25/01/1991 \\
\hline Clínicas & 2 & 1 & Metrô & Metrô & $12 / 09 / 1992$ \\
\hline Sumaré & 2 & 1 & Metrô & Metrô & $21 / 11 / 1998$ \\
\hline Vila Madalena & 2 & 1 & Metrô & Metrô & $21 / 11 / 1998$ \\
\hline Palmeiras-Barra Funda & 3 & 0 & Metrô & Metrô & $17 / 12 / 1988$ \\
\hline Marechal Deodoro & 3 & 0 & Metrô & Metrô & $17 / 12 / 1988$ \\
\hline Santa Cecília & 3 & 0 & Metrô & Metrô & $24 / 04 / 1982$ \\
\hline República & 3 & 0 & Metrô & Metrô & $24 / 04 / 1982$ \\
\hline Anhangabaú & 3 & 0 & Metrô & Metrô & $26 / 11 / 1983$ \\
\hline Sé & 3 & 0 & Metrô & Metrô & $10 / 03 / 1979$ \\
\hline Pedro II & 3 & 0 & Metrô & Metrô & $10 / 09 / 1980$ \\
\hline Brás & 3 & 0 & Metrô & Metrô & $10 / 03 / 1979$ \\
\hline Bresser-Mooca & 3 & 0 & Metrô & Metrô & $23 / 08 / 1980$ \\
\hline Belém & 3 & 0 & Metrô & Metrô & $15 / 09 / 1981$ \\
\hline Tatuapé & 3 & 0 & Metrô & Metrô & $15 / 11 / 1981$ \\
\hline
\end{tabular}


Tabela 5 - continuação

\begin{tabular}{|c|c|c|c|c|c|}
\hline Estação & Linha & Sentido & Sistema & Operadora & Inauguração \\
\hline Carrão & 3 & 0 & Metrô & Metrô & 13/09/1986 \\
\hline Penha & 3 & 0 & Metrô & Metrô & $13 / 09 / 1986$ \\
\hline Vila Matilde & 3 & 0 & Metrô & Metrô & $27 / 08 / 1988$ \\
\hline Guilhermina Esperança & 3 & 0 & Metrô & Metrô & $27 / 08 / 1988$ \\
\hline Patriarca & 3 & 0 & Metrô & Metrô & $17 / 09 / 1988$ \\
\hline Artur Alvim & 3 & 0 & Metrô & Metrô & $17 / 09 / 1988$ \\
\hline Corinthians-Itaquera & 3 & 0 & Metrô & Metrô & $01 / 10 / 1988$ \\
\hline Corinthians-Itaquera & 3 & 1 & Metrô & Metrô & $01 / 10 / 1988$ \\
\hline Artur Alvim & 3 & 1 & Metrô & Metrô & $17 / 09 / 1988$ \\
\hline Patriarca & 3 & 1 & Metrô & Metrô & $17 / 09 / 1988$ \\
\hline Guilhermina Esperança & 3 & 1 & Metrô & Metrô & $27 / 08 / 1988$ \\
\hline Vila Matilde & 3 & 1 & Metrô & Metrô & $27 / 08 / 1988$ \\
\hline Penha & 3 & 1 & Metrô & Metrô & $13 / 09 / 1986$ \\
\hline Carrão & 3 & 1 & Metrô & Metrô & $13 / 09 / 1986$ \\
\hline Tatuapé & 3 & 1 & Metrô & Metrô & $15 / 11 / 1981$ \\
\hline Belém & 3 & 1 & Metrô & Metrô & $15 / 09 / 1981$ \\
\hline Bresser-Mooca & 3 & 1 & Metrô & Metrô & $23 / 08 / 1980$ \\
\hline Brás & 3 & 1 & Metrô & Metrô & 10/03/1979 \\
\hline Pedro II & 3 & 1 & Metrô & Metrô & $10 / 09 / 1980$ \\
\hline Sé & 3 & 1 & Metrô & Metrô & 10/03/1979 \\
\hline Anhangabaú & 3 & 1 & Metrô & Metrô & $26 / 11 / 1983$ \\
\hline República & 3 & 1 & Metrô & Metrô & $24 / 04 / 1982$ \\
\hline
\end{tabular}


Tabela 5 - continuação

\begin{tabular}{|c|c|c|c|c|c|}
\hline Estação & Linha & Sentido & Sistema & Operadora & Inauguração \\
\hline Santa Cecília & 3 & 1 & Metrô & Metrô & $24 / 04 / 1982$ \\
\hline Marechal Deodoro & 3 & 1 & Metrô & Metrô & $17 / 12 / 1988$ \\
\hline Palmeiras-Barra Funda & 3 & 1 & Metrô & Metrô & $17 / 12 / 1988$ \\
\hline São Paulo-Morumbi & 4 & 0 & Metrô & Via Quatro & $27 / 10 / 2018$ \\
\hline Butantã & 4 & 0 & Metrô & Via Quatro & $28 / 03 / 2011$ \\
\hline Pinheiros & 4 & 0 & Metrô & Via Quatro & $16 / 05 / 2011$ \\
\hline Faria Lima & 4 & 0 & Metrô & Via Quatro & $25 / 05 / 2010$ \\
\hline Fradique Coutinho & 4 & 0 & Metrô & Via Quatro & $15 / 11 / 2014$ \\
\hline Oscar Freire & 4 & 0 & Metrô & Via Quatro & $04 / 04 / 2018$ \\
\hline Paulista & 4 & 0 & Metrô & Via Quatro & $25 / 05 / 2010$ \\
\hline Higienópolis-Mackenzie & 4 & 0 & Metrô & Via Quatro & $23 / 01 / 2018$ \\
\hline República & 4 & 0 & Metrô & Via Quatro & $15 / 09 / 2011$ \\
\hline Luz & 4 & 0 & Metrô & Via Quatro & $15 / 09 / 2011$ \\
\hline Luz & 4 & 1 & Metrô & Via Quatro & $15 / 09 / 2011$ \\
\hline República & 4 & 1 & Metrô & Via Quatro & $15 / 09 / 2011$ \\
\hline Higienópolis-Mackenzie & 4 & 1 & Metrô & Via Quatro & $23 / 01 / 2018$ \\
\hline Paulista & 4 & 1 & Metrô & Via Quatro & $25 / 05 / 2010$ \\
\hline Oscar Freire & 4 & 1 & Metrô & Via Quatro & $04 / 04 / 2018$ \\
\hline Fradique Coutinho & 4 & 1 & Metrô & Via Quatro & $15 / 11 / 2014$ \\
\hline Faria Lima & 4 & 1 & Metrô & Via Quatro & $25 / 05 / 2010$ \\
\hline Pinheiros & 4 & 1 & Metrô & Via Quatro & $16 / 05 / 2011$ \\
\hline Butantã & 4 & 1 & Metrô & Via Quatro & $28 / 03 / 2011$ \\
\hline
\end{tabular}


Tabela 5 - continuação

\begin{tabular}{|c|c|c|c|c|c|}
\hline Estação & Linha & Sentido & Sistema & Operadora & Inauguração \\
\hline São Paulo-Morumbi & 4 & 1 & Metrô & Via Quatro & $27 / 10 / 2018$ \\
\hline Capão Redondo & 5 & 0 & Metrô & Via Mobilidade & $20 / 10 / 2002$ \\
\hline Campo Limpo & 5 & 0 & Metrô & Via Mobilidade & $20 / 10 / 2002$ \\
\hline Vila das Belezas & 5 & 0 & Metrô & Via Mobilidade & $20 / 10 / 2002$ \\
\hline Giovanni Gronchi & 5 & 0 & Metrô & Via Mobilidade & $20 / 10 / 2002$ \\
\hline Santo Amaro & 5 & 0 & Metrô & Via Mobilidade & $20 / 10 / 2002$ \\
\hline Largo Treze & 5 & 0 & Metrô & Via Mobilidade & $20 / 10 / 2002$ \\
\hline Adolfo Pinheiro & 5 & 0 & Metrô & Via Mobilidade & $12 / 02 / 2014$ \\
\hline Alto da Boa Vista & 5 & 0 & Metrô & Via Mobilidade & $06 / 09 / 2017$ \\
\hline Borba Gato & 5 & 0 & Metrô & Via Mobilidade & $06 / 09 / 2017$ \\
\hline Brooklin & 5 & 0 & Metrô & Via Mobilidade & $06 / 09 / 2017$ \\
\hline Eucaliptos & 5 & 0 & Metrô & Via Mobilidade & $02 / 03 / 2018$ \\
\hline Moema & 5 & 0 & Metrô & Via Mobilidade & $05 / 04 / 2018$ \\
\hline AACD-Servidor & 5 & 0 & Metrô & Via Mobilidade & $31 / 08 / 2018$ \\
\hline Hospital São Paulo & 5 & 0 & Metrô & Via Mobilidade & $28 / 09 / 2018$ \\
\hline Santa Cruz & 5 & 0 & Metrô & Via Mobilidade & $28 / 09 / 2018$ \\
\hline Chácara Klabin & 5 & 0 & Metrô & Via Mobilidade & $28 / 09 / 2018$ \\
\hline Chácara Klabin & 5 & 1 & Metrô & Via Mobilidade & $28 / 09 / 2018$ \\
\hline Santa Cruz & 5 & 1 & Metrô & Via Mobilidade & $28 / 09 / 2018$ \\
\hline Hospital São Paulo & 5 & 1 & Metrô & Via Mobilidade & $28 / 09 / 2018$ \\
\hline AACD-Servidor & 5 & 1 & Metrô & Via Mobilidade & $31 / 08 / 2018$ \\
\hline Moema & 5 & 1 & Metrô & Via Mobilidade & $05 / 04 / 2018$ \\
\hline
\end{tabular}


Tabela 5 - continuação

\begin{tabular}{|c|c|c|c|c|c|}
\hline Estação & Linha & Sentido & Sistema & Operadora & Inauguração \\
\hline Eucaliptos & 5 & 1 & Metrô & Via Mobilidade & $02 / 03 / 2018$ \\
\hline Brooklin & 5 & 1 & Metrô & Via Mobilidade & 06/09/2017 \\
\hline Borba Gato & 5 & 1 & Metrô & Via Mobilidade & 06/09/2017 \\
\hline Alto da Boa Vista & 5 & 1 & Metrô & Via Mobilidade & $06 / 09 / 2017$ \\
\hline Adolfo Pinheiro & 5 & 1 & Metrô & Via Mobilidade & $12 / 02 / 2014$ \\
\hline Largo Treze & 5 & 1 & Metrô & Via Mobilidade & $20 / 10 / 2002$ \\
\hline Santo Amaro & 5 & 1 & Metrô & Via Mobilidade & $20 / 10 / 2002$ \\
\hline Giovanni Gronchi & 5 & 1 & Metrô & Via Mobilidade & $20 / 10 / 2002$ \\
\hline Vila das Belezas & 5 & 1 & Metrô & Via Mobilidade & $20 / 10 / 2002$ \\
\hline Campo Limpo & 5 & 1 & Metrô & Via Mobilidade & $20 / 10 / 2002$ \\
\hline Capão Redondo & 5 & 1 & Metrô & Via Mobilidade & $20 / 10 / 2002$ \\
\hline Luz & 7 & 0 & CPTM & CPTM & $16 / 02 / 1867$ \\
\hline Palmeiras-Barra Funda & 7 & 0 & CPTM & CPTM & $17 / 12 / 1988$ \\
\hline Água Branca & 7 & 0 & СРТM & СРТM & $16 / 02 / 1867$ \\
\hline Lapa & 7 & 0 & CPTM & СРTM & $20 / 02 / 1899$ \\
\hline Piqueri & 7 & 0 & CPTM & CPTM & 01/07/1960 \\
\hline Pirituba & 7 & 0 & CPTM & CPTM & $01 / 02 / 1885$ \\
\hline Vila Clarice & 7 & 0 & CPTM & СРТМ & 01/09/1955 \\
\hline Jaraguá & 7 & 0 & CPTM & СРТМ & 01/10/1891 \\
\hline Vila Aurora & 7 & 0 & СРТМ & CPTM & 09/09/2013 \\
\hline Perus & 7 & 0 & СРТМ & CPTM & $16 / 02 / 1867$ \\
\hline Caieiras & 7 & 0 & CPTM & СРТМ & $16 / 02 / 1867$ \\
\hline
\end{tabular}


Tabela 5 - continuação

\begin{tabular}{|c|c|c|c|c|c|}
\hline Estação & Linha & Sentido & Sistema & Operadora & Inauguração \\
\hline Franco da Rocha & 7 & 0 & CPTM & CPTM & $01 / 02 / 1888$ \\
\hline Baltazar Fidélis & 7 & 0 & CPTM & CPTM & $01 / 07 / 1955$ \\
\hline Francisco Morato & 7 & 0 & CPTM & CPTM & $16 / 02 / 1867$ \\
\hline Botujuru & 7 & 0 & CPTM & CPTM & $17 / 09 / 1908$ \\
\hline Campo Limpo Paulista & 7 & 0 & CPTM & CPTM & $10 / 01 / 1881$ \\
\hline Várzea Paulista & 7 & 0 & CPTM & CPTM & $01 / 07 / 1891$ \\
\hline Jundiaí & 7 & 0 & CPTM & CPTM & $16 / 02 / 1867$ \\
\hline Jundiaí & 7 & 1 & CPTM & CPTM & $16 / 02 / 1867$ \\
\hline Várzea Paulista & 7 & 1 & СРТМ & CPTM & $01 / 07 / 1891$ \\
\hline Campo Limpo Paulista & 7 & 1 & CPTM & CPTM & $10 / 01 / 1881$ \\
\hline Botujuru & 7 & 1 & СРTM & CPTM & $17 / 09 / 1908$ \\
\hline Francisco Morato & 7 & 1 & СРTM & CPTM & $16 / 02 / 1867$ \\
\hline Baltazar Fidélis & 7 & 1 & СРTM & СРTM & $01 / 07 / 1955$ \\
\hline Franco da Rocha & 7 & 1 & СРТМ & CPTM & $01 / 02 / 1888$ \\
\hline Caieiras & 7 & 1 & CPTM & CPTM & $16 / 02 / 1867$ \\
\hline Perus & 7 & 1 & СРТМ & CPTM & $16 / 02 / 1867$ \\
\hline Vila Aurora & 7 & 1 & СРТM & CPTM & 09/09/2013 \\
\hline Jaraguá & 7 & 1 & CPTM & CPTM & 01/10/1891 \\
\hline Vila Clarice & 7 & 1 & СРTM & СРTM & 01/09/1955 \\
\hline Pirituba & 7 & 1 & СРТМ & СРТМ & $01 / 02 / 1885$ \\
\hline Piqueri & 7 & 1 & СРТМ & CРTM & 01/07/1960 \\
\hline Lapa & 7 & 1 & СРTM & CPTM & 20/02/1899 \\
\hline
\end{tabular}


Tabela 5 - continuação

\begin{tabular}{|c|c|c|c|c|c|}
\hline Estação & Linha & Sentido & Sistema & Operadora & Inauguração \\
\hline Água Branca & 7 & 1 & CPTM & СРТМ & $16 / 02 / 1867$ \\
\hline Palmeiras-Barra Funda & 7 & 1 & CPTM & CPTM & $17 / 12 / 1988$ \\
\hline Luz & 7 & 1 & CPTM & CPTM & $16 / 02 / 1867$ \\
\hline Júlio Prestes & 8 & 0 & CPTM & СРТМ & $10 / 07 / 1872$ \\
\hline Palmeiras-Barra Funda & 8 & 0 & СРТМ & CРTM & $17 / 12 / 1988$ \\
\hline Lapa & 8 & 0 & CPTM & CPTM & $25 / 01 / 1979$ \\
\hline Domingos de Moraes & 8 & 0 & CPTM & CPTM & $25 / 06 / 1920$ \\
\hline Imperatriz Leopoldina & 8 & 0 & СРТМ & CРTM & $25 / 01 / 1979$ \\
\hline Presidente Altino & 8 & 0 & СРТМ & CPTM & $25 / 01 / 1979$ \\
\hline Osasco & 8 & 0 & CPTM & СРТМ & $02 / 08 / 1895$ \\
\hline Comandante Sampaio & 8 & 0 & CPTM & СРТМ & $25 / 01 / 1979$ \\
\hline Quitaúna & 8 & 0 & СРТМ & CPTM & $25 / 01 / 1979$ \\
\hline General Miguel Costa & 8 & 0 & CPTM & CPTM & $25 / 01 / 1979$ \\
\hline Carapicuíba & 8 & 0 & СРТМ & СРТМ & $25 / 01 / 1979$ \\
\hline Santa Terezinha & 8 & 0 & CPTM & CPTM & $25 / 01 / 1979$ \\
\hline Antônio João & 8 & 0 & CPTM & CPTM & $25 / 11 / 1982$ \\
\hline Barueri & 8 & 0 & СРТM & CPTM & $10 / 07 / 1875$ \\
\hline Jardim Belval & 8 & 0 & СРТМ & CPTM & $11 / 03 / 1983$ \\
\hline Jardim Silveira & 8 & 0 & СРТМ & СРТМ & $11 / 03 / 1983$ \\
\hline Jandira & 8 & 0 & CPTM & CPTM & $20 / 03 / 1931$ \\
\hline Sagrado Coração & 8 & 0 & CPTM & CPTM & $01 / 01 / 1950$ \\
\hline Engenheiro Cardoso & 8 & 0 & CPTM & CPТM & $20 / 01 / 1987$ \\
\hline
\end{tabular}


Tabela 5 - continuação

\begin{tabular}{|c|c|c|c|c|c|}
\hline Estação & Linha & Sentido & Sistema & Operadora & Inauguração \\
\hline Itapevi & 8 & 0 & CPTM & СРTM & $10 / 07 / 1875$ \\
\hline Santa Rita & 8 & 0 & CPTM & СРTM & $21 / 06 / 1985$ \\
\hline Amador Bueno & 8 & 0 & СРTM & CРTM & $21 / 06 / 1985$ \\
\hline Cimenrita & 8 & 0 & CPTM & CPTM & $00 / 01 / 1900$ \\
\hline Ambuitá & 8 & 0 & CPTM & CPTM & $00 / 01 / 1900$ \\
\hline Amador Bueno & 8 & 1 & CPTM & CРTM & $21 / 06 / 1985$ \\
\hline Santa Rita & 8 & 1 & СРTM & CPTM & $21 / 06 / 1985$ \\
\hline Itapevi & 8 & 1 & CРTM & CPTM & $10 / 07 / 1875$ \\
\hline Engenheiro Cardoso & 8 & 1 & CPTM & CPTM & $20 / 01 / 1987$ \\
\hline Sagrado Coração & 8 & 1 & СРTM & CPTM & $01 / 01 / 1950$ \\
\hline Jandira & 8 & 1 & CPTM & CРTM & $20 / 03 / 1931$ \\
\hline Jardim Silveira & 8 & 1 & CPTM & CPTM & $11 / 03 / 1983$ \\
\hline Jardim Belval & 8 & 1 & CPTM & CPTM & $11 / 03 / 1983$ \\
\hline Barueri & 8 & 1 & CPTM & CPTM & $10 / 07 / 1875$ \\
\hline Antônio João & 8 & 1 & CPTM & CPTM & $25 / 11 / 1982$ \\
\hline Santa Terezinha & 8 & 1 & CPTM & CPTM & $25 / 01 / 1979$ \\
\hline Carapicuíba & 8 & 1 & CPTM & CPTM & $25 / 01 / 1979$ \\
\hline General Miguel Costa & 8 & 1 & CPTM & CPTM & $25 / 01 / 1979$ \\
\hline Quitaúna & 8 & 1 & CPTM & CPTM & $25 / 01 / 1979$ \\
\hline Comandante Sampaio & 8 & 1 & CPTM & CPTM & $25 / 01 / 1979$ \\
\hline Osasco & 8 & 1 & CPTM & CPTM & $02 / 08 / 1895$ \\
\hline Presidente Altino & 8 & 1 & CPTM & CPTM & $25 / 01 / 1979$ \\
\hline
\end{tabular}


Tabela 5 - continuação

\begin{tabular}{|c|c|c|c|c|c|}
\hline Estação & Linha & Sentido & Sistema & Operadora & Inauguração \\
\hline Imperatriz Leopoldina & 8 & 1 & CPTM & CPTM & $25 / 01 / 1979$ \\
\hline Domingos de Moraes & 8 & 1 & CPTM & CPTM & $25 / 06 / 1920$ \\
\hline Lapa & 8 & 1 & CPTM & CPTM & $25 / 01 / 1979$ \\
\hline Palmeiras-Barra Funda & 8 & 1 & CPTM & СРТМ & $17 / 12 / 1988$ \\
\hline Júlio Prestes & 8 & 1 & CPTM & CРTM & $10 / 07 / 1872$ \\
\hline Ambuitá & 8 & 1 & CPTM & CPTM & $00 / 01 / 1900$ \\
\hline Cimenrita & 8 & 1 & CPTM & CPTM & 00/01/1900 \\
\hline Osasco & 9 & 0 & СРТМ & CРTM & $25 / 01 / 1979$ \\
\hline Presidente Altino & 9 & 0 & СРТМ & CPTM & $25 / 01 / 1979$ \\
\hline Ceasa & 9 & 0 & CPTM & CPTM & 04/04/1981 \\
\hline Vila Lobos - Jaguaré & 9 & 0 & CPTM & СРТМ & 04/04/1981 \\
\hline Cidade Universitária & 9 & 0 & CPTM & CPTM & 04/04/1981 \\
\hline Pinheiros & 9 & 0 & СРТМ & CPTM & 04/04/1981 \\
\hline Hebraica - Rebouças & 9 & 0 & СРТМ & СРТМ & $14 / 06 / 2000$ \\
\hline Cidade Jardim & 9 & 0 & CPTM & CPTM & $03 / 06 / 2000$ \\
\hline Vila Olímpia & 9 & 0 & CPTM & CPTM & $23 / 03 / 2001$ \\
\hline Berrini & 9 & 0 & CPTM & CPTM & $14 / 06 / 2000$ \\
\hline Morumbi & 9 & 0 & СРТМ & СРТМ & $30 / 06 / 2000$ \\
\hline Granja Julieta & 9 & 0 & СРТМ & СРТМ & $04 / 05 / 2000$ \\
\hline Santo Amaro & 9 & 0 & СРТМ & СРТМ & $26 / 01 / 1986$ \\
\hline Socorro & 9 & 0 & CPTM & CPTM & $04 / 05 / 2000$ \\
\hline Jurubatuba & 9 & 0 & СРTM & CРTM & $14 / 03 / 1987$ \\
\hline
\end{tabular}


Tabela 5 - continuação

\begin{tabular}{|c|c|c|c|c|c|}
\hline Estação & Linha & Sentido & Sistema & Operadora & Inauguração \\
\hline Autódromo & 9 & 0 & СРTM & CPTM & $17 / 10 / 2007$ \\
\hline Primavera-Interlagos & 9 & 0 & CPTM & CPTM & $21 / 04 / 2008$ \\
\hline Grajaú & 9 & 0 & CPTM & СРТМ & $21 / 04 / 2008$ \\
\hline Grajaú & 9 & 1 & СРТM & СРТМ & $21 / 04 / 2008$ \\
\hline Primavera-Interlagos & 9 & 1 & CPTM & СРТМ & $21 / 04 / 2008$ \\
\hline Autódromo & 9 & 1 & CPTM & CPTM & $17 / 10 / 2007$ \\
\hline Jurubatuba & 9 & 1 & CPTM & CPTM & $14 / 03 / 1987$ \\
\hline Socorro & 9 & 1 & СРТМ & СРТМ & $04 / 05 / 2000$ \\
\hline Santo Amaro & 9 & 1 & СРТМ & CPTM & $26 / 01 / 1986$ \\
\hline Granja Julieta & 9 & 1 & СРТM & CPTM & $04 / 05 / 2000$ \\
\hline Morumbi & 9 & 1 & CPTM & СРТМ & $30 / 06 / 2000$ \\
\hline Berrini & 9 & 1 & CPTM & CPTM & $14 / 06 / 2000$ \\
\hline Vila Olímpia & 9 & 1 & СРТМ & CPTM & $23 / 03 / 2001$ \\
\hline Cidade Jardim & 9 & 1 & CPTM & CРTM & $03 / 06 / 2000$ \\
\hline Hebraica - Rebouças & 9 & 1 & CPTM & CPTM & $14 / 06 / 2000$ \\
\hline Pinheiros & 9 & 1 & СРТM & CPTM & 04/04/1981 \\
\hline Cidade Universitária & 9 & 1 & CPTM & CPTM & 04/04/1981 \\
\hline Vila Lobos - Jaguaré & 9 & 1 & СРТМ & СРТМ & 04/04/1981 \\
\hline Ceasa & 9 & 1 & СРТМ & СРТМ & 04/04/1981 \\
\hline Presidente Altino & 9 & 1 & СРTM & СРТМ & $25 / 01 / 1979$ \\
\hline Osasco & 9 & 1 & CPTM & CPTM & $25 / 01 / 1979$ \\
\hline Brás & 10 & 0 & CPTM & CPTM & $16 / 02 / 1867$ \\
\hline
\end{tabular}


Tabela 5 - continuação

\begin{tabular}{|c|c|c|c|c|c|}
\hline Estação & Linha & Sentido & Sistema & Operadora & Inauguração \\
\hline Juventus-Mooca & 10 & 0 & CPTM & CPTM & $07 / 09 / 1898$ \\
\hline Ipiranga & 10 & 0 & CPTM & СРTM & $01 / 04 / 1886$ \\
\hline Tamanduateí & 10 & 0 & СРТМ & CPTM & $25 / 10 / 1947$ \\
\hline $\begin{array}{l}\text { São Caetano do Sul - Pre- } \\
\text { feito Walter Braido }\end{array}$ & 10 & 0 & СРTM & СРTM & $01 / 05 / 1983$ \\
\hline Utinga & 10 & 0 & СРTM & CPTM & 01/08/1933 \\
\hline Prefeito Saladino & 10 & 0 & СРТМ & CРTM & $29 / 11 / 1952$ \\
\hline $\begin{array}{l}\text { Prefeito Celso Daniel - } \\
\text { Santo André }\end{array}$ & 10 & 0 & СРTM & СРТМ & $16 / 02 / 1867$ \\
\hline Capuava & 10 & 0 & СРТM & CPTM & $15 / 09 / 1920$ \\
\hline Mauá & 10 & 0 & СРТМ & CРTM & $01 / 04 / 1883$ \\
\hline Guapituba & 10 & 0 & СРTM & СРTM & $01 / 06 / 1883$ \\
\hline $\begin{array}{l}\text { Ribeirão Pires - Antônio } \\
\text { Bespalec }\end{array}$ & 10 & 0 & СРTM & СРTM & $01 / 03 / 1885$ \\
\hline Rio Grande da Serra & 10 & 0 & СРТM & CPTM & $16 / 02 / 1867$ \\
\hline Rio Grande da Serra & 10 & 1 & СРТМ & CPTM & $16 / 02 / 1867$ \\
\hline $\begin{array}{l}\text { Ribeirão Pires - Antônio } \\
\text { Bespalec }\end{array}$ & 10 & 1 & СРTM & СРTM & $01 / 03 / 1885$ \\
\hline Guapituba & 10 & 1 & СРTM & CPTM & $01 / 06 / 1883$ \\
\hline Mauá & 10 & 1 & CPTM & CРTM & $01 / 04 / 1883$ \\
\hline Capuava & 10 & 1 & CPTM & CPTM & $15 / 09 / 1920$ \\
\hline $\begin{array}{l}\text { Prefeito Celso Daniel - } \\
\text { Santo André }\end{array}$ & 10 & 1 & СРTM & CPTM & $16 / 02 / 1867$ \\
\hline Prefeito Saladino & 10 & 1 & CPTM & CPTM & $29 / 11 / 1952$ \\
\hline Utinga & 10 & 1 & CPTM & CPTM & 01/08/1933 \\
\hline
\end{tabular}


Tabela 5 - continuação

\begin{tabular}{|c|c|c|c|c|c|}
\hline Estação & Linha & Sentido & Sistema & Operadora & Inauguração \\
\hline $\begin{array}{l}\text { São Caetano do Sul - Pre- } \\
\text { feito Walter Braido }\end{array}$ & 10 & 1 & CPTM & CPTM & $01 / 05 / 1983$ \\
\hline Tamanduateí & 10 & 1 & CPTM & СРTM & $25 / 10 / 1947$ \\
\hline Ipiranga & 10 & 1 & СРTM & СРTM & $01 / 04 / 1886$ \\
\hline Juventus-Mooca & 10 & 1 & CPTM & CPTM & $07 / 09 / 1898$ \\
\hline Brás & 10 & 1 & CРTM & CPTM & $16 / 02 / 1867$ \\
\hline Luz & 11 & 0 & CPTM & CРTM & $16 / 02 / 1867$ \\
\hline Brás & 11 & 0 & CРTM & CРTM & $16 / 02 / 1867$ \\
\hline Tatuapé & 11 & 0 & CPTM & CPTM & $16 / 02 / 1867$ \\
\hline Corinthians-Itaquera & 11 & 0 & & & $00 / 01 / 1900$ \\
\hline Dom Bosco & 11 & 0 & CPTM & CPTM & $27 / 04 / 2000$ \\
\hline José Bonifácio & 11 & 0 & СРТМ & CPTM & $27 / 05 / 2000$ \\
\hline Guaianases & 11 & 0 & CPTM & CPTM & $27 / 05 / 2000$ \\
\hline Antônio Gianetti Neto & 11 & 0 & CРTM & CРTM & $10 / 01 / 1998$ \\
\hline Ferraz de Vasconcelos & 11 & 0 & CPTM & CPTM & $29 / 07 / 1926$ \\
\hline Poá & 11 & 0 & CPTM & CPTM & $06 / 11 / 1875$ \\
\hline Calmon Viana & 11 & 0 & CPTM & CPTM & $07 / 02 / 1926$ \\
\hline Suzano & 11 & 0 & CPTM & CPTM & $06 / 11 / 1875$ \\
\hline Jundiapeba & 11 & 0 & СРTM & CPTM & $20 / 07 / 1914$ \\
\hline Brás Cubas & 11 & 0 & СРТМ & CPTM & $20 / 08 / 1914$ \\
\hline Mogi das Cruzes & 11 & 0 & CPTM & CPTM & $06 / 11 / 1875$ \\
\hline Estudantes & 11 & 0 & СРТМ & CРTM & $10 / 11 / 1976$ \\
\hline Estudantes & 11 & 1 & СРТM & СРТМ & $10 / 11 / 1976$ \\
\hline
\end{tabular}


Tabela 5 - continuação

\begin{tabular}{|c|c|c|c|c|c|}
\hline Estação & Linha & Sentido & Sistema & Operadora & Inauguração \\
\hline Mogi das Cruzes & 11 & 1 & CPTM & CPTM & $06 / 11 / 1875$ \\
\hline Brás Cubas & 11 & 1 & CPTM & СРTM & $20 / 08 / 1914$ \\
\hline Jundiapeba & 11 & 1 & CPTM & CPTM & $20 / 07 / 1914$ \\
\hline Suzano & 11 & 1 & CPTM & CPTM & $06 / 11 / 1875$ \\
\hline Calmon Viana & 11 & 1 & CPTM & CPTM & $07 / 02 / 1926$ \\
\hline Poá & 11 & 1 & CPTM & CPTM & $06 / 11 / 1875$ \\
\hline Ferraz de Vasconcelos & 11 & 1 & CPTM & CPTM & $29 / 07 / 1926$ \\
\hline Antônio Gianetti Neto & 11 & 1 & CPTM & CPTM & $10 / 01 / 1998$ \\
\hline Guaianases & 11 & 1 & CPTM & CPTM & $27 / 05 / 2000$ \\
\hline José Bonifácio & 11 & 1 & CPTM & CPTM & $27 / 05 / 2000$ \\
\hline Dom Bosco & 11 & 1 & CPTM & CPTM & $27 / 04 / 2000$ \\
\hline Tatuapé & 11 & 1 & CPTM & CPTM & $05 / 11 / 1981$ \\
\hline Corinthians-Itaquera & 11 & 1 & CPTM & CPTM & $16 / 02 / 1867$ \\
\hline Luz & 11 & 1 & CPTM & CPTM & $16 / 02 / 1867$ \\
\hline Brás & 11 & 1 & CPTM & CPTM & $16 / 02 / 1867$ \\
\hline Brás & 12 & 0 & CPTM & CPTM & $16 / 02 / 1867$ \\
\hline Tatuapé & 12 & 0 & CPTM & CPTM & $05 / 11 / 1981$ \\
\hline Engenheiro Goulart & 12 & 0 & CPTM & CPTM & 01/01/1934 \\
\hline USP Leste & 12 & 0 & CРTM & CPTM & $29 / 01 / 2008$ \\
\hline Comendador Ermelino & 12 & 0 & CPTM & CPTM & 01/01/1934 \\
\hline São Miguel Paulista & 12 & 0 & CРTM & CPTM & $01 / 01 / 1934$ \\
\hline Jardim Helena-Vila Mara & 12 & 0 & CPTM & CPTM & $28 / 05 / 2008$ \\
\hline
\end{tabular}


Tabela 5 - continuação

\begin{tabular}{|c|c|c|c|c|c|}
\hline Estação & Linha & Sentido & Sistema & Operadora & Inauguração \\
\hline Itaim Paulista & 12 & 0 & CPTM & CPTM & $07 / 02 / 1926$ \\
\hline Jardim Romano & 12 & 0 & CPTM & СРTM & $16 / 07 / 2008$ \\
\hline Engenheiro Manoel Feio & 12 & 0 & CPTM & CPTM & $07 / 02 / 1926$ \\
\hline Itaquaquecetuba & 12 & 0 & CPTM & CPTM & $07 / 02 / 1926$ \\
\hline Acararé & 12 & 0 & СРТМ & CPTM & $20 / 08 / 1950$ \\
\hline Calmon Viana & 12 & 0 & CPTM & CPTM & $07 / 02 / 1926$ \\
\hline Calmon Viana & 12 & 1 & CPTM & CPTM & $07 / 02 / 1926$ \\
\hline Acararé & 12 & 1 & CPTM & CPTM & $20 / 08 / 1950$ \\
\hline Itaquaquecetuba & 12 & 1 & СРТМ & CPTM & $07 / 02 / 1926$ \\
\hline Engenheiro Manoel Feio & 12 & 1 & CPTM & CPTM & $07 / 02 / 1926$ \\
\hline Jardim Romano & 12 & 1 & CPTM & CPTM & $16 / 07 / 2008$ \\
\hline Itaim Paulista & 12 & 1 & CPTM & CPTM & $07 / 02 / 1926$ \\
\hline Jardim Helena-Vila Mara & 12 & 1 & CPTM & CPTM & $28 / 05 / 2008$ \\
\hline São Miguel Paulista & 12 & 1 & CPTM & CPTM & $01 / 01 / 1934$ \\
\hline Comendador Ermelino & 12 & 1 & CPTM & CPTM & $01 / 01 / 1934$ \\
\hline USP Leste & 12 & 1 & CPTM & CPTM & $29 / 01 / 2008$ \\
\hline Engenheiro Goulart & 12 & 1 & CPTM & CPTM & $01 / 01 / 1934$ \\
\hline Tatuapé & 12 & 1 & CPTM & CPTM & 05/11/1981 \\
\hline Brás & 12 & 1 & CРTM & CPTM & $16 / 02 / 1867$ \\
\hline Engenheiro Goulart & 13 & 0 & СРТM & CРTM & $04 / 08 / 2017$ \\
\hline Guarulhos-Cecap & 13 & 0 & СРTM & CPTM & $31 / 03 / 2018$ \\
\hline Aeroporto-Guarulhos & 13 & 0 & CPTM & CPTM & $31 / 03 / 2018$ \\
\hline
\end{tabular}


Tabela 5 - continuação

\begin{tabular}{|c|c|c|c|c|c|}
\hline Estação & Linha & Sentido & Sistema & Operadora & Inauguração \\
\hline Engenheiro Goulart & 13 & 1 & СРTM & CPTM & $04 / 08 / 2017$ \\
\hline Guarulhos-Cecap & 13 & 1 & CPTM & CPTM & $31 / 03 / 2018$ \\
\hline Aeroporto-Guarulhos & 13 & 1 & CРTM & CPTM & $31 / 03 / 2018$ \\
\hline Vila Prudente & 15 & 0 & Metrô & Metrô & $30 / 08 / 2014$ \\
\hline Oratório & 15 & 0 & Metrô & Metrô & $30 / 08 / 2014$ \\
\hline São Lucas & 15 & 0 & Metrô & Metrô & $06 / 04 / 2018$ \\
\hline Camilo Haddad & 15 & 0 & Metrô & Metrô & $06 / 04 / 2018$ \\
\hline Vila Tolstói & 15 & 0 & Metrô & Metrô & $06 / 04 / 2018$ \\
\hline Vila União & 15 & 0 & Metrô & Metrô & $06 / 04 / 2018$ \\
\hline Vila União & 15 & 1 & Metrô & Metrô & $06 / 04 / 2018$ \\
\hline Vila Tolstói & 15 & 1 & Metrô & Metrô & $06 / 04 / 2018$ \\
\hline Camilo Haddad & 15 & 1 & Metrô & Metrô & $06 / 04 / 2018$ \\
\hline São Lucas & 15 & 1 & Metrô & Metrô & 06/04/2018 \\
\hline Oratório & 15 & 1 & Metrô & Metrô & $30 / 08 / 2014$ \\
\hline Vila Prudente & 15 & 1 & Metrô & Metrô & $30 / 08 / 2014$ \\
\hline
\end{tabular}




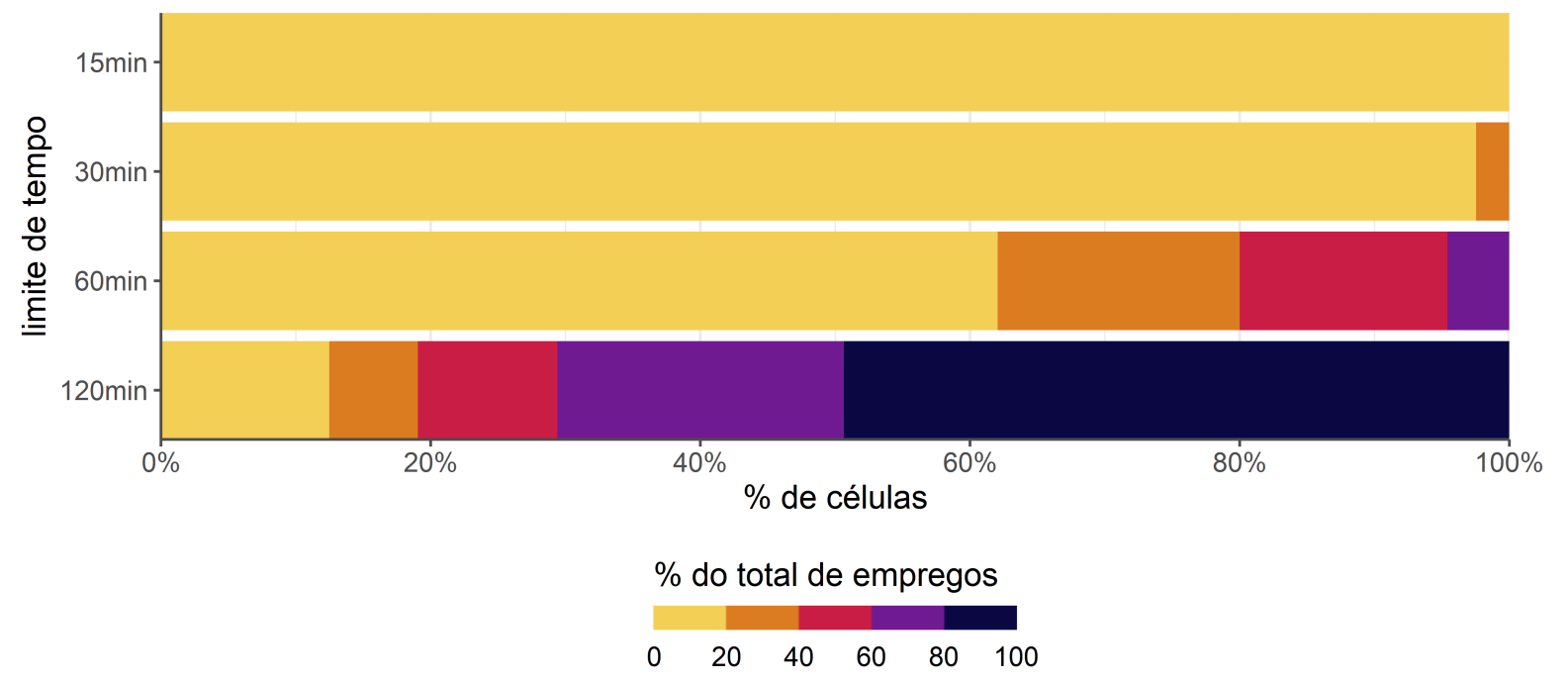

Figura 33 - Distribuição das células por acessibilidade e limite de tempo 


\section{APÊNDICE B - Estudo de caso}

\section{B.1 Empreendimentos do mercado formal}

Testamos outros limites de valor de empreendimento para fazer a divisão por tipo além dos limites propostos pelo PMCMV, conforme abaixo:

a) divisão proposta por Hoyler (2016), caso a:

- até 250mil reais para baixa renda;

- entre 250mil a 650mil para empreendimentos para população de renda média;

- acima de 650mil para alta renda;

b) emulação de financiamento com juros médio do período a 9,4\% a.a., restringindo o valor médio da parcela a $30 \%$ da renda. Usamos os seguintes limites de renda determinados:

- pelo PDE 2002 (Quadro 2), caso b:

- até 125 mil reais para baixa renda (renda até 6SM, sendo 1 SM em 2002, ajustado pelo IGP-DI para dezembro de 2013 , é igual a $\mathrm{R} \$ 456,41$ );

- entre $125 \mathrm{mil}$ e $325 \mathrm{mil}$ reais (renda entre 6SM a 16SM);

- acima de 325mil para alta renda (renda acima de 16SM);

- pelo PMCMV fase 1 (Tabela 1), caso c:

- até 85mil reais para baixa renda (renda até 3SM, sendo 1 SM em 2009, ajustado pelo IGP-DI para dezembro de 2013, é igual a $\mathrm{R} \$ 611,91)$;

- entre 85mil a 275mil reais (renda entre 3SM a 10SM);

- acima de 275mil para alta renda (renda acima de 16SM).

Resultando na Figura 34. Decidimos pelo caso usado (limites propostos pelo PMCMV) por ser mais conservador, não arbitrário e não depender de valores médios. 


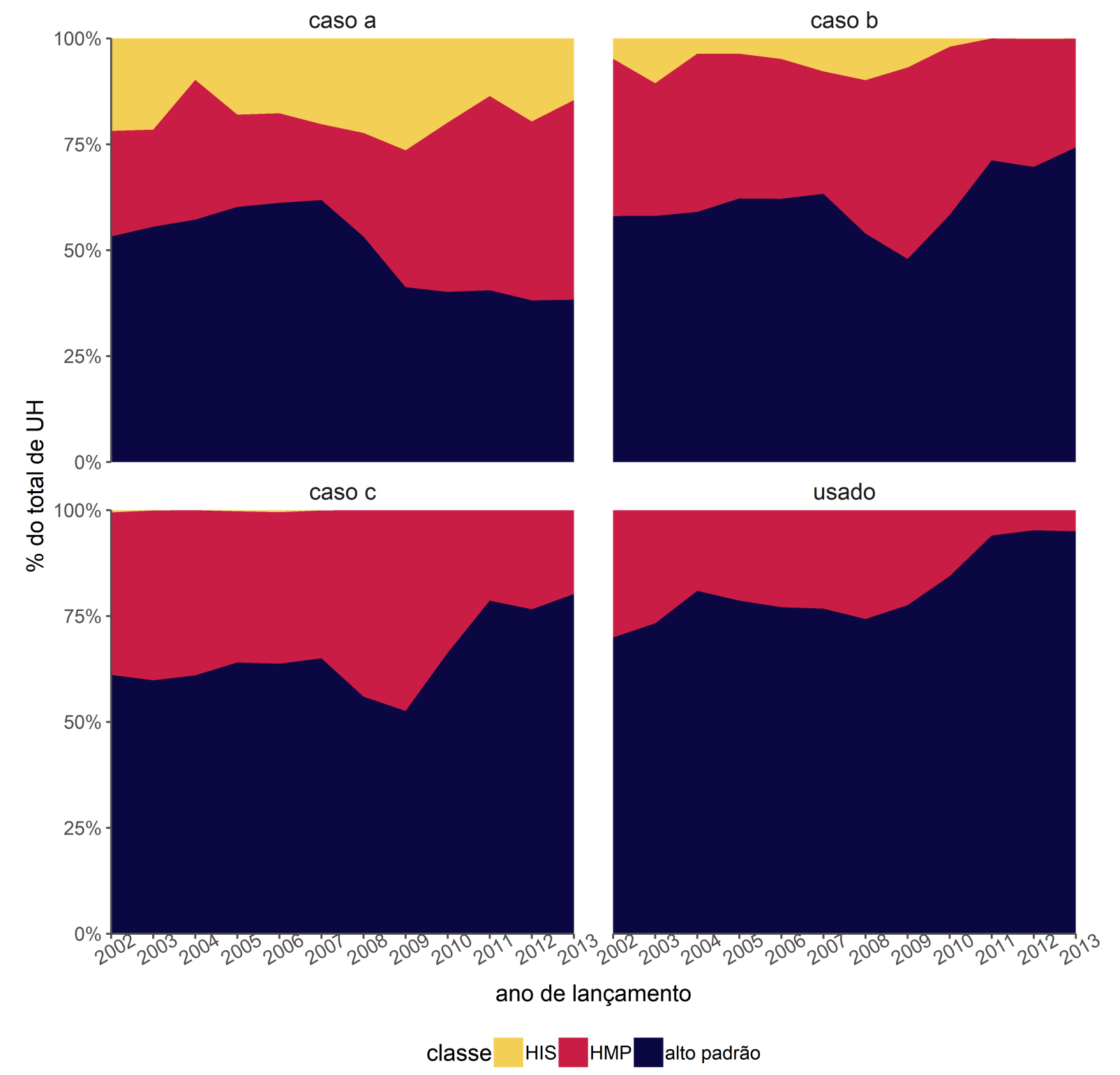

Figura 34 - Total de unidades (\%) lançadas por tipo de empreendimento e caso 


\section{B.2 Acessibilidade}

Testamos outra divisão de escala para a análise de acessibilidade, sendo 5 percentis definidos para cada ano.

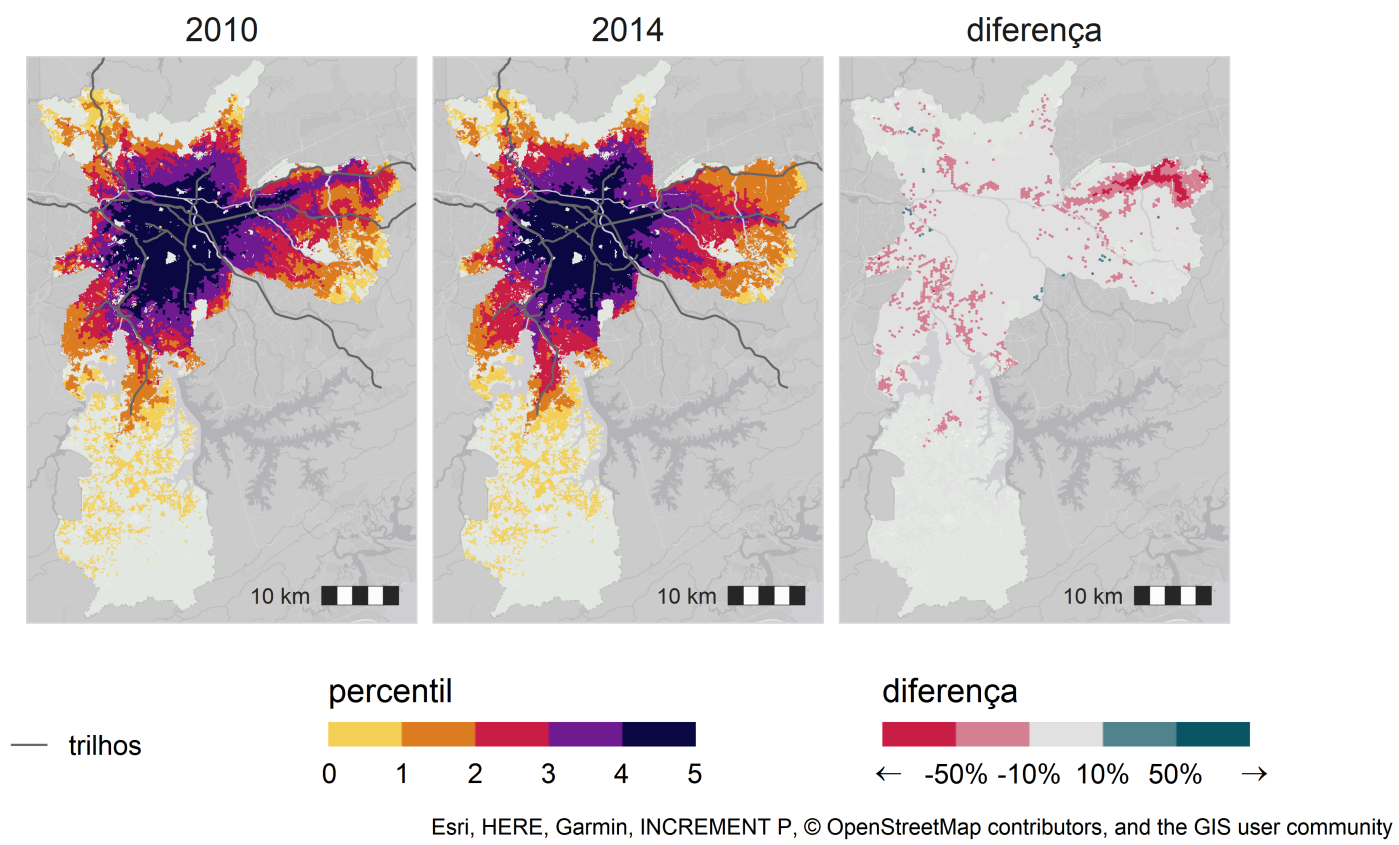

Figura 35 - Mapas de acessibilidade de 2010 e 2014, escala em percentil por ano 
Era prevista a análise de inserção urbana dos empreendimentos e das ZEIS durante todo o período das ZEIS do PDE 2002 (2002 a 2014). Portanto, a partir das base de empregos organizada pelo NEREUS para os anos de 2002 e 2007 (Figura 36) e com a criação do GTFS, usando o mesmo procedimento descrito no Capítulo 4, temos os níveis acessibilidade para os anos de 2003 e 2007 (Figura 38).


Esri, HERE, Garmin, INCREMENT P, ๑ OpenStreetMap contributors, and the GIS user community

Figura 36 - Mapas de empregos de 2002, 2007, 2010 e 2014

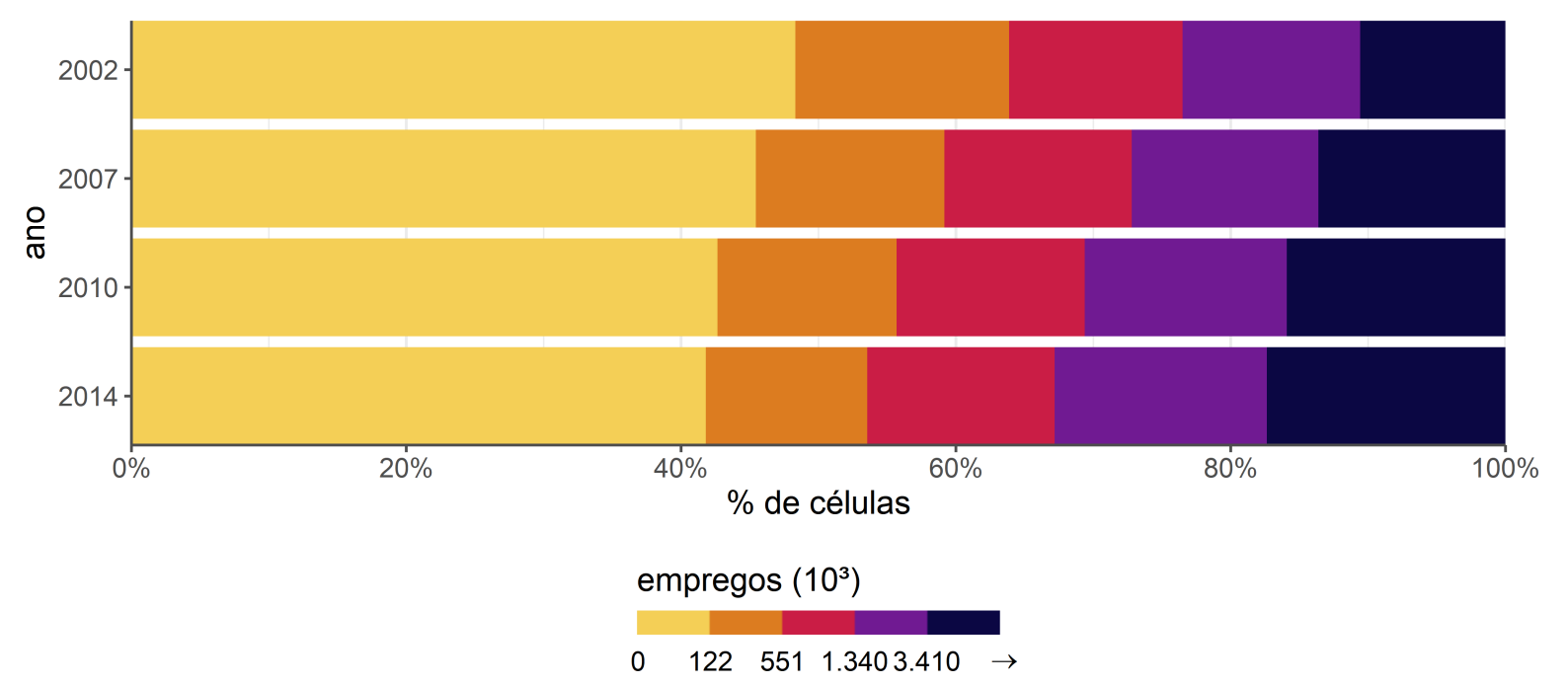

Figura 37 - Distribuição das células por emprego e ano 

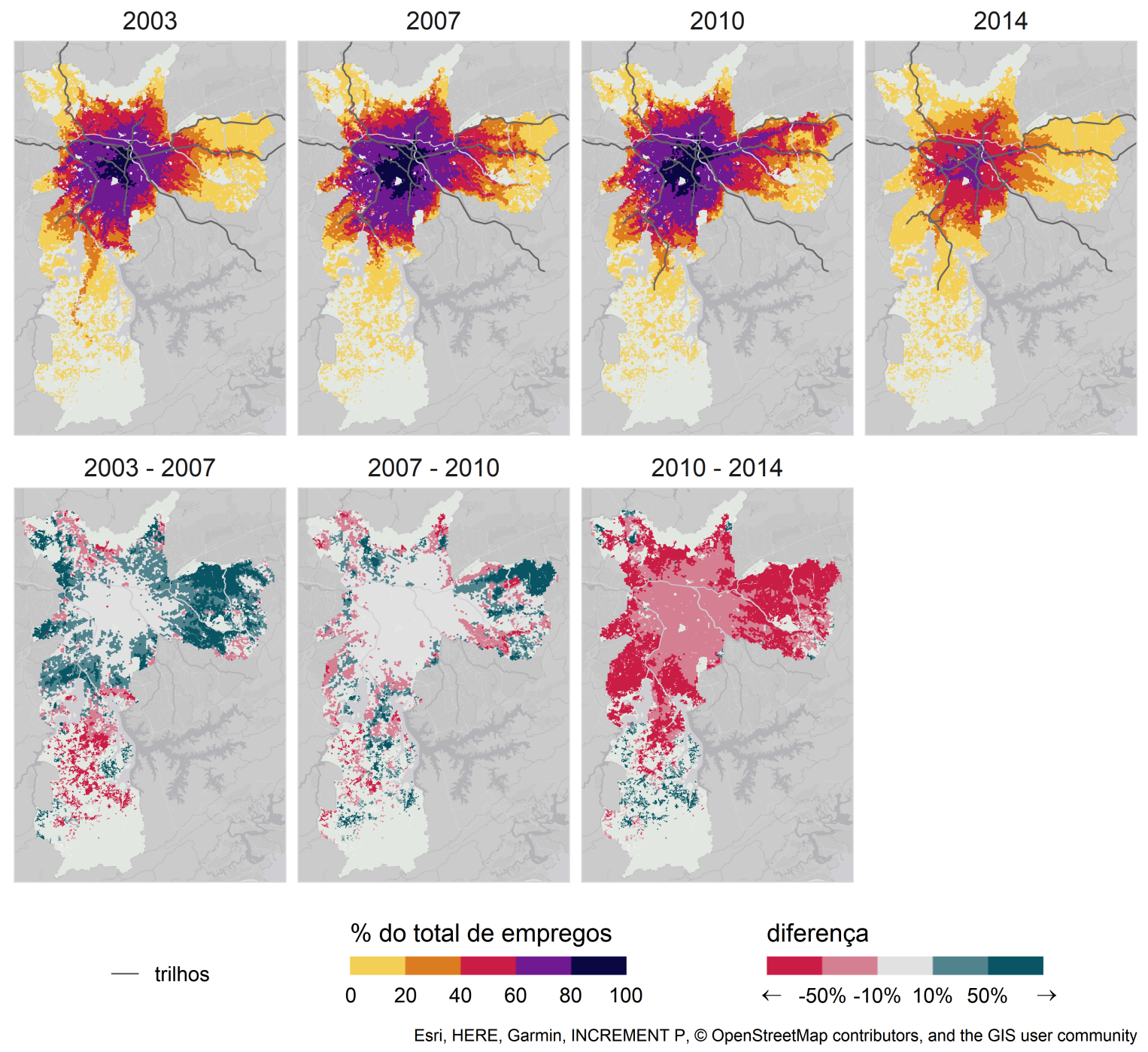

Figura 38 - Mapas de acessibilidade de 2003, 2007, 2010 e 2014, escala relativa ao total de empregos por ano

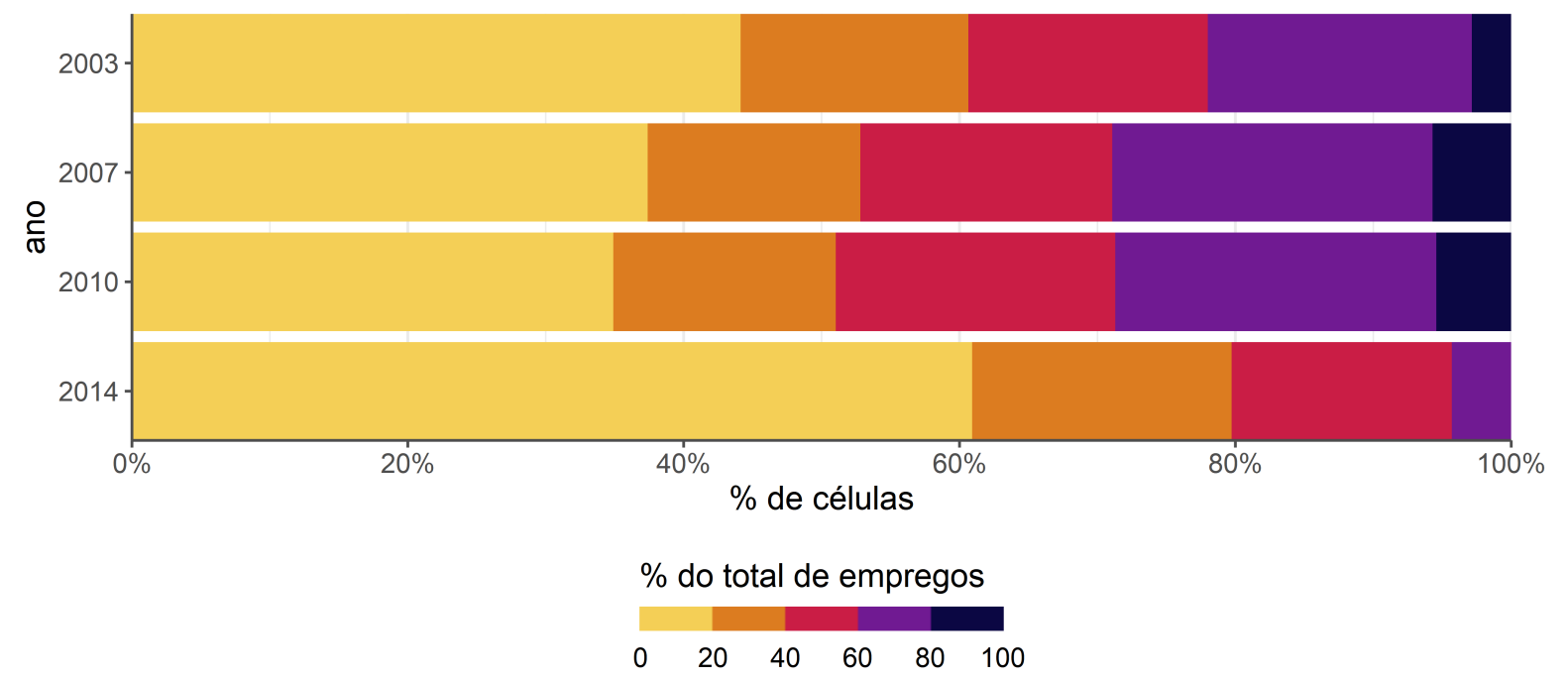

Figura 39 - Distribuição das células por acessibilidade e ano 